\title{
Agentes comunes en las aspergilosis humanas: conceptos prima- rios en la diferenciación de sus complejos de especies
}

\author{
(Common agent in human aspergillosis: primary concepts in their \\ complex species differentiation)
}

\author{
Eduardo Piontelli L. \\ Universidad de Valparaíso, Escuela de \\ Medicina. Cátedra de Micología \\ Casilla 92 V Valparaíso <email: \\ eduardopiontelli@hotmail.com>
}

\section{RESUMEN}

Las especies del género Aspergillus P.Micheli ex Haller, son consideradas como importantes organismos integrantes de la microbiota en distintos tipos de suelos en todas las latitudes. Presentan grandes capacidades fermentativas industriales, son agentes comunes en microbiología de alimentos, grandes biodescomponedores junto a las bacterias, contaminantes de productos agrícolas y de importancia en salud humana y animal. El género se asocia a 9 o más teleomorfos, formando un clado monofilético estrechamente relacionado con el género Penicillium. Debido al elevado número de especies, su dinámica taxonómica y sus frecuentes cambios en la nomenclatura, han complicado a menudo al investigador en algún campo de la biología, en especial cuando éste guarda relación con la industria o la medicina. Estos hongos productores de grandes cantidad de esporas secas de dispersión aérea, constituyen una fuente constante de exposición para los humanos, especialmente en los ambientes internos. Si bien es cierto, que los integrantes del género Aspergillus (en especial A. fumigatus) pueden causar un amplio espectro de enfermedades invasoras o no invasoras, la incidencia de otras especies del género reportadas en la literatura como agentes de aspergilosis, ha aumentado y complicado el trabajo taxonómico, genético y clínico en los últimos decenios. La presente revisión abarca el tema desde un punto de vista primario que incluye básicamente la morfofisiología de 34 especies involucradas en diversos casos clínicos geográficamente dispersos en todos los continentes. Se destacan algunos aspectos taxonómicos, ecológicos, patológicos, moleculares y el empleo de cultivos comunes en el diagnóstico en 3 de los subgéneros más frecuentes en clínica (Fumigati, Circumdati y Nidulantes) y 7 de sus secciones: Fumigati, Clavati, Nigri, Flavi, Terrei, Nidulantes y Usti. Se aportan referencias útiles, descripción de especies y claves tentativas morfofisiológicas para completar su diagnóstico primario en la rutina común de laboratorio en muchos centros asistenciales, junto a la información necesaria para el diagnóstico secundario a nivel molecular.

\section{ABSTRACT}

Species of the genus Aspergillus P.Micheli ex Haller, are considered important members of the organisms of mycrobiota in different tipes of soils in all latitudes. They prsent large industrial fermentative capacity, are common agents in food microbiology, major biodeterioration agents with bacteria, contaminants in agricultural products, and important in human and animal health. The genus is associated with 9 or more teleomorphs, forming a monophyletic clade closely related to the genus Penicillium. Due to the high number of species, their taxonomic dynamic and frequent changes in nomenclature have often complicated the researcher in any field of biology, especially when related to industry or medicine. These fungi producing large amount of dry spores of aerial dispersion, and they are a constant source of exposure for humans, especially in indoor environments. While it is true, that members of the genus Aspergillus (especially A. fumigatus) can cause a wide spectrum invasive or non-invasive disease, the incidence of other species of the genus reported in the literature as agents of aspergillosis has increased and complicated the taxonomic, genetic and clinical work in recent decades. The present review covers the topic from a primary morphophysiology view and basically includes 34 species involved in various clinical cases geographically dispersed in all continents.

It highlights some taxonomic, ecological, pathological and molecular aspects and the use of common culture media in the diagnosis in 3 of the most common clinical subgenera (Fumigati, Circumdati and Nidulantes) and 7 sections: Fumigati, Clavati, Nigri, Flavi, Terrei, Nidulantes and Usti. Useful references, description of key species and morphophysiological attempts to complete their work in the common routine in primary diagnostic in the laboratory in many medical centers are also included, along with the necessary information for the secondary diagnosis at the molecular level. 


\section{Introducción}

Aspergillus, pertenece a la Divisón Ascomycota (Euascomycetes, Eurotiales, Aspergillaceae (Houbraken \& Samson 2011), que es integrada por especies anamórficas con conocidas o presumidas nueve o más formas telomórficas, además incluye 4 subgéneros (Aspergillus, Fumigati, Circumdati, Nidulantes), que a su vez se subdividen en 19 secciones que integran a varios complejos de especies (Geiser, 2009; Samson, \& Varga, 2010; Houbraken et al, 2014, Samson et al, 2014) (Tabla 1). El género está integrado actualmente por 338 especies según los autores (Samson $e t$ $a l, 2014)$, de las cuales, unas 40 se han reportado como causantes de infecciones en humanos y otros animales, principalmente incluidas en las secciones Fumigati, Circumdati, Flavi y Nigri, las cuales a su vez tienen gran relevancia en biotecnología. Otras características del género que caracterizan sus aislados, es la producción de perfiles de extrolitros, cuyos compuestos químicos proveen una importante información en la producción de micotoxinas, las cuales se determinan mediante análisis de HPLC (Frisvald \& Thrane 1987; Smedsgaard,1997).

Se reconoce a Link (1809) como al autor que validó al género (CINB), a pesar que Micheli (1729) fue el primero que lo describió, situación que actualmente se ha enmendado (Vea pág.6). En el siglo XX se publicaron varias monografías del género (Thom \& Church, 1926; Thom \& Raper, 1945), pero la más completa en su época y aún consultada, fue la escrita por Raper \& Fennel en el año 1965, que incluyó varias nuevas especies; sin embargo, a pesar de incluir la dignosis latina de los nuevos taxas, no se designó en ellos la especie tipo, describiendo además los teleomorfos bajo el mismo nombre de los anamorfos (ICN) (considerado un error en esos tiempos). La monografía acepta 132 especies subdivididas en 18 grupos, una obra que sigue siendo aún una literatura valorable y útil. Los aportes posteriores fueron agregando nuevas especies y reordenando el género hacia una línea más acorde al Código Internacional de Nomenclatura Botánica (CINB) y dilucidando sus relaciones con los teleomorfos de Aspergillus. Las nuevas especies descritas desde 1965 fueron publicadas en la literatura por Samson $(1979,1993$, Samson \& Pitt, 2000; Al Musallam, 1980; Christensen, 1982, Samson \&Varga.2007, entre muchos otros), aportándose al mismo tiempo, varios métodos de identificación por la extrema importancia de este género en relación a su biología, patogenicidad, producción de micotoxinas (Bennett \& Klich, 1992; Smith, 1994; Samson et al. 2006) sin olvidar los aspectos taxonómicos y los filogenéticos (Samson \& Pitt,2000; Larsen et al, 2005)

Estos organismos (desde enero 2013) pertenecen ahora al nuevo código «International Code of Nomenclature for algae, fungi and plant», donde todos los organismos incluidos tienen un solo nombre, ya sea perteneciente al anamorfo o al teleomorfo, según el que prime normalmente en los cultivos o el más empleado en la literatura (Taylor, 2011; Hawksworth, 2012).

La taxonomía tradicional del género, se basa principalmente en sus caracteres fenotípicos y fisiológicos, los cuales han aportado satisfactorias delimitaciones de las especies; sin embargo, existen variaciones morfológicas en varias secciones que han llevado a controversias en sus esquemas taxonómicos. En el nuevo siglo 21, Aspergillus y sus teleomorfos asociados han sido recientemente investigados con métodos polifásicos (morfológicos, fisiológicos, moleculares y ecológicos) para examinar la variabilidad entre sus especies (Samson \& Pitt, 2000; Samson et al, 2006-2011; Samson \& Varga, 2007; Peterson 2008; Varga \& Samson, 2008; Hong et al., 2010a; Varga et al, 2010; Abdin et al., 2010, Samson et al, 2014,entre otros).

Aspectos ecológicos. Las especies de Aspergillus, se consideran entre las más importantes de los taxones fúngicos en el mundo. No son muy selectivas en referencia a las condiciones abióticas de crecimiento y pueden crecer a amplios rangos de temperatura $\left(6-55^{\circ} \mathrm{C}\right)$ en relativa baja humedad. De hecho, A. penicilloides es uno de los hongos entre los más xerofílicos (Williams \& Hallsworth 2009). Además las especies de Aspergillus se nutren mediante una larga variedad de sustratos, incluyendo las heces humanas y tejidos humanos. Sin embargo, se encuentran predominantemente en polímeros vegetales complejos (Bennett 2010) y se consideran entre los hongos más comunes que deterioran alimentos. El suceso de su éxito ambiental se atribuye a su efectiva dispersión de sus esporas a cortas y largas distancias en el aire.

Morfología del género (Fig.2). Las colonias son usualmente de crecimiento rápido, de varios colores que van desde el blanco, amarillo, amarillo-café, café a negro o tonos del verde-

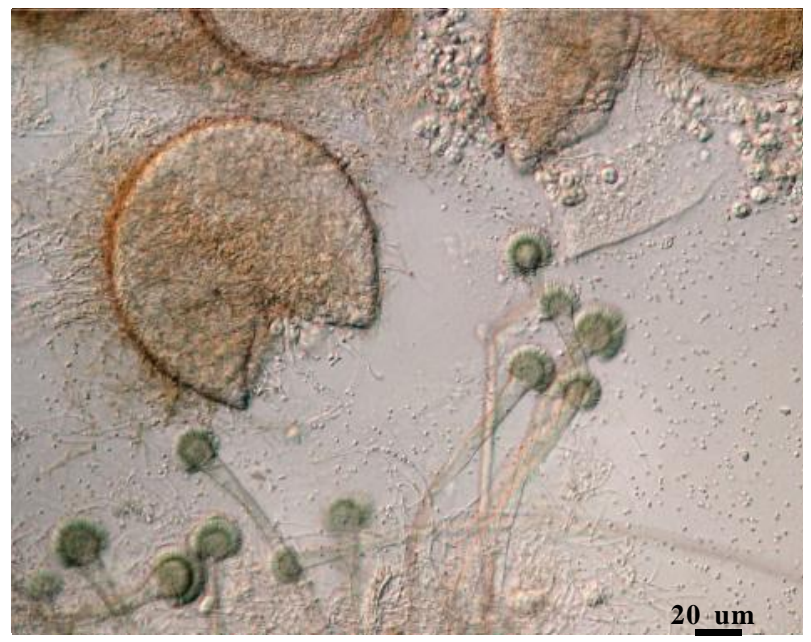

Figura 1. A. quadricingens (neosartorya morph). Se aprecian las 2 fases de ciclo biológico de la especie, con conidióforos, conidios, cleistotecios, ascos y ascosporas. 


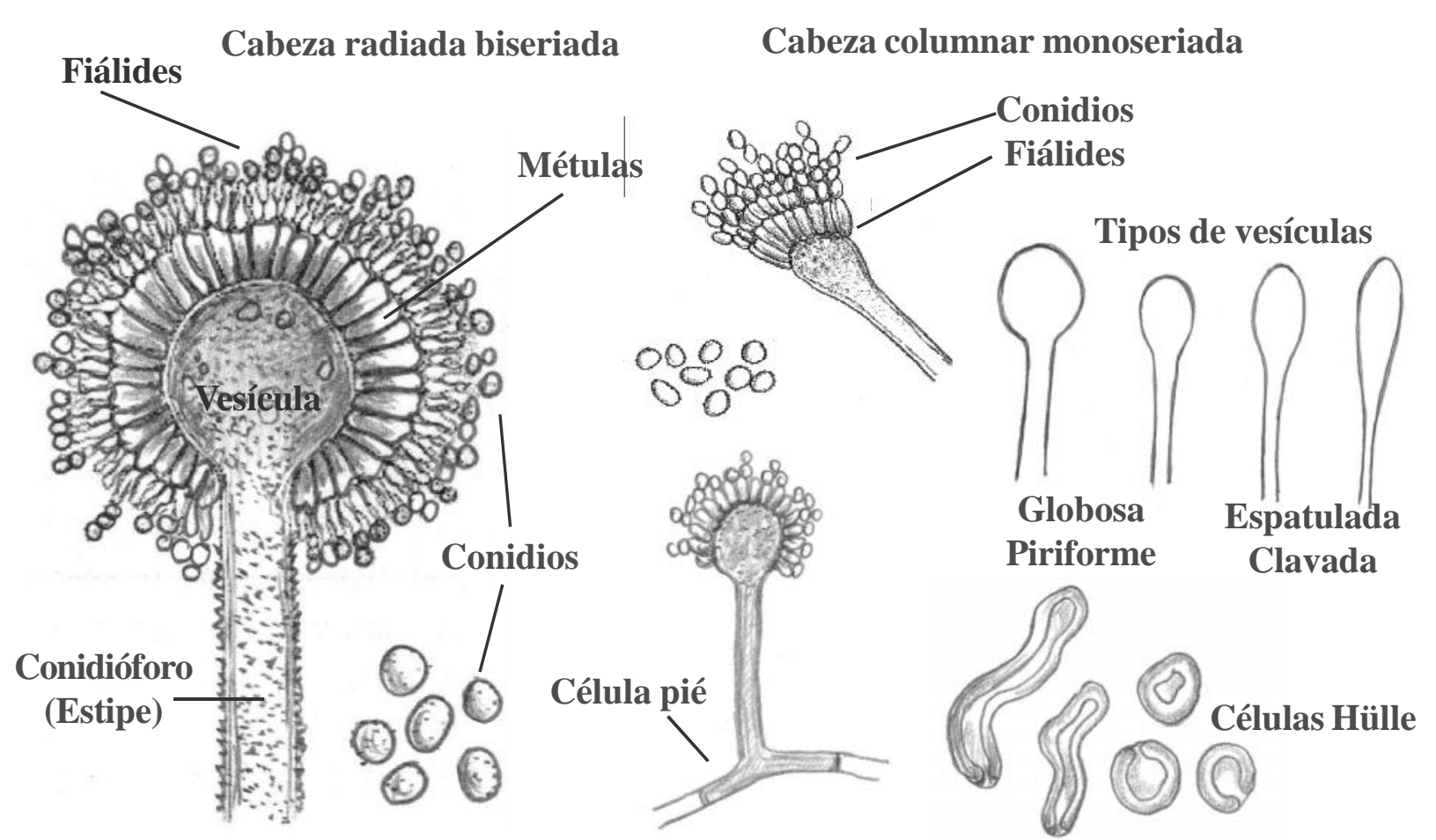

Figura 2. Estructuras morfológicas en el género Aspergillus (como anamorfo) a considerar en las observaciones: cabezas radiadas o columnares, célula pié, tipos de vesículas, fiálides métulas, conidios, y células de Hülle.

grisáceo o verde-azulado. Se presentan como un denso fieltro con conidióforos erectos (en algunos pocos casos son dramáticamente diferentes, como en Dichotomomyces, Phialosimplex, Polypaecilum y Cristaspora (Vea Samson et al, 2014), que terminan en una vesícula cubierta parcialmente o en su totalidad por una empalizada de fiálides (uniseriada) o con una capa inferior basal de células de soporte llamadas métulas, las cuales soportan un pequeño número compacto de fiálides (biseriada). El conjunto forma lo que se llama cabeza aspergilar, que puede ser estrictamente uniseriada, estrictamente biseriada o mixtas (algunas mono y otras biseradas, ej. Aspergillus flavus, un dato importante en taxonomía). Los conidios son unicelulares, redondos, ovalados, elípticos, lisos o rugosos, hialinos o pigmentados, de paredes gruesas o finas, producidos en largas cadenas secas que pueden ser divergentes (radiadas) o agregadas en compactas columnas (columnares) o en columnas laxas (que tienden a abrirse). Unas pocas especies producen otros tipos de conidios además de las fiálides y métulas sobre la vesícula, sino directamente sobre las hifas vegetativas, de aspecto redondo a ovoides llamados aleuroconidios (Ej. en Aspergillus terreus complex). Algunas especies pueden producir células de Hülle solitarias (Ej.A.versicolor, A.ustus, A.calidoustus) o envolviendo los cleistotecios de uno de los teleomorfos asociados ( Ej. Aspergillus nidulans complex (emericella morph). En los tipos de ascomata, se presenta una gran variación morfológica, desde los rodeados por hifas laxas, de apariencia lisa pseudoparenquimatosa a las compactas estructuras esclerotiales, así como al tamaño, ornamentación y superficie de las ascosporas (Fig. 3). Los 4 subgéneros y 19 secciones que se aceptan en Aspergillus, se describen en Tabla.1: estas secciones forman un único clado monofilético con soporte estadístico bajo. Según Houbraken \& Samson (2011), las especies tipo de Polypaecilum y Phialosimplex, muestran relaciones con las secciones Cremei y Aspergillus y los incluyeron en Aspergillus. Varga et al (2007a), demostró que Dichotomomyces con un anamorfo semejante a polypaecilum es estrechamente relacionado con la sección Fumigati y Clavati y propuso la sinonimía de este género con Aspergillus. Todos estos datos son importantes en taxonomía y deben considerarse (Ver: Raper \& Fennel 1965; Samson et al. 2004b; Samson et al, 2006; Samson \& Varga 2007; Varga \& Samson 2008; Varga et al, 2010; Samson \& Varga, 2010, Houbraken et al, 2014, entre otros).

Debido a que el esquema de clasificación puede ser complejo para los no taxónomos que buscan una identificación a nivel de especie, es bueno conocer que las especies dentro de las secciones Fumigati, Nigri, Flavi, Nidulantes, Usti, y Terrei sean reportadas como «complejo de especies» (Fig. 4): Por ejemplo complejo Aspergillus fumigatus (Balaje et al,2007). Para estos aislados considerados como un complejo de especies, la morfología sola es problemática, 
debido a la sobreposición de las estructuras morfológicas del organismo a determinar. Los estudios moleculares, han revelado la presencia de varias especies crípticas de Aspergillus entre los aislados identificados solo como morfoespecie (Balajee et al, 2005a; Varga et al, 2008). Por ej.,
A. lentulus fue descrito en 2005 como nueva especie dentro del complex A. fumigatus; inicialmente desde pacientes en USA y posteriormente aislados de pacientes en otras regiones geográficas del mundo y desde el ambiente (Balaje et al, 2005b -2009; Hong, et al, 2005; Yaguchi et al, 2007).

\section{Tabla 1. Subgéneros, secciones y teleomorfos del género Aspergillus}

(Basada en Peterson et al, 2008; Varga et al, 2010; Houbraken \& Samson 2011; Houbraken et al, 2014)

*El subgenero Ornati y Warcupi no pertenecen a los Aspegillus y deben ser transferidos a otros géneros

\begin{tabular}{|c|c|c|}
\hline Subgénero & Secciones & Teleomorfos \\
\hline \multirow[t]{2}{*}{ Aspergillus } & Aspergillus & (Eurotium) \\
\hline & Restricti & (Eurotium) \\
\hline \multirow[t]{3}{*}{ Fumigati } & Fumigati & (Neosartorya) \\
\hline & Clavati & $\begin{array}{l}\text { (Neocarpenteles, } \\
\text { Dichotomomyces) }\end{array}$ \\
\hline & Cervini & - \\
\hline \multirow{6}{*}{ Circumdati } & Circumdati & (Neopetromyces) \\
\hline & Nigri & (Petromyces) \\
\hline & Flavi & (Petromyces) \\
\hline & Candidi & - \\
\hline & Terrei & (Fennelia) \\
\hline & Flavipedes & (Fennelia) \\
\hline \multirow[t]{8}{*}{ Nidulantes* } & Nidulantes & (Emericella) \\
\hline & Usti & (Emericella) \\
\hline & Bispori & - \\
\hline & Sparsi & - \\
\hline & Aeni & (Emericella) \\
\hline & Ochraceorosei & - \\
\hline & Cremei & (Chaetosartorya) \\
\hline & Silvati & - \\
\hline
\end{tabular}
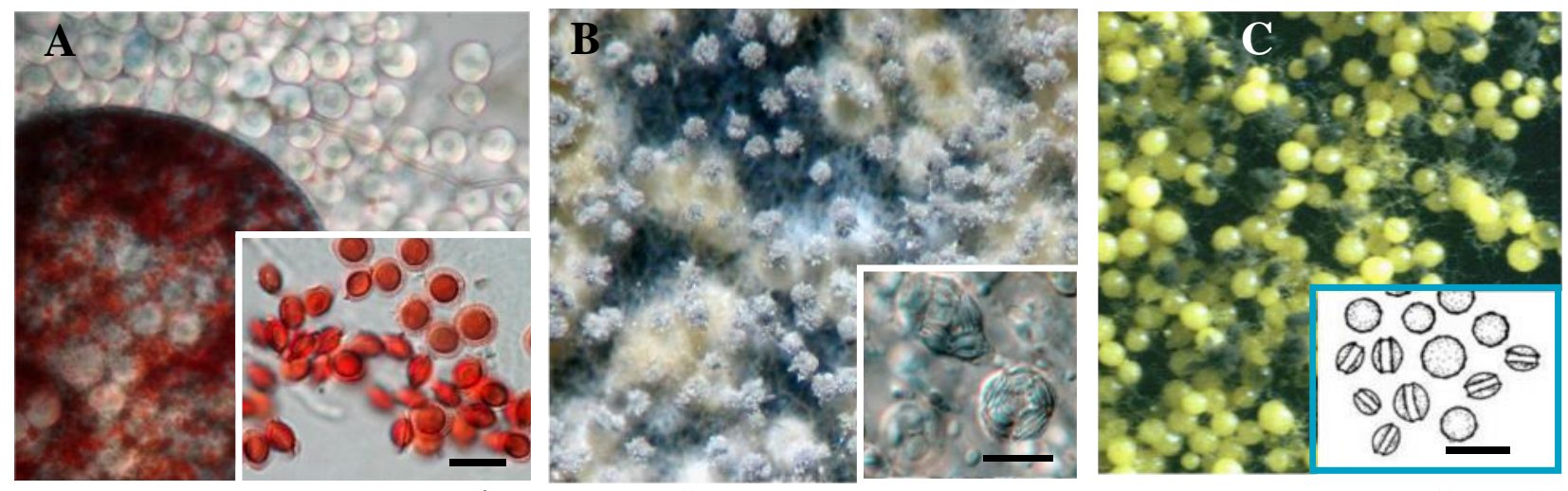

Figuras 3. Tres taxas comunes del género Aspergillus y sus frecuentes teleomorfos asociados. A. Aspergillus nidulans ('emericella-morph'), Cleistotecio, células de Hulle y ascosporas en el recuadro, B. Aspergillus quadricingens ('neosartorya morph') Cleistotecios tomentosos y cabezas conidiales bajo la lupa; recuadro, ascos y ascospsoras C. Aspergillus glaucus ('eurotium morph'), cleistotecios amarillos y cabezas conidiales bajo la lupa;ascosporas en el recuadro. Barrra $10 \mu \mathrm{m}$. 


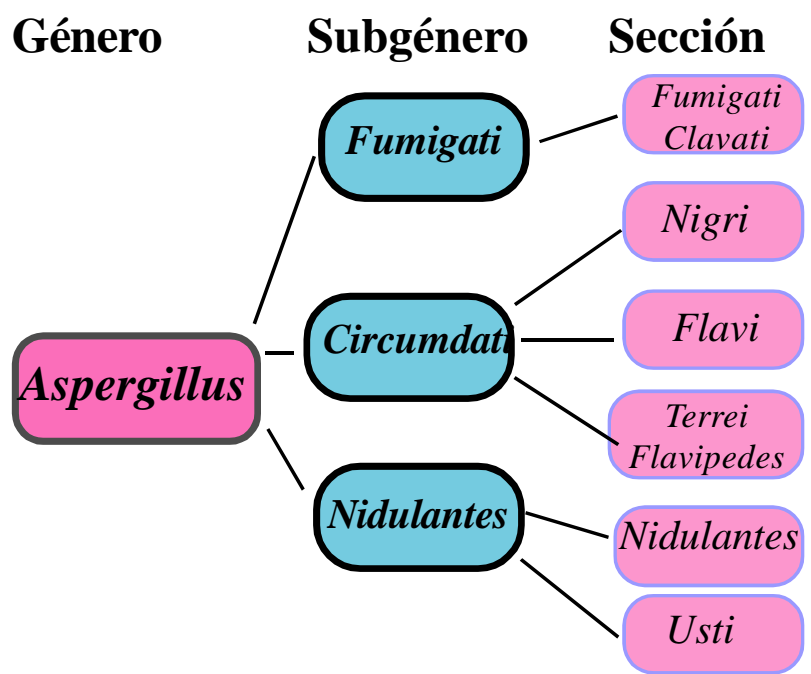

Figura 4. Principales subgéneros y secciones de Aspergillus que contienen especies de interés clínico

Diagnóstico molecular. The International Society for Human and Animal Mycology, patrocinador del Grupo de Trabajo en Aspergillus, recomienda el uso del método de identificación de secuencias de bases comparativas mediante el empleo de las regiones de los espacios ribosomales de transcripción interna (ITS). Marcadores secundarios similaras a las ITS, son fáciles de amplificar y en contraste con las ITS pueden distinguir entre todas las especies mediante locus de codificación de proteínas tales como la región de B-tubulina (BenA), Calmodulina ( $\mathrm{CaM}$ ) o el gen rodlet A (Balajee et al, 2005a-2007; Hong et al, 2005; Samson et al, 2011; Hubka \& Kolarik, 2012, Visagie et al, 2014). Samson et al. (2014), recomiendan como estándar en la identificación de Aspergillus la calmodulina $(C a M)$, como un marcador secundario de identificación (Vea también Fig 5).

Patogenicidad y toxicidad. Aspergillus incluye muchas especies inplicadas en infecciones oportunistas diversas en humanos y otros animales. Muchos casos son causadas por un complejo de especies que incluyen primeramente $\boldsymbol{A}$. fumigatus, seguido de A. flavus y A. niger, sin embargo, A. nidulans puede ser el segundo patógeno más común en el mundo. La aspergilosis, incluye variados cuadros clínicos; alergias, aspergillosis (aspergiloma), osteomielitis, rinitis, la enfermedad pulmonar del granjero, infecciones cutáneas, otomicosis, traqueobronquitis, entre otras (Segal, 2009). Las invasoras se presentan principalmente en individuos con compromiso inmune y son las más comunes causadas por las spp. de Aspergillus (Pagano et al, 2007). En éstas generalmente se presentan integrantes de los complejos $\boldsymbol{A}$. fumigatus (principalmente A.fumigatus s.st.), sin embargo, otras especies pertenecientes a los complejos $\boldsymbol{A}$. flavus, $\boldsymbol{A}$. nidulans y A. terreus han sido reportadas entre otras especies (Verweij,\& Brandt,2007; Nam et al, 2010; Denning et al, 2011).
Las infecciones primarias invasivas, envuelven el tracto seno-pulmonar, siendo el pulmón el común sitio de invasión (Segal 2009). Signos clínicos sugestivos de sinusitis invasiva, incluyen, dolor facial, dolor de cabeza, aumento asimétrico de la cara, epistaxis, proptosis, anormalidad en los nervios craneales, isquemia del paladar, dolor de cabeza y erosión de los huesos. La fiebre y la disnea son los síntomas más comunes, pero no específicos de la aspergilosis pulmonar invasora. La invasión vascular puede presentarse como un dolor pleural en el pecho. Si la enfermedad no es tratada, puede ocurrir que la diseminación hematógena comprometa cualquier órgano. La condición más seria es el compromiso del SNC, con derrame cerebral (Segal, 2009). Como se ha recalcado, la Aspergilosis puede ocurrir en una variedad de órganos ya sea en humanos como en otros animales.

Todos los animales y muchas plantas tienen mecanismos altamente eficientes para prevenir por si mismos la infección por los Aspergillus (sistema inmune específico e inespecífico), solo cuando estos sistemas son defectuosos en alguna medida, permiten que los Aspergillus pueden colonizar e invadir diverso tejidos (Erjavec, et al, (2009). Alternativamente la aspergilosis puede ocurrir en personas inmunocompetentes, donde se presente un daño previo en los tejidos (tuberculosis, enfermedaes crónicas pulmonares obstructivas o bronquiestásis o alguna enfermedad subyacente). Los factores de riesgo para una aspergilosis invasora incluyen pacientes con tratamiento esteroidal o quimioterapia que resultan en una severa neutropenia, las células madres, el transplante de órganos sólidos, el estado tardío de SIDA y las enfermedades genéticas como las granulomatosis crónicas.

Epidemiología. La presencia de especies de Aspergillus, se encuentran ampliamente distribuidas en el ambiente en todo el mundo, especialmente en zonas tropicales y subtropicales (Ryan, 2004). Sin embargo, las especies de este género, en especial A.fumigatus s st, sigue siendo uno entre los más frecuente causantes de enfermedades invasoras por hongos filamentosos (Segal, 2009). Las infecciones invasoras se asocian con una alta tasa de mortalidad y morbilidad, especialmente en individuos con compromiso inmune, tales como pacientes con transplantes (Verweij, et al, 2007; Segal 2009). En los Estados Unidos, el número de aspergilosis con causa de muerte en pacientes inmunocomprometidos, aumentó desde un 0,04 por 100.000 personas en 1980 a 0,15 muertes por 100.000 personas en 1997 (McNeil, et al, 2001). Mientras Pagano et al, (2007) reportaron una mortalidad de un $13 \%$ en el año 2006 . Si se compara con el año 2003, la mortalidad asociada a las aspergilosis invasoras en leucemias agudas, decreció desde un $24 \%$, y su incidencia aumentó desde un 5,8\%.(Mc Neil et al, 2001: Pagano et al, 2007).

Medios de cultivo empleados. Los cultivos se inoculan en 3 puntos en placas de Petri de $9 \mathrm{~cm}$, usando una densa suspensión de conidios y se incuban a $25^{\circ}$ y $37^{\circ} \mathrm{C}$ por 


\section{Figura 5 . Diagrama de flujo que resume los métodos recomendados para la identificaciòn de las especies de Aspergillus}

(Tomado de Samson et al, 2014)

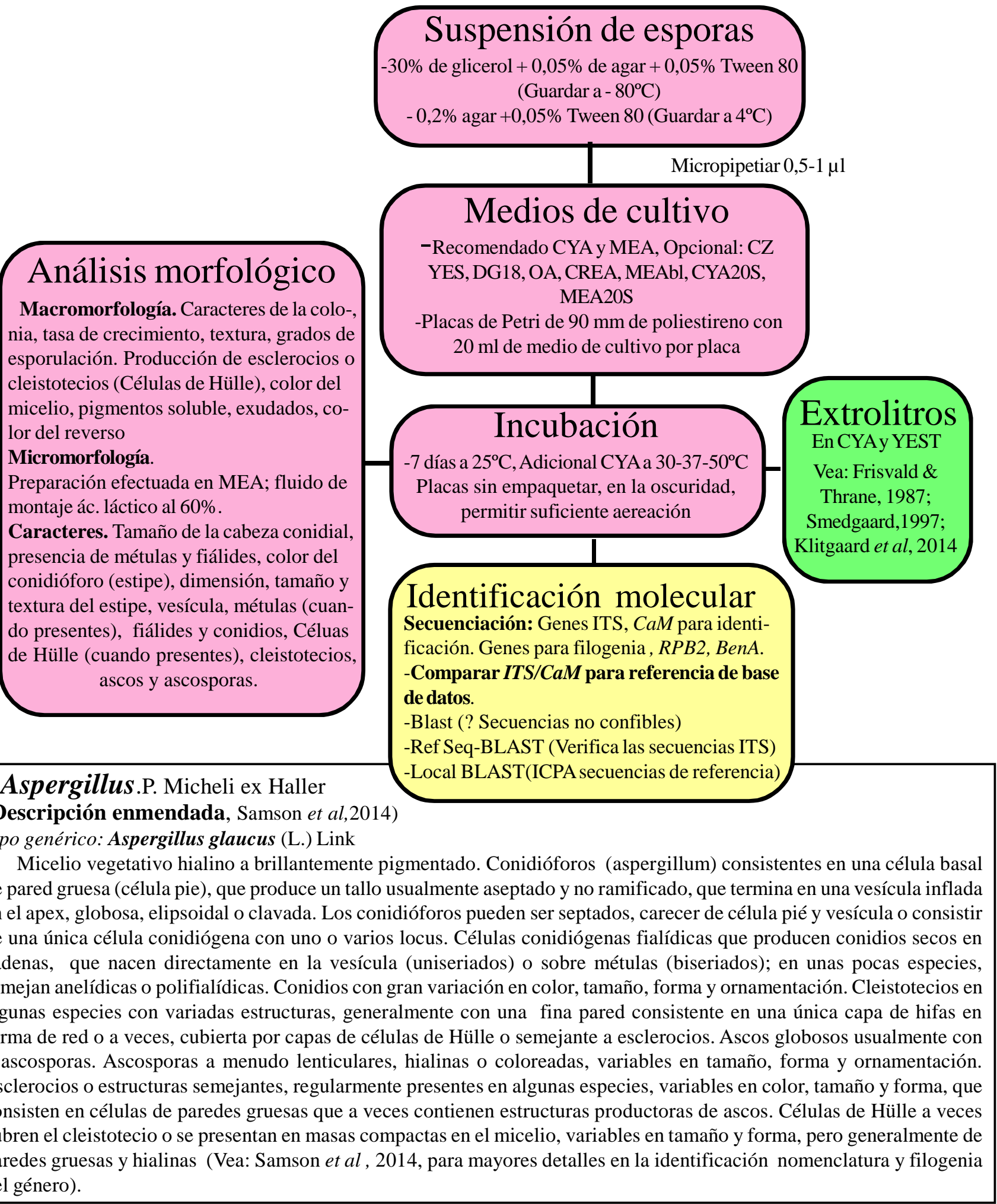


7 días en oscuridad en los siguientes medios : CYA y MEA y se examinan también a los 10 días en MEA y 14 días CYA y para los rangos máximos y mínimos se incuba a 10-15-30-40$45-50^{\circ} \mathrm{C}$. Puede emplearse también Agar avena y YES (estracto de levadura sucrosa), u otros medios específicos según la especie. El diámetro de las colonias se mide mediante una regla. Las estructuras finas de todos los aislados se examinan bajo aceite de inmersión a 1000 x y los preparados a examinar se obtienen del medio agar Malta, empleando ácido et al,2010)

(Vea Fig.5).

Diagnosis: La diagnosis puede hacerse por detección de las especies de Aspergillus por biopsia, cultivo y microscopía de las muestras de tejidos, radiografías pulmonares, resonancia magnética y la detección de antígeno en el cuerpo (Platelia Aspergillus).

Vea tambien los métodos de identificación en Fig.5.

\section{Complejos de especies de Aspergillus de interés clínico}

\section{A). Subgénero Fumigati, Sección Fumigati.}

El subgénero Fumigati incluye la sección Fumigati (neosartorya morph), la sección Clavati, que se destaca por sus largas vesículas clavadas (neocarpenteles y dichotomomyces-morph) y la sección Cervini (sin teleomorfo conocido). Dichotomomyces, (D.cejpii) es un hongo cosmopolita que pertenece a la familia Trichocomaceae y sus ascosporas son muy resistentes al calor (Mayer et al. 2007). Dichotomomyces y Neosartorya son hermanas del clado de Neocarpenteles, especialmente en la producción de extrolitros. Sin embargo, se necesitan mayores estudios para el estatus taxonómico de Dichotomomyces con anamorfos en Polypaecilum. Los integrantes de la sección Cervini, presentan cabezas conidiales uniseradas de color ante, contiene integrantes poco estudiados (Peterson, 2000; Varga et al.2007a)

Nuevas especies morfológicamente similares a $\boldsymbol{A}$. fumigatus se han descrito recientemente e incluidas en la sección Fumigati (Samson et al, 2007a). Los errores en la identificación de tales especies, particularmente oportunistas en humanos, tales como: A. lentulus, A.fumigatiaffinis, A.fumisynnematus, A. felis, A.fischerianus, A.hiratsukae, A. thermomutatus y A.udagawae, han sido reportadas con cierta frecuencia en la literatura clínica (Vargas et al, 2000; Balajee et al, 2005a-b-2006; Samson et al, 2007a; Samson \& Vargas, 2007; Hong et al,2006- 2008; Vinh, et al, 2009: Segui et al, 2010; Gyotoku et al,2012; Bars et al, 2013). Sin embargo, A. fumigatus aún se reporta en más de un $90 \%$ de los casos de aspergilosis invasoras.

La Sección Fumigati incluye unas 40 especie uniseriadas, con cabezas conidiales columnares en tonos de verde y vesículas en forma de frasco (Raper \& Fennell 1965). Los teleomorfos asociados fueron colocados por Malloch \& Cain
(1972) en el género Neosartorya. Las características de las colonias en los medios estandar son a menudo similares a $\boldsymbol{A}$. fumigatus, pero los conidios pueden ser diferentes. Las especies que producen cleistotecios (neosartorya-morph) tienen ascosporas resitentes al calor.

\section{Aspergillus fumigatus Fresenius}

(=Neosartorya fumigata) (Fig.6).

Colonias con diám. en CYA25 en 7 días, 21-67 mm; en MEA25, 25-69 mm; en YES25, 48-74 mm; en agar avena (OA) a $25^{\circ} \mathrm{C}, 34-62 \mathrm{~mm}, \mathrm{CYA} 37,60-75 \mathrm{~mm}$, CREA: pobre desarrollo, sin ácido o muy leve. Colonias aterciopeladas a flocosas, de color gris turquesa o turquesa oscuro a verde oscuro profundo. Conidios abundante (raramente lo contrario), reverso en CYA: crema, amarillo a naranja.

Micromorfología. Cabezas conidiales columnares, con estipe de 50-350 x 3,5-10 $\mu \mathrm{m}$. Vesículas con un diám, 10-26 $\mu \mathrm{m}$, piriformes a subclavadas a veces subglobosas, pero raramente globosas. Conidios globosos a elipsoidales, 2-3,5(-6) $\mu \mathrm{m}$, lisos a finamente rugosos. Hongo heterotálico que bajo condiciones especiales y con cepas de polos opuestos forma clestotecios. La especie crece a $50^{\circ} \mathrm{C}$ o más pero no a $10^{\circ} \mathrm{C}$. Distribución mundial.

Muchos aislados hetero y homotálicos de la sección, semejan fuertemente A. fumigatus, pero demuestran un crecimiento lento a $37^{\circ} \mathrm{C}$ o una baja esporulación en los cultivos y no crecen generalmente a $50^{\circ} \mathrm{C}$, pero si a $47^{\circ}, 45^{\circ} \mathrm{C}$ o solo hasta $42^{\circ} \mathrm{C}$, como es el caso específico de A.udagawae, que crece a $10^{\circ} \mathrm{C}$ pero no a más de $42^{\circ} \mathrm{C}$ y sus conidios necesitan un largo período de incubación para germinar a $37^{\circ} \mathrm{C}$. Esto sugiere que son más susceptibles al ataque de los neutrófilos y al peróxido de nitrógeno, lo que disminuye su virulencia y permite apreciar la sutil distinción causada por estas 2 especies (Sugui et al, 2010). Mediante análisis de secuencias de multilocus, estos integrantes pueden semejarse fenotípicamente a varias especies relacionadas con A.fumigatus, pero filogenéticamente distintas.

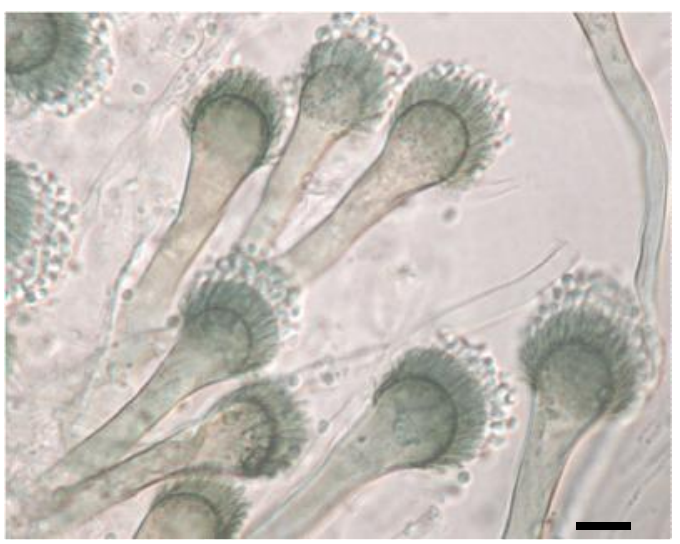

Figura 6 A.fumigatus, típicos conidióforos y vesículas mayoritariamente clavadas y disposición de las fiálides sobre la vesícula. Barra $=10 \mu \mathrm{m}$ 
2. Aspergillus lentulus Balajee \& Marr (neosartorya-morph)( Fig. 7).

Colonias con diám en CYA25, (19-)25-56 mm, en 7 días; MEA25, (30) 40-70 mm; YES25, 42-80 mm; OA25, 44-59 $\mathrm{mm}$; CYA37, 54-70 mm, CREA crecimiento débil, sin producción de ácido. Color de la colonia: blanca con conidios entremezclados gris verdosos, flocosa, conidiación pobre, pero abundante en algunos aislados. Reverso de la colonia en (CYA), pálido amarillento a gris naranja café.

Micromorfología. Cabezas conidiales cortas columnares con estipe, 20-500 × 4-7 $\mu \mathrm{m}$, liso a veces sinuoso o contreñido en el cuello, vesícula, (6-)10-25 $\mu \mathrm{m}$, globosa a piriforme, usualmente subglobosa, conidios, 2-3,2 $\mu \mathrm{m}$, globosos a ampliamente elipsoidales, lisos a finamente rugosos. Hongo heterotálico.

Características importantes: estipe (<7um diám.), vesículas globosas, crece a $10^{\circ} \mathrm{C}$ pero no a $50{ }^{\circ} \mathrm{C}$. Distribución: aparentemente mundial. Swilaiman et al, (2013), descubrieron su estado sexual mediante recombinación de polos opuestos (neosartorya morph). Este descubrimiento tiene gran importancia en el manejo de le resistencia a drogas y el control de la aspergilosis invasora por este hongo emergente.

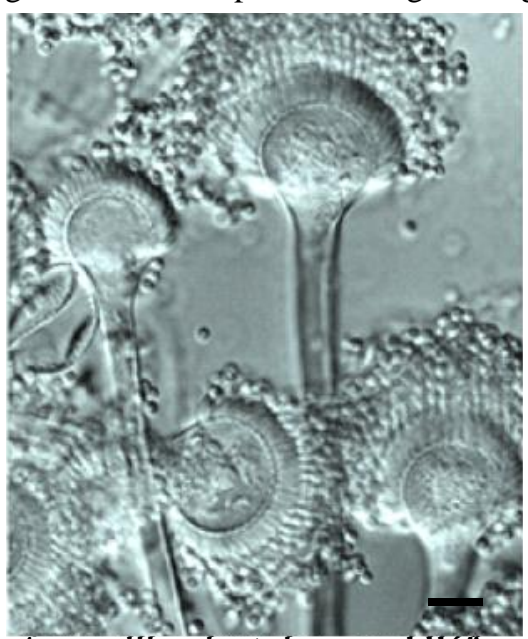

Figura 7. Aspergillus lentulus, conidioforos, vesícula redonda, fiálides y conidios. Barra $10 \mu \mathrm{m}$ (Tomado de; Samson et al. 2007).

3. Aspergillus fumigatiaffinis Hong, Frisvad \& Samson (Fig. 8).

Colonia con diám. en CYA25, 46-49 mm en 7 días; MEA25, 53-60 mm; YES25, 67-74 mm; CYA37, 65-70 mm; CREA: crecimiento débil con buena producción de ácido. Colonias flocosas, de color blanco con el centro verde opaco, de conidiación limitada. Reverso en CYA: amarillento a gris naranja. Micromorfología. Cabezas conidiales columnares cortas con estipe de 6-8 $\mu \mathrm{m}$ en diám, vesículas 18-24 $\mu \mathrm{m}$, globosas a subglobosas, a veces dispuestas en ángulo ('nodding'), conidios 2-3 $\mu \mathrm{m}$, globosos a subglobosos, lisos.

Características importantes: tiene comparativamente pequeñas vesículas (sub)globosas $(16-24 \mu \mathrm{m})$; crece a $10{ }^{\circ} \mathbf{C}$, no a $50{ }^{\circ}$ C. Distribución: USA, España

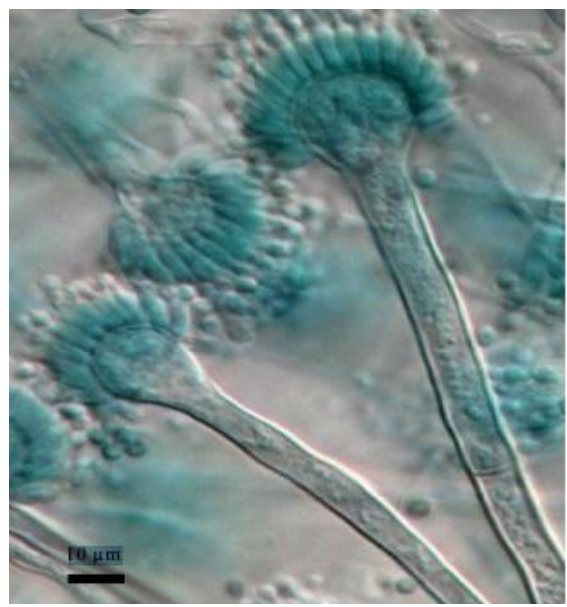

Figura 8. A. fumigatiaffinis, conidióforos, vesículas, fiálides y conidios.

4. A. fumisynnematus Horie, Miyaji, Nishi-

mura,Taguchi et Udagawa.(Fig.9)

Colonias con diám en CYA25, 44-48 mm; MEA25, 5660 mm; YES25, 35-39 mm; OA25, 42-46; CYA37, 57-61 mm, CREA: crecimiento pobre sin producción de ácido. Colonias flocosas, de color grisáceo, de limitada conidiación. Reverso en naranja blanco o naranja gris.

Micromorfología. Cabezas conidiales columnares cortas, con estipe de hasta 210 x 6-8,5 (-10) $\mu \mathrm{m}$, vesículas de un diámetro de 16-20 (-25) $\mu \mathrm{m}$, hemiesféricas; conidios 2,8 -3,2 x 2,42,8 $\mu \mathrm{m}$, ampliamente elipsoidales, verrugulosos.

Características importantes: producción de sinnemata en MEA en el tiempo (1,4-2,3 mm de alto, 30-40 $\mu \mathrm{m}$ en diám.). Crece $\mathrm{a}^{\circ} \mathrm{C}$ pero negativo a $50^{\circ} \mathrm{C}$. Distribución: Brasil, Venezuela, España.

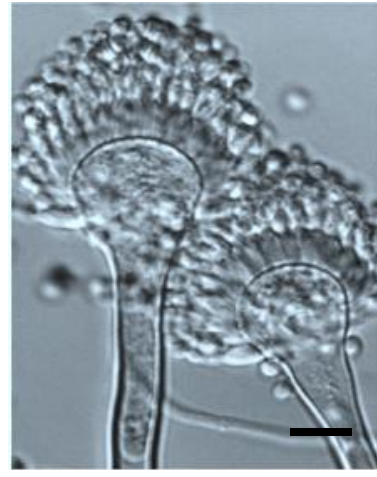

Especies semejantes: $\boldsymbol{A}$. fumigatus, A.lentulus, A.novofumigatus, A.fumigatiaffinis.

Figura 9. A. fumisynnematus, conidióforos, vesículas, fiálides y conidios. Barra $10 \mu \mathrm{m}$ (Figura tomada de: Samson et al. 2007).

5. Aspergillus felis Barrs, van Doorn, Varga \& Samson (Fig.10)

Colonias de crecimiento rápido en CYA25, $5-5,5 \mathrm{~cm}$. diám. en 7días, MEA, $5,5 \mathrm{~cm}$. En CYA, la textura de la colonia es generalmente flocosa y blanca en color, con pobre esporulación; en MEA, las colonias son más o menos 
aterciopeladas con abundante esporulación verdosa entre los 5 a 7 días, con reverso crema a ligeramente verdoso. En OA25 crece similar al MEA,en CYA 37, > 50 mm diám.

Micromorfología. Conidióforos uniseriados con estipe verdosos y cabezas subclavadas o dobladas hacia un lado 'nodding'. Vesículas subclavadas con un diam. de 15-16,5 $\mu \mathrm{m}$. Conidios verdes globosos a subglobosos, finamente rugosos, 1,5-2,5 $\mu \mathrm{m}$. Como es un hongo heterotálico al cruzarse con la cepa compatible opuesta forma cleistotecios (neosartorya-morph) blanco-crema, 100-230 $\mu$ m en diám, con ascos globosos, 8- esporas, 12-16 $\mu \mathrm{m}$ en diám. Ascosporas lenticulares con 2 prominentes crestas ecuatoriales y una corta superficie convexa equinulada $5-7 \times 3,5-5 \mu \mathrm{m}$

Distribución. Esta especie se ha encontrado en gatos con rinosinusitis fúngica crónica invasiva o con una infección cavitaria sinusal, en un perros con aspergilosis invasora, en humanos con aspergilosis pulmonar invasora y en una muestra de aire en ambiente interno en Alemania (vea: Barrs et al, 2013). Parece tener amplia distribución mundial (Piontelli et al, 2013).

A. felis, es integrante del complejo A. viridinutans y se ha confundido en la literatura con esta especie, sin embargo, este último no crece a $45^{\circ} \mathrm{C}$ ( solo a $42^{\circ} \mathrm{C}$ ). Fenotípicamente es relacionado con Neosartorya aureola y A. udagawae; difiere de N. aureola en que es una especie heterotálica (Samson et al,2007a, Kano et al, 2013 ). Este complejo está integrado por otras especies como: A.aureo lus, A.udagawae, A.wyomingensis, A.felis y A. viridinutans s.st. La presencia de sus vesículas en ángulo ("nodding appearence'), es una situación no exclusiva del complejo, como comenta Nováková et al., (2014), debido a que se observa en otros representantes de la sección Fumigati como: A. brevipex, A.duricaulis, A. marvanovae, A. fumisinnematus, A.unilateralis, A.thermomutatus (=Neosartorya pseudofischeri) y las 2 nuevas especies recientemente descritas A.brevistipitatus y A. conversis. (Nováková et al., 2014).

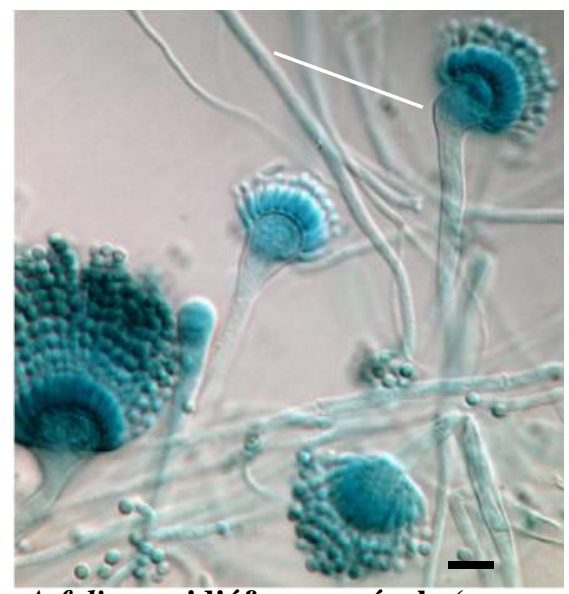

Figura. 10. A.felis, conidióforos vesícula (una en ángulo), fiálides y conidios, Barra $=10 \mu \mathrm{m}$

\section{A. fischeranus Kozakiewicz (neosartorya morph)} (=N.fischeri(Wehmer) Malloch \& Cain) (Fig. 11)

Colonia en CYA25, con diám. de 45-68 mm en 7 días; MEA25, 66-80 mm; YES25, 70-80 mm; OA25, 58-80 mm; CYA37, 65-84 mm; CREA: pobre crecimiento sin producción de ácido. Color de la colonia en (CZA): blanca a amarillo pálido, velutinosa, conidiación dispersa pálida, reverso sin color o color carne.

Micromorfología. Cabezas columnares; estipe, 300 -500 x 4$7 \mu \mathrm{m}$,vesículas, $12-18 \mu \mathrm{m}$, en diám. en forma de frasco. Conidios 2-2,5 $\mu \mathrm{m}$, globosos a subglobosos, microtuberculados. Hongo homotálico con cleistotecios de hasta 400 $\mu \mathrm{m}$, crema pálidos, que nacen únicos o en pequeños racimos, envueltos en hifas laxas. Ascosporas, 7-8 x 3-4 $\mu \mathrm{m}$, convexas, que originan 2 crestas anastomosadas (reticuladas). Especie similar: N. tatenoi. Distribución: mundial: suelo, arroz, algodón, papas, nueces, cuero, productos del papel, productos envasados, patogénica en humanos y otros animales (Coriglione et al. 1990; Lonial et al. 1997; Mellado et al. 2006)
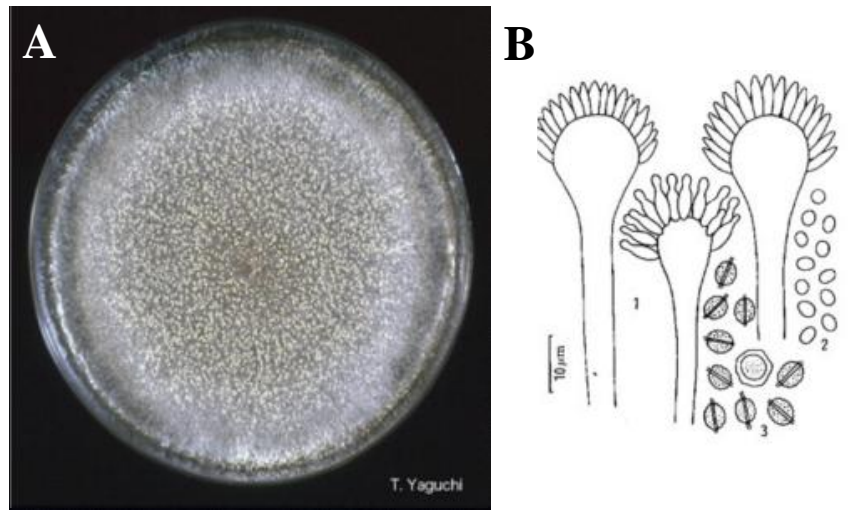

Figuras 11 .A-B. A. fischerianus, A.Cleistotecios despues de 3-6 semanas en MEA, B. (1) Conidióforos, (2) conidios y (3) ascosporas . Tomado de: Species 2000 Catalogue of Life, China: Annual Checklist 2009

\section{A. hiratsukae Udagawa, Tsubouchi \& Horie} (neosartorya morph $)(=$ Neosartorya hiratsukae Udagawa, Tsubouchi \& Horie) (Fig. 12).

Colonias de crecimiento lento en CYA25, 12-14 mm en 7 días ; MEA25, 26-39 mm; YES25, 42-45 mm; OA25, 42-45 mm; CYA37, 27-30 mm; CREA: más bien crecimiento pobre sin producción de ácido. Colonias aterciopeladas de color gris verdoso en CZA, con moderada conidiación, reverso en (CZA), café pálido.

Micromorfología. Cabezas conidiales, columnares cortas con estipe, 120-380 x 5-7 um. Vesículas de 15-24 $\mu \mathrm{m}$, en forma de frasco,con conidios de, 2-2,5 $\mu \mathrm{m}$, globosos a subglobosos, lisos o delicadamente rugosos. Homotálico Cleistotecios: 130-220 $\mu \mathrm{m}$, de color crema pálido, con ascosporas, 4,5-5 $\mu \mathrm{m}$, lenticulares, con crestas ecuatoriales apretadas, de superficie convexa, fínamente reticulada. 
Características importantes: crecimiento restringido en CZA, pequeños cleistotecios con ascosporas finamente reticuladas. Especies similares: A fischerianum, A. tateno $i$ (Ambas homotálicas)

Distribución: Japón, Brasil, Korea del Sur. Hábitat: suelo, jugos de frutas, aire interno.

Patogenicidad: patogénico en humanos (Guarro et al. 2002; Mellado et al. 2006)

Nota: no crece sobre $\operatorname{los} 48^{\circ} \mathrm{C}$.
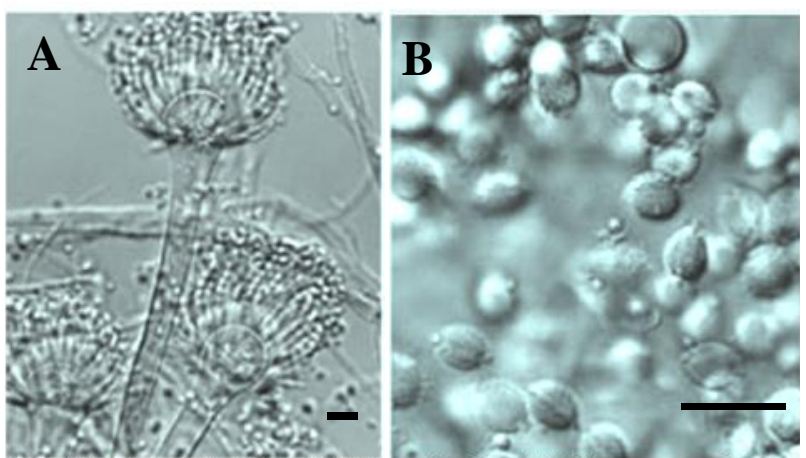

Figuras 12. A-B. A.hiratsukae, A. Conidioforos, vesículas y conidios (Barra $10 \mu \mathrm{m}$ ), B. Ascosporas (Tomado de: Samson et al. 2007)

8. A.thermomutatus (Paden) Peterson (neosartorya morph) (=Neosartorya pseudofischeri Peterson) (Fig. 13)

Colonias en CYA25, 60-70 mm en 7 días; MEA25, 90 $\mathrm{mm}$, color de la colonia, blanca a crema pálido conidiación escasa; reverso en (CZA): claro o amarillo débil, colonia aterciopelada con cabezas conidiales laxamente columnares. Micromorfología. Estipe 200-300 x 4-7 $\mu \mathrm{m}$. Vesículas con un diám, 10-17 $\mu \mathrm{m}$, subglobosas, a veces en ángulo sobre el estipe, conidios 3-4 $\mu \mathrm{m}$, globosos a subglobosos, lisos. Homotálico que presenta cleistotecios de, 150-300 $\mu \mathrm{m}$, blancos. Ascosporas: 4,5-6 $\mu \mathrm{m}$, subglobosas, con 2 crestas ecuatoriales de $1 \mu \mathrm{m}$ de ancho, de superficie convexa con levantados alerones que semejan proyecciones triangulares

Diagnóstico diferencial, ascosporas con diferente ornamentación.

Distribución: U.S.A., Canada, Holanda, Korea del Sur, España, Dinamarca, Estonia.

Hábitat: suelo, ambiente interno.

Patogenicidad: patogenico en humanos (Padhye et al., 1994; Jarv et al. 2004; Balajee et al. 2005a ; Lau et al. 2007) y en animales (Barrs et al. 2007).

9. A. udagawae Horie, Miyaji \& Nishim. (neosartorya morph) (=Neosartorya udagawae Horie, Miyaji \& Nishim.) (Fig. 14).

Colonia en CYA25, 33-36 mm en 7 días; MEA25, 63- 68 mm; YES25, 64-68 mm; OA25, 51-55 mm; CYA37, 61-65mm; CREA: crecimiento pobre sin producción de ácido. Color de la colonia en (CZA), azul oscuro, de aspecto aterciopelado con abundante conidiación; reverso ligeramente anaranjado a gris-naranja.
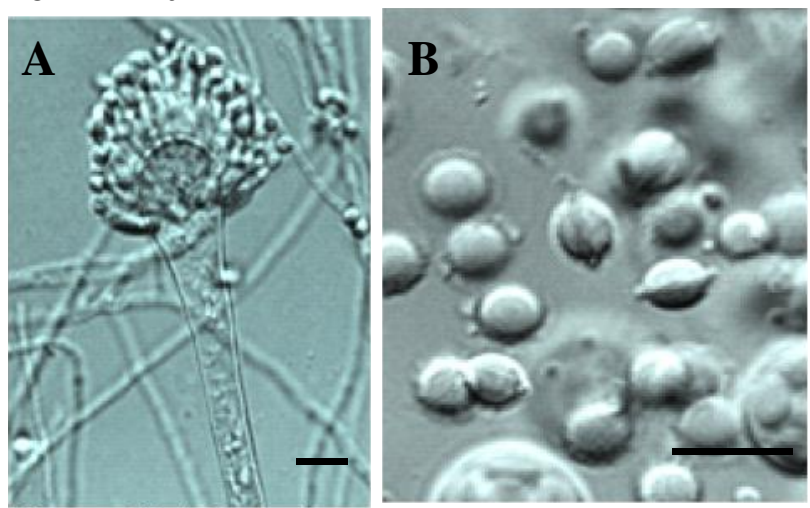

Figuras 13, A-B. A. thermomutatus, A. Conidióforos y conidios, B. Ascos y ascosporas (Tomada de: Samson et al.

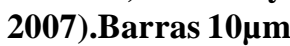

Micromorfología. Cabezas conidiales columnares, estipe hasta 530 x 4-6 $\mu \mathrm{m}$, vesículas, 12-15 $\mu \mathrm{m}$, hemiesféricas a forma de frasco, conidios, 3,2- 6 × 2,4-2,6 $\mu \mathrm{m}$, subglobosos a ampliamenmte elipsoidales, lisos. Heterotálico.

Cleistotecios con presencia de polos opuestos, 310$620 \times 280-530 \mu \mathrm{m}$, amarillo blanco a amarillo pálido, rodeados de hifas laxas hialinas a amarillo pálido a café. Ascosporas, 55,5 x 4-5 $\mu \mathrm{m}$, ampliamente lenticulares con dos crestas ecuatoriales a menudo irregulares, con superficie convexa tuberculada.

Diagnostico diferencial: especie heterotálica con características ornamentaciones tuberculadas en las ascosporas. Especie similar: N. aureola, A. viridinutans

Distribución: Brasil, U.S.A., España, Japón, Argentina.

Hábitat: suelo y patogénica en humanos (Balajee et al. 2006; Moragues et al. 2006).

Las comparaciones micológicas de A.udagawae y $\boldsymbol{A}$. fumigatus por Segui et al, (2010) y Gyotoku et al, (2012) muestran que A.udagawae es menos sensitivo a la anfotericina $\mathrm{B}$, menos virulento y más sensitivo al peróxido de nitrógeno que A. fumigatus. Además las colonias en cultivo no son similares: $A$. udagawae crece más lento que A. fumigatus y no crece a $45^{\circ} \mathrm{C}$. El color de las colonias es verdoso-blanco y la superficie de los conidios es aparentemente lisa, mientras las colonias típicas de $\boldsymbol{A}$. fumigatus, son azul grisáceas y sus conidios espinosos.

\section{A. laciniosus Hong, Frisvad \& Samson} (neosartorya morph) (=Neosartorya laciniosa Hong, Frisvad \& Samson) (Fig.15).

Colonia en CYA25, 38-58 mm diám en 7 días; MEA25, 53-67 mm; YES25, 60-78 mm; OA25, 52-59 mm; CYA37, 70$80 \mathrm{~mm}$; CREA: pobre crecimiento sin producción de ácido. Color de las colonias en CYA, blancas a amarillo pálido con 


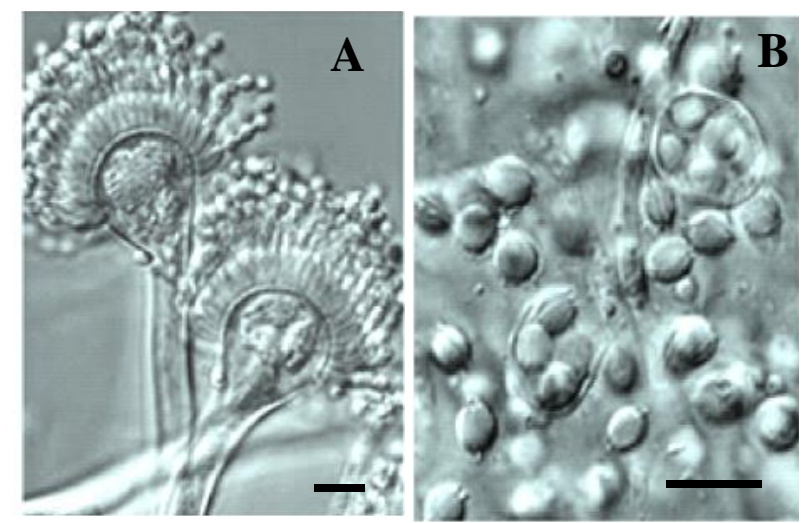

Figuras 14. A-B. A. udagawae. A. Conidióforos, vesículas, fiálides y conidios, B. Ascos y ascosporas (Tomada: de Samson et al. 2007. Barras $10 \mu \mathrm{m})$.

conidiación dispersa, con textura surcada a granular, reverso gris naranja a amarillo naranja.

Micromorfología. Cabezas conidiales columnares, con estipe de 3-4 $\mu \mathrm{m}$ de ancho, vesículas 10-14 $\mu \mathrm{m}$, subclavadas, conidios, 2,5-3,5 $\mu \mathrm{m}$, globosos a subglobosos, lisos.

Hongo Homotálico con cleistotecios, 300-400 $\mu \mathrm{m}$, blancos a amarillo pálido, con ascosporass, 4-5 $\mu \mathrm{m}$, ampliamente lenticulares con 2 distintivas crestas ecuatoriales derechas, que pueden tener una separación de hasta $2 \mu \mathrm{m}$.
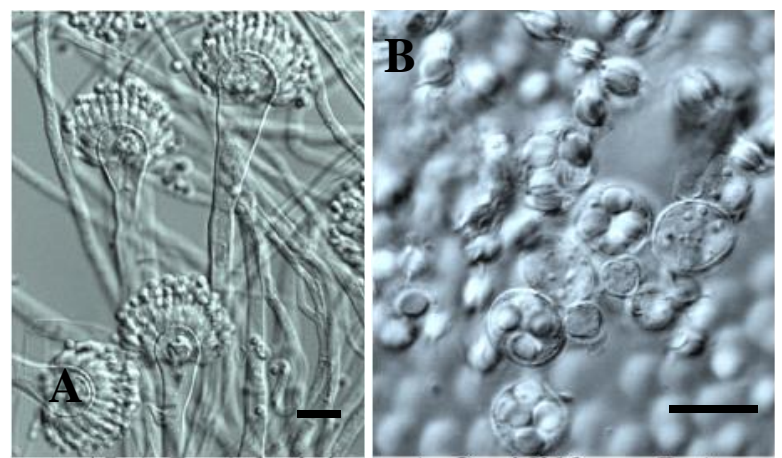

Figuras 15. A-B, A. laciniosus. A. Conidióforos, B. Ascos y ascosporas (Barra $10 \mu \mathrm{m}$ ) Tomado de: Hong et al, 2006.

Diagnostico diferencial: cleistotecios rodeados por hifas laxas hialinas a amarillentas de 2-4 $\mu \mathrm{m}$ de ancho, microtuberculadas, con ascosporas con 2 curvados y 2 nítidos anillos ecuatoriales con pequeñas proyecciones. $\boldsymbol{A}$. udagawae difiere de A. lacinosus en ser heterotálica, por no crecer sobre $\operatorname{los} 42^{\circ} \mathrm{C}$ y es refractaria a la terapia antifúngica (Barrs etal. 2012).

Especies similares: $A$. spinosus (=N. spinosa) y A.coreanus (=N. coreana). Distribution: suelo en Korea del Sur U.S.A, Canadá, Pakistan, Holanda, Surinam, República Dominicana, Kenya. Patogenicidad: un caso reportado en Canadá de aspergilosis invasora seno-orbital (Malejczyk et al, 2013).

\section{B). Subgénero Fumigati Sección Clavati}

Las especies de Aspergillus en la sección Clavati son alcalino y acido tolerantes, de hábitat diversos y su especie más común (A.clavatus), es seguramente cosmopolita y aislada frecuentemente en excrementos de herbívoros, el suelo y cereales almacenados con alto contenido de humedad. La producción de variadas micotoxinas es común en sus especies integrantes, en especial la producción de patulina (Varga et al.2003a). Los análisis filogenéticos de las secuencias de ITS, B tubulina y Calmodulina, indican que esta sección incluye 6 especies: A. clavatus (sinónimos: $=A$. apicalis, A. pallidus), A. giganteus, A.rhizopodus, A. longivesica, A.acanthosporus (neocarpenteles-morph) y A. clavatonanicus. A.acanthosporus es el único que posee teleomorfo en la sección, el cual mediante datos de secuencias corresponde a un género hermano de Neosartorya y Dichotomomyces (Varga et al. 2007b). Las especies de Aspergillus con teleomorfos a sociados a Neosartorya $\mathrm{y}$ Neocarpenteles, tienen anamorfos con conidios verdes, mientras los anamorfos de Dichotomomyces, pertenecen a un género diverso como Polypaecilum, de colonias de color blanco cremas y sus ascomata y ascosporas tienen una morfología similar a las de Neosartorya y Neocarpenteles.

En esta sección solo es de importancia clinica $\boldsymbol{A}$, clavatus, que se ha descrito solo una vez en una onicomicosis y A clavatonanicus en Brasil (Batista et al. 1955).

\section{Aspergillus clavatus Desmazires (Fig.16)}

Diámetro de las colonias en CYA25, 28-45 mm en 7 días; MEA25, 25-44 mm; YES25, 29-45 mm; Agar avena 25, 31-47 mm; CYA37, 9-26 mm; CREA25, muy buen crecimiento con moderado a muy fuerte producción de ácido (algunas aislados pueden crecer poco y no producir (o producir muy poco ácido). Colonias aterciopeladas de color azul verdosas, de abundante esporulación, reverso en CZA, sin color o algo de cafesoso en algunos aislamientos con la edad.

Micromorfología. Cabezas conidiales clavadas, comunmente largas, entre los 150 a $400 \mu \mathrm{m}$ de largo, que frecuentemente se abren con la edad en 2-3 o más columnas divergentes. Estipe 1500-3000 x 20-30 $\mu \mathrm{m}$, con vesículas de 200-250 x 40-60 $\mu \mathrm{m}$, clavadas. Conidios , 3 -4,5 x 2,5-3 $\mu \mathrm{m}$, elípticos, lisos.

Diagnóstico diferencial: cabeza conidial hasta de $4 \mathrm{~mm}$ en largo. Distribución cosmopolita, principalmente en países tropicales, subtropicales y regiones mediterráneas. Común en suelo, cereales, malta y excremento de herbívoros. Patógeno oportunista en humanos y animales, produciendo alveolitis alérgica extrínsica, (Lopes-Días \& Flannigan 1997) neurotoxicosis ( McKenzie et al, 2004) endocarditis (Opal et $a l, 1986)$ y puede ser un efectiva herramienta para el manejo y proliferación de larvas de mosquito (Aedes aegypti) (Seye et al, 2009). 


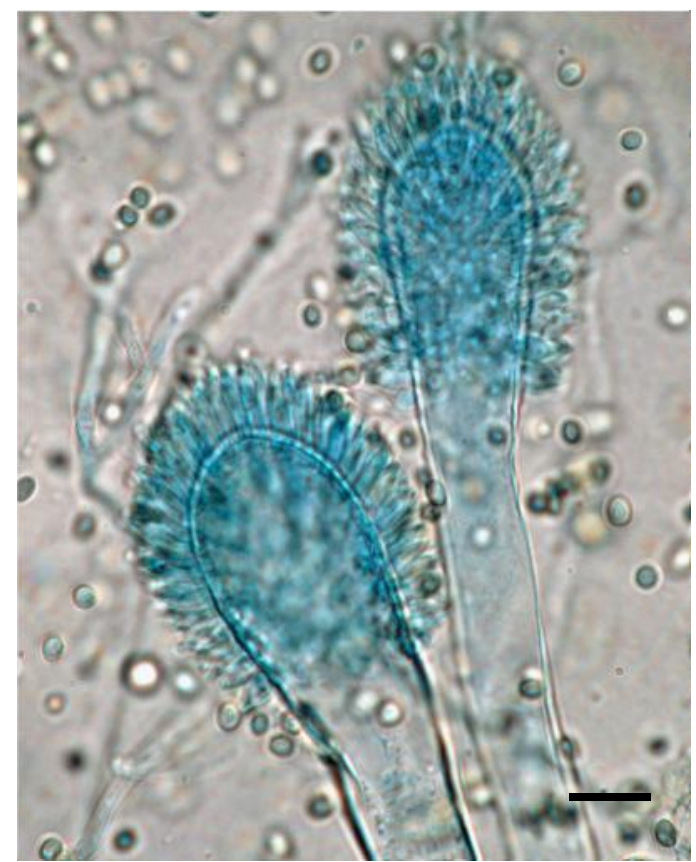

Figura 16. Conidióforos monoseriados con vesículas clavadas y conidios . Barra10 $\mu \mathrm{m}$

\section{Clave tentativa de las especies oportunistas del subgénero Aspergillus}

Las claves dicotómicas o politómicas no tienen mucha utilidad, especialmente en las especies heterotálicas, debido a sus similitudes morfológicas; son más útiles en algunas especies homotálicas, sin embargo, algunos datos morfofisiológicos son útiles en un diagnóstico primario. Es esencial el empleo de la biología molecular para el diagnóstico definitivo.

1.- $\quad$ Especies heterotálicas ........................................2

Especies homotálicas ...........................................

2.- $\quad$ Especies con vesículas monoseriadas, redondas, subglobosas o piriformes.

Especie con vesículas monoseriadas, clavadas y largas A.clavatus Desmazières

3.- $\quad$-Aislados que crecen a $50^{\circ} \mathrm{C}$

-Aislados que crecen hasta $45^{\circ} \mathrm{C}$.........................5

-Aislados que crecen hasta $42^{\circ} \mathrm{C}$. A.udagawae Horie, Miyaji \& Nishim. (Requiere largos príodos de incubación para esporular a $37^{\circ} \mathrm{C}$, conidios lisos).

4.- -Aislados que crecen a temperatura de $50^{\circ} \mathrm{C}$, pero no a $10^{\circ} \mathrm{C}$ A.fumigatus Fresenius

- Aislados que crecen a 10 y $50^{\circ} \mathrm{C}$, fiálides que ocupan los 3/4 de la vesíscula (saprotrofo?)...... ..... (A.turcosus S.B. Hong, Frisvad and Samson. Vea: Hong et al, 2008).

5.- Sinnemata presente en el tiempo en MEA, conidios ampliamente elipsoidales, verrugosos.. .......A.fumisynnematus Horie, Miyaji, Nishimura,Taguchi et Udagawa

-Sinnemata ausente en el tiempo en MEA .6

6.- $\quad$-Estipe $<$ de $7 \boldsymbol{\mu m}$ de ancho, vesículas 10-25 $\mu \mathrm{m}$ de diám., conidios ampliamente elipsoidales, lisos a finamente rugosos, 2-3,2 $\mu \mathrm{m}$. CREA sin ácido A.lentulus Balajee \& Marr.

-Estipe < de7 $\boldsymbol{\mu m}$ de ancho, vesículas pequeñas, 15-16 um diám., algunas dobladas en ángulo ('nodding'), conidios pequeños, verdes globosos a subglobosos, finamente rugosos, $1,5-2,5 \mu \mathrm{m}$,

Varga \& Samson A.felis Barrs, van Doorn,

-Estipe, 6-8 $\mu \mathrm{m}$ de ancho, conidios globosos a subglobosos lisos, CREA buena producción de ácido ......... A.fumigatiaffinis Hong, Frisvad \& Samson.

7.- $\quad$-Colonias de crecimiento rápido en CYA $>$ de $50 \mathrm{~mm}$ en 7 días. 8

-Colonias de crecimiento lento en CYA $<$ de 20 mm en 7 días ...........A. hiratsukae Udagawa, Tsubouchi \& Horie. Cleistotecios pequeños 130$220 \mu \mathrm{m}$, ascosporas, 4,5-5 $\mu \mathrm{m}$, lenticulares, con crestas ecuatoriales apretadas.

8.- $\quad$ - Ascosporas 7-8 x 3-4 $\boldsymbol{\mu m}$, convexas, con 2 crestas ecuatoriales anastomosadas, reticuladas o irregularmente acordonadas.... A.fischerianus Kozakiewicz.

- Ascosporas 4,5-6 $\mu \mathrm{m}$, subglobosas, con 2 crestas ecuatoriales de $1 \mu \mathrm{m}$ de ancho, de superficie convexa con levantados alerones, que semejan proyecciones triangulares. A.thermomutatus (Paden) Peterson.

-Ascosporas, 4-5 $\mu \mathrm{m}$, ampliamente lenticulares con 2 distintivas crestas ecuatoriales derechas, que pueden tener una separación de hasta $2 \mu \mathrm{m}$ .......... A.laciniosus Hong, Frisvad \& Samson.

\section{B). Subgénero Circumdati Sección Nigri}

La mayoría de las especies incluidas en este subgénero son biseriadas, salvo algunas especies (Clado 
aculiatus), mientras las incluidas en la sección Nigri (especie grupo Aspergillus niger, Rapel y Fennel, 1965; Aspergillus sección Nigri Gams et al. 1985), se consideran entre los organismos más comunes en ambientes internos y externos ya sea en el suelo y su cobertura vegetal como en la contaminación de los alimentos. Tienen gran importancia en la industria por sus cualidades fermentativas en la producción de enzimas hidrolíticas tales como, lipasas, amilasas, ácidos orgánicos (cítrico y glucorónico), así como su manipulación genética en biotecnología (Kozakievicz, 1989; Samson \& Varga, 2010) y la capacidad de algunas especies de producir ocratoxinas, en especial A.carbonarius, pero a veces también A.niger y A tubingensis (Samson et al, 2004a-b; Franco, 2006; Kizis, 2014). Debe destacarse además, la capacidad de algunas especies de esta sección como grupo de hongos de importancia médica (Howard et al,2011).

Los llamados Aspergillus negros, son un grupo problemático en su identificación (Samson et al, 2007b) que fue aumentando en su número de especies desde las 12 descritas por Raper \& Fennel (1965). Al Musalem (1980) revisa el grupo A.niger mediante morfofisiología e incluye 7 especies y considera A.niger como un agregado con siete variedades y 2 formas, mientras Kozakievicz (1989), mediante microscopía electrónica, separa las especies con conidios equinuladas de los otros aspergilos negros con conidios verrugosos. En el nuevo siglo 21, la biología molecular ha efectuado diversos aportes en la Sección, la que actualmente acumula unas 25 especies (vea datos bibliográficos y taxonómicos en: Samson et al, 2004 a; Noanim et al, 2008; Samson \& Varga 2010; Varga et al, 2011; Jurjevic et al, 2012: Hubka \& Kolarik, 2012; Kizis et al, 2014, entre otros).

Patogenia: Las especies que pertenecen a los Aspergillus de esta sección en especial A.niger, han sido identificados como patógenos oportunistas, particularlmente en casos de otomicosis (Kaya, \& Kiraz, 2007) y se consideran la tercera causa de aspergilosis pulmonar (Denning, 2006), entre otras localizacines; sin embargo, en muchos casos la determinación de la especie se ha basado solo en la morfología (Samson et al. 2007b). Empleando biología molecular, Lázló et al, (2008), aislan A. tubingensis y A.brasiliensis de infecciones corneales, Howard et al,(2011), obtuvieron de 45 aislados clínicos 5 clados, A. awamori (55.6\%), A. tubingensis (17.8\%), A. niger (13.3\%), A. acidus (6.7\%), y un grupo desconocido (6.7\%); Bathoorn et al. (2013), aislan de una osteomielitis A.tubingensis, Perrone et al, ( 2012) aislan A.aculiatinus desde un conducto lagrimal (dacriocistitis), mientras Vermeulen et al,(2013) aislan 5 cepas de A.tubingensis en 6 casos de aspergilosis invasoras en Bélgica.

Biología molecular. Filogenéticamente las especies de Aspergillus de esta sección, son estrechamente relacionadas entre si, lo que hace difícil su separación taxonómica solo por la morfología, en especial el complejo Aspergillus niger que constituye un importante grupo de especies comu- nes en alimentos, biotecnología y micología médica. Representan uno de los subgrupos taxonómicos más complicados, debido a que contienen 8 (a la fecha) taxas indistinguibles morfológicamente: A.niger, A.tubingensis, A.brasiliensis, A.luchuensis, A.costaricaensis, A.lacticoffeatus, A.piperis y A.vadensis, siendo los métodos polifásicos los empleados actualmente para un buen diagnóstico (Samson et al, 2007b; Samson \& Varga, 2009; Abdin et al,2010). Algunas especies tienen propiedades bioquímicas diferentes tales como: crecimiento nutricional y diferencias en sus hidrolasas (Meijer et $a l, 2011$ ). Sus metabolitos secundarios a pesar de ser a menudo únicos para esta sección, no permiten aún diferenciar las especies solamente con estas propiedades metabólicas.

La Beta-tubulina (benA, tub-2) y calmodulina ( $c a M)$, son genes cruciales en la taxonomía de esta sección de Aspergillus (Varga et al, 2011). Los 'primers' ampliamente usados de la B-tubulina no son específicos para algunos taxones como en el gen benA, debido a que preferentemente amplifican el parálogo $t u b C$. Las secuencias del parálogo del $t u b C$ se combinan ampliamente con las secuencias del benA como se han apreciado en recientes trabajos taxonómicos, resultando en árboles genéticos incongruentes (Hubka \& Kolarik, 2012). Estos autores, determinaron que las identidades del clado A. aculeatus, usada en previos estudios moleculares fue revisada empleando datos moleculares combinados (ITS, benA, caM), junto con 2 métodos de PCR, lo que indicó que A. japonicus debe ser tratado como sinónimo de A. violaceofuscus y A. fijiensis como sinónimo de $\boldsymbol{A}$. brunneoviolaceus.

Varias especies de la sección Nigri están asociadas a alimentos fermentados en Asia del Este; por ej., A.luchuensis y A.welwitschae (hongos negros del koji) que se asocian con la producción de awamori, un destilado alcohólico producido en Okinawa (Japón), mientras A.luchuensisy se emplea en la producción de shochu y makgeolli (Yu et al, 2004a). La posición taxonómica de las especies usadas en la producción de fermentaciones del koji blanco y negro fueron investigadas junto a otras especies mediante los métodos moleculares actuales: ITS, secuencias de genes de la btubulina, calmodulina y perfiles del RAPD. La posición taxonómica de A. awamori sensu Perrone et al. (2011), fueron reinvestigadas y se concluyó que A. luchuensis, A. kawachii y A. acidus son la misma especie y A. luchuensis es el nombre que tiene prioridad (Hong et al, 2013).

Las cepas de A. awamori guardadas en el National Research Institute of Brewing en Japan, no corresponden a esta especie y el neotipo de $\boldsymbol{A}$. awamori (CBS 557.65 = NRRL 4948), no es originario de las fermentaciones de awamori y considerado idéntico a un nuevo taxon denominado $\boldsymbol{A}$. welwitschiae (Hong et al, 2013).

Como puede conconcluirse, la Seccion Nigri de Aspergillus se ha revisado varias veces y ha sufrido constantes cambios (Raper \& Fennel, 1965; Murakami, 1979; Al- 


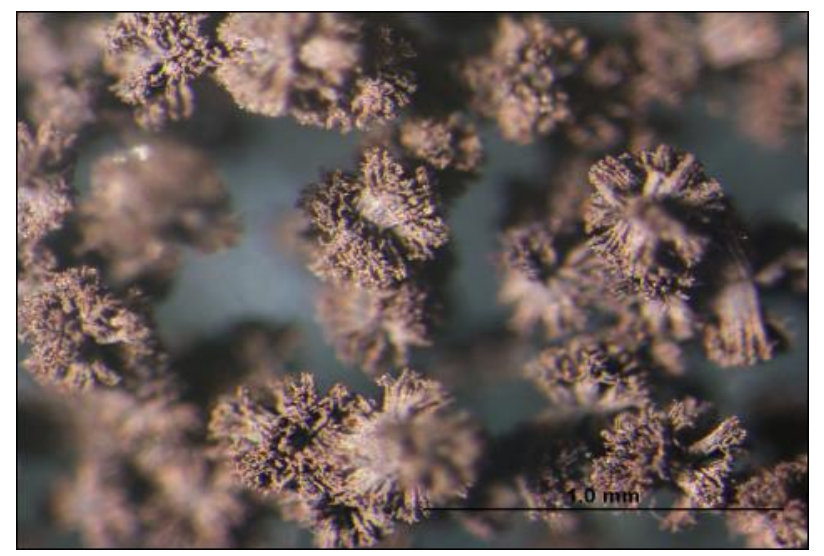

Figura 17. Cabezas apergilares de $A$. niger mostrando su forma redondeda con tendencia a abrirse formando columas cortas (Tomada de: Institut National de Santé Publique Québec).

Mussalam, 1980; Samson et al, 2007b; 2011, entre otros) y aún se espera dilucidar la posición taxonómica de algunos de sus integrantes.

Identificación morfofisiológica.

Los cultivos se inoculan en 3 puntos en placas de Petri de $9 \mathrm{~cm}$, usando una densa suspensión de conidios e incubados a $25^{\circ} \mathrm{C}$ por 7 días en oscuridad en los diferentes medios descritos anteriormente. Pueden emplearse medios especiales como el Boscalid, para ver las habilidades de crecer y esporular de las cepas en MEA con este compuesto siguiendo la técnica de Samson et al, 2004a).

Creatina sucrosa Agar (CREA) (Fig.18). El crecimiento y producción de ácido en este medio semiselectivo y muy empleado en la clasificación de los Penicillium (Samson et al, 2004b; Frisvad \& Samson, 2004), como de los Aspergillus, siguiendo la misma técnica de siembra en 3 puntos y observando su crecimiento y esporulación después de 3 y 7 días de incubación a $25^{\circ} \mathrm{C}$ (vea Samson et al, 2007a; Varga et al, 2011). El crecimiento y los perfiles de hidrolasas pueden ser usadas para distinguir A.niger de otros Aspergillus negros, pero se necesitan equipos especiales (Meijer et al, 2011).

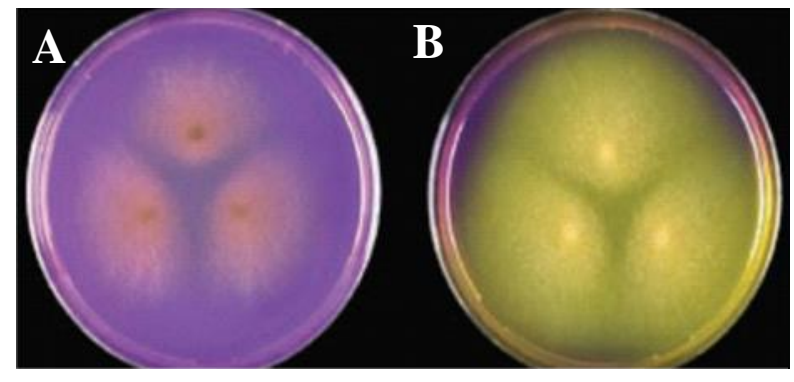

Figura 18. A.- CREA con moderado crecimiento sin producción de ácido, B.-Buen crecimiento con producción de ácido(Tomado de: Samson et al, 2007a)

\section{Especies del grupo A.niger aisladas en clínica}

1.- Aspergillus aculiatinus, Noonim,Frisvald,Varga \& Samson (Fig.19).

Diámetro de las colonias en CYA25 a los 7 días, $85 \mathrm{~mm}$; MEA, 78-85 mm; YES, 85 mm; CZA, 33-43; OAT, 55-64 mm, and CREA, 13-52 mm. CYA a $37^{\circ} \mathrm{C}, 22-33 \mathrm{~mm}$. En CYA y MEA, los conidióforos se producen abundantemente con áreas conidiales ligeramente café; esclerocios presentes en algun aislados pero no en cultivos del ex tipo; pequeños $(0,4-$ $0,6 \mathrm{~mm}$ ), globosos a subglobosos, de color crema a ligeramente amarillos. Reverso de la colonia en CYA, ligeramente café, surcado en MEA y amarillo brillante en YES.

Micromorfología. Cabezas conidiales radiadas, que se abren en 2 a 6 columnas poco definidas en el tiempo; estipes cortos (mínimo 380-) o entre 500 - 620 (-800 máximo) x (9-) 11-14 (-16) $\mu \mathrm{m}$, paredes delgadas, lisas, hialinas; vesículas (43-) 55-65 (82) $\mu \mathrm{m}$ de diám., globosas, uniseriadas; fiálides en forma de frasco que cubren la entera superficie de la vesícula, 1,8-3,5 x 6,1-9 $\mu \mathrm{m}$; conidios subglobosos a elipsoidales, 2-4 x 2,3-4,4 $\mu \mathrm{m}$, eqinulados. Ehrlich (-)*

La cepa tipo, CBS 121060T (5IBT 29077T), fue aislada de Coffea arabica en Tailandia y desde una infección del conducto lagrimal (Perrone et al, 2012).

*El test de Ehrlich usado por Frisvad \& Samson (2004), para distinguir los integrantes del subgén. Penicillium, se basa en la detección de alcaloides que reaccionan con este reactivo. Se emplea un trozo de papel filtro $(1 \mathrm{x} 1 \mathrm{~cm}$.) que se coloca sobre una porción de la colonia $(5 \mathrm{~mm})$ tomada desde el centro de crecimiento de ésta (cultivada en CYA por 5-9 días a $25^{\circ} \mathrm{C}$ ). Este trozo que puede sacarse con sacabocado o un recorte con bisturí estéril, se lleva a un portaobjeto y se

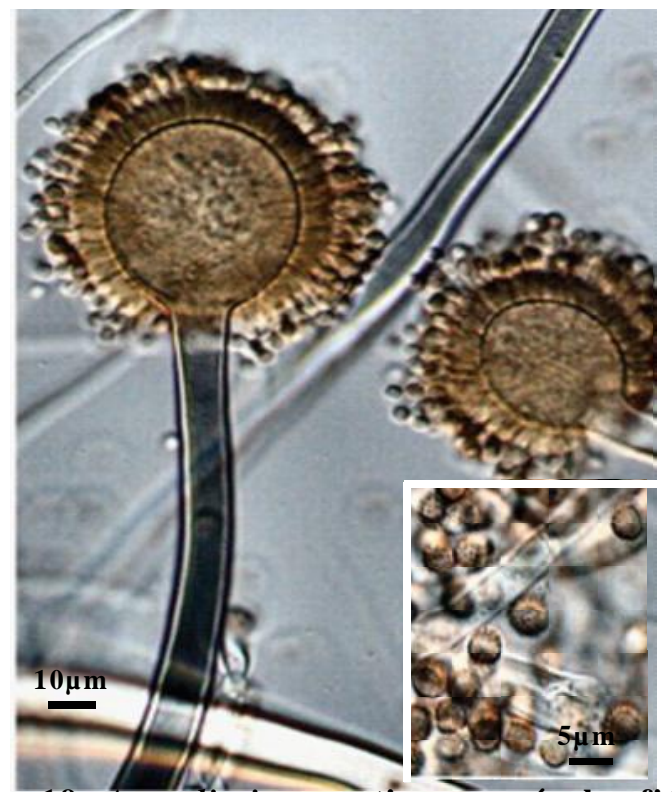

Figura 19. A.aculiatinus, estipe y vesícula, fiálides (monoseriada) y conidios en el recuadro (Figuras tomadas de:Noomin et al, 2008) 
cubre con el trocito de papel. Se agregan 2 gotas del reactivo sobre el papel filtro y si aparece un anillo violeta después de 2-6 min, el cultivo contiene ác. ciclopiazónico o alcaloides relacionados. Si la reacción aparece después de 7-10 min, se considera débil; después de 10 min. el anillo violeta puede desaparecer. Algunos hongos producen alcaloides que reaccionan dando anillos rosados o amarillo.

\section{2.- $\quad$ Aspergillus brasiliensis Varga, Frisvad \&}

Samson (Fig.20).

Diámetro de las colonias en CYA a 25 y $37^{\circ} \mathrm{C}$ y CYAS a $25^{\circ} \mathrm{C}, 71-76 \mathrm{~mm}$ : MEA, 52-70 mm; YES ,75-80 mm; OA, 32-36 $\mathrm{mm}$; CREA 32-44 mm, pobre crecimiento y fuerte producción de ácido. Colonias al inicio blancas, luego en el tiempo café oscuro a negro. Exudado ausente, reverso crema a café claro Cabezas conidiales inicialmente globosas y posteriormente radiadas, ocasionalmente desarrollan varias columnas conidiales.

Micromorfología. Estipes 700 -1700 x 8-13 $\mu \mathrm{m}$, de paredes gruesas, lisos, café pálidos; vesículas 30-45 $\mu \mathrm{m}$ cercanas a lo globoso; biseriadas, con métulas que cubren virtualmente la entera superficie de la vesícula, 22-30 x 3-6 $\mu \mathrm{m}$; fiálides en forma de frasco, 7-9 x 3-4 $\mu \mathrm{m}$; conidios subglobosos, 3,5-4,8 $\mu \mathrm{m}$, equinulados. Esclerocios ausentes en el cultivo del extipo, pero pueden presentarse de color blanco en algunos aislados.Todos los aislados producen varias nafto-c-pironas (incluyendo aurasperona B), tensidol A y B y pirofen. Los aislados muestran en su distribución geográfica un buen grado de variabilidad genética que se diferencia en 2 grupos: en uno los aislados de Portugal y en el segundo los países restantes indicados. a continuación: Brasil, USA, Australia y Holanda (Varga et al, 2007).
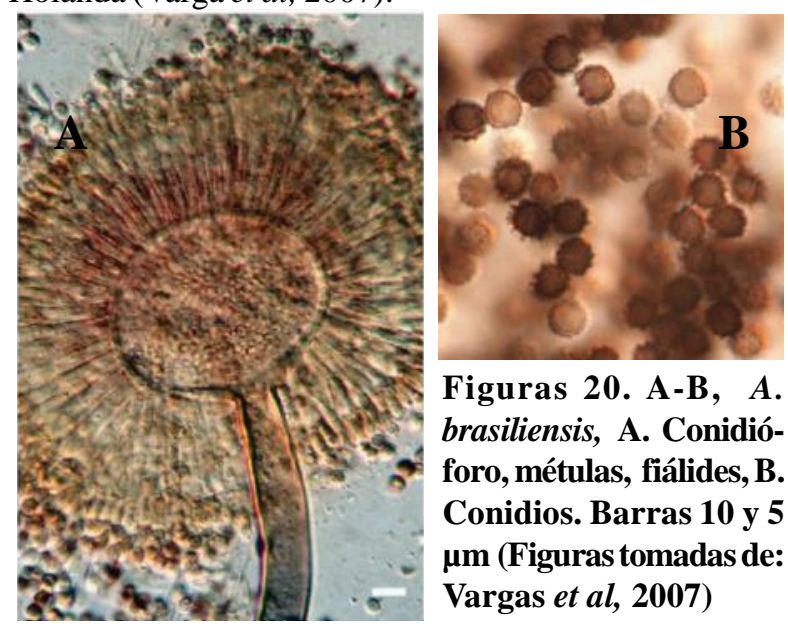

Figuras 20. A-B, A. brasiliensis, A. Conidióforo, métulas, fiálides, $B$. Conidios. Barras 10 y 5 $\mu \mathrm{m}$ (Figuras tomadas de: Vargas et al, 2007)

3. Aspergillus brunneoviolaceus Batista \& Maia, . (=A.fijiensis Varga et al.2011) (Fig. 21)

Diámetro de las colonias en CYA, en 7 días a $25^{\circ} \mathrm{C}$, > $85 \mathrm{~mm}$; cabezas conidiales café a cercano al negro; MEA, $7 \mathrm{~d}$, $25^{\circ} \mathrm{C}, 45-75 \mathrm{~mm}$; YES, $7 \mathrm{~d}$. $25^{\circ} \mathrm{C}, 74-80 \mathrm{~mm}$; OA, $25^{\circ} \mathrm{C}, 50-70$ $\mathrm{mm}$; CYA37, 12-26 mm; CREA: crecimiento pobre, con moderada producción de ácido; moderada producción de ácido; CYAS, 52-57 mm (CREA, pobre esporulación buena producción de ácido). Reverso de la colonia en CYA: beig a amarillo, reverso en YES, amarillo.

Micromorfología. Conidióforos largos, uniseriados, con vesículas globosas a elipsoidales, 35-70 (-90) $\mu \mathrm{m}$ de ancho, estipe de paredes lisas a finamente rugosas cerca de la vesícula, hialinos o pigmentados, 10-15 $\mu \mathrm{m}$. Fiálides 7-9 x 3,5$4,5 \mu \mathrm{m}$, conidios globosoa a elipsoidales, $3,5-4,5 \mu \mathrm{m}$, café, toscamente rugosos a equinulados. Esclerocios no observados (Jurjevic' et al, 2012). Esta especie puede crecer a $37^{\circ} \mathrm{C}$ y produce asperparalinas y okaraminas.

Perrone et al. (2013), aislaron esta especie desde un lavado bronquial causando un aspergiloma con bronquiestásia.

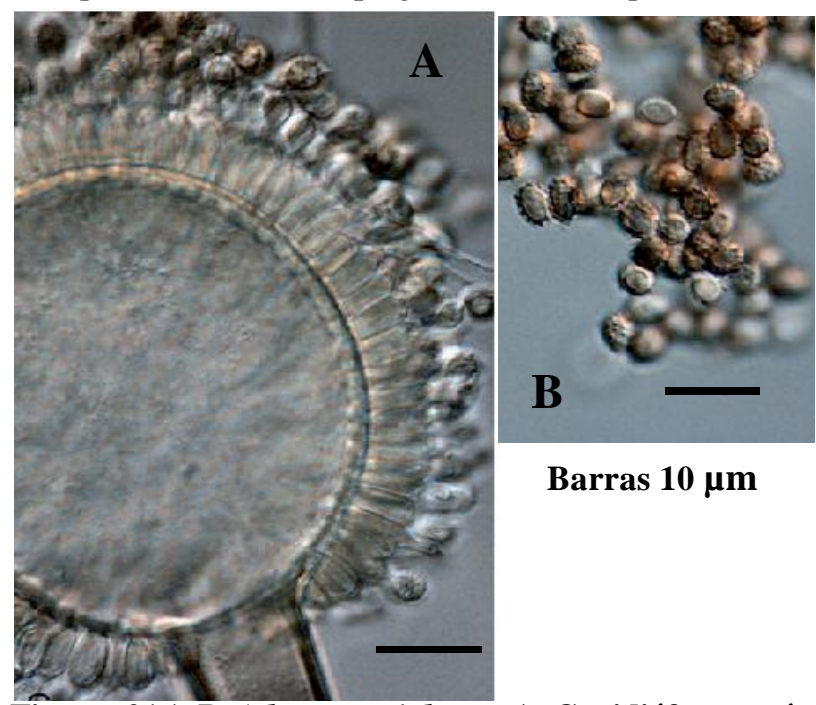

Figuras 21 A-B. A.brunneoviolaceus A- Conidióforo, vesícula y monofiálides, B. Conidios (Figuras tomadas de: Varga et al, 2011)

\section{4.- Aspergillus luchuensis Inui (Fig. 22)}

= Aspergillus perniciosis Inui

= Aspergillus awamori Nakazawa pro parte

= Aspergillus aureus var. acidus Nakaz., Simo \& A. Watan.

= Aspergillus foetidus var. acidus (Nakaz., Simo \& A.

Watan.)Thom \& Raper

= Aspergillus kawachii Kitahara \& Yoshida

= Aspergillus acidus Kozak.

= Aspergillus coreanus Yu et al.

Diámetro de las colonias en 7días en CYA, 37mm; DG18, $33 \mathrm{~mm}$; CREA, $29 \mathrm{~mm}$; MEA, $53 \mathrm{~mm}$; $M E A 37^{\circ} \mathrm{C}, 50 \mathrm{~mm}$. En CYA, micelio estéril blanco con áreas conidiales grises a negras, radialmente surcadas y flocosas, reverso crema a café. En MEA, similares al CYA. En CREA, pobre crecimiento y fuerte producción de ácido.

Micromorfología. Cabezas conidiales radiadas; estipes largos hasta 1,5 $\mu \mathrm{m}$, ancho 10-13 $\mu \mathrm{m}$, de paredes gruesas, lisas y hialinas ; vesículas, 20 - $40 \mu \mathrm{m}$ diám., casi esféricas, uniseriadas cuando jóvenes con formación irregular de 
métulas, posteriormente en el tiempo predominantemente biseriadas, las métulas cubren casi la entera superficie de la vesícula, 17- 26 x 4,5-8,1 $\mu \mathrm{m}$, fiálides ampuliformes, 5,6-8,4 x 3,5-4,9 $\mu \mathrm{m}$; conidios, globosos, lisos, 3,5-4,5 $\mu \mathrm{m}$, café oscuros. Las cepas tipo, fueron aisladas desde awamorikoji en Okinawa (Japón).

Las cepas de A. luchuensis muestran variables características morfológicas. El color de la colonia es blanco a gris o café a negro; estipes de 8-30 $\mu \mathrm{m}$ de ancho, con un largo de hasta $1,5 \mathrm{~mm}$; las cabezas conidiales son predominantemente biseriadas, pero cabezas aberrantes uniseriadas pueden observarse, vesículas de15-90 $\mu \mathrm{m}$; métulas 5-26 $\mu \mathrm{m}$; fiálides de 5,4-12,5 $\mu$ m y conidios de 3-4,5 $\mu \mathrm{m}$, lisos o finamente rugosos, raramente rugosos. Estas características son similares a las producidas por $\boldsymbol{A}$. niger y $\boldsymbol{A}$. tubingensis y difíciles para diferenciar en esta especie solo en bases morfológicas. Las secuencias de DNA de Btubulina y calmodulina son útiles para diferenciar esta especies de otras de la Sección Nigri. Ninguno de los extrolitos producidos por A. luchuensis son tóxicos y no producen ningún tipo de aflatoxinas ni fumonisinas y es considerado un hongo industrial del koji blanco o negro en Japón y el este de Asia (vea: Hong et al, 2013). Se ha aislado en otomicosis (Kamal et al, 2010) y en aspergiloma pulmonar (sin información anexa).

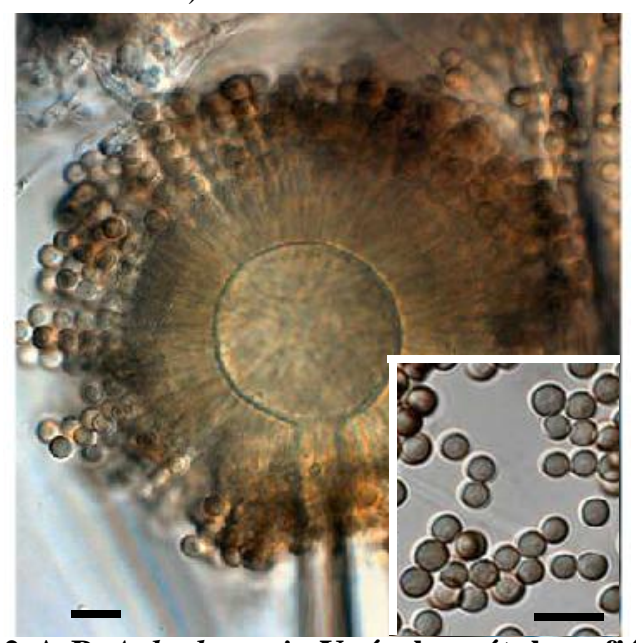

Figura 22. A-B. A. luchuensis. Vesícula, métulas y fiálides, En el recuadro, conidios, Barras 10um (Figuras tomadas de: Hong et al, 2013).

\section{Aspergillus niger van Tieghem s. strictus} (Fig.23).

Diámetro de las colonias en CYA25 durante 7 días 67$70 \mathrm{~mm}$, de color negro a café oscuro, reverso amarillo claro; MEA25, 53-69 mm, de color negro, reverso incoloro, MEA $37^{\circ} \mathrm{C}, 65-80 \mathrm{~mm}$. No crece en 3 días en Boscalid y no germina en 7 días en este medio, en CREA, buen crecimiento con buena producción de ácido.

Micromorfología. Cabezas conidiales en MEA grandes, biseriadas, 150 a $300 \mu \mathrm{m}$ o más en diámetro, globosas a radiales, que tienden a formar columnas laxas de conidios, estipes de paredes lisas y gruesas, hialinos o cafesosos cerca del ápice o en toda su extensión, generalmente entre 1300$2700 \mu \mathrm{m}$, vesículas hialinas que se tornan café en el tiempo, globosas a subglobosas, $40-70(-100) \mu \mathrm{m}$, fértiles en toda su superficie, métulas hialinas a café, 15-20,5 (-40) x 4,5-6 $\mu \mathrm{m}$, fiálides hialinas en forma de frasco uniformes en tamaño, 79,5 × 3-4 $\mu \mathrm{m}$, conidios globosos a subglobosos, con diferentes tipos de ornamentaciones, 3,5-5 $\mathrm{m}$, a menudo con irregulares crestas y barras. Esclerocios ausentes o raramente presentes, 0,8 a $1,2 \mu \mathrm{m}$, globosos a subglobosos, de color crema cuando jóvenes, luego gris rosados a gris café.

Hábitat y Ecología. A. niger es cosmopolita y muy común en presencia, es un hongo mesofílico con optimo crecimiento a temperaturas entre los 20 y $40^{\circ} \mathrm{C}$ y un buen crecimiento a 37 ${ }^{\circ} \mathrm{C}$. Crece aerobicamente en sustratos orgánicos diversos, como en la litera y en material vegetal en descomposición, se aisla también de frutas y semillas, materiales textiles no tratados, carnes, huevos y por su xerofilía en especias y frutos desacados, como también en ambientes internos y marinos. Es uno de los más importantes microorganismos usados en biotecnología y por ende de enorme significado económico. Puede crecer a muy bajos $\mathrm{pH}(2,0)$ y algunos aislados pueden producir ocratoxinas (Shuster et al ,2002).

Patología. A. niger, al contrario de A. fumigatus y A.flavus, es un causante poco común de aspergilosis invasora. La presencia de cristales de exalato de calcio en los especímenes histopatológicos es clásico en las infecciones por $\boldsymbol{A}$. niger y puede ser útil en un diagnóstico aún en ausencia de conidios (Person et al, 2010).
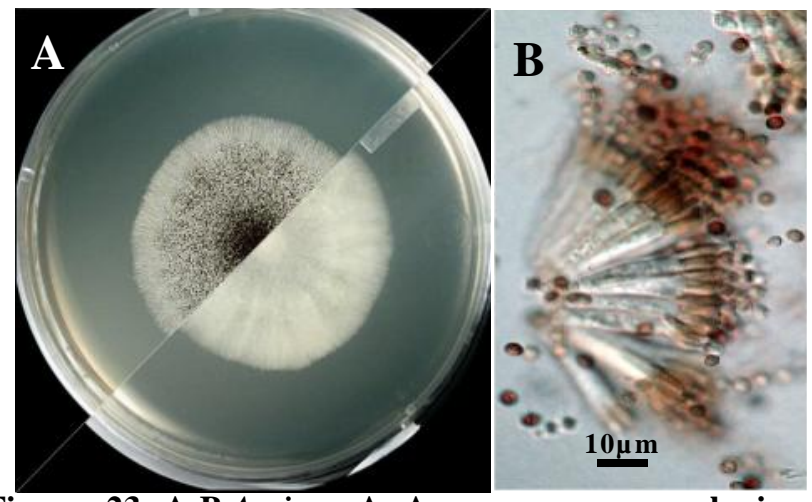

Figuras 23. A-B A.niger. A. Anverso y reverso colonia en MEA, B. Métulas, fiálides y conidios (Figura A tomada de: Institut National de Santé Publique Québec).

\section{Apergillus tubingensis Mosseray (Fig.24) (=A. pulverulentus McAlpine) Wehmer)}

La especie A.tubingensis es morfológicamente muy similar a $\boldsymbol{A}$. niger, situación que dificulta su distinción basándonos solo en datos morfológicos. En CREA Aspergillus foetidus, A. niger y A. tubingensis presentan moderado crecimiento y buena producción de ácido, sin embargo, Silva et al. (2011), consideran que $\boldsymbol{A}$. tubingensis puede distinguirse 
macroscópicamente por su producción de esclerocios, de colores blancos a rosados. Samson et al. (2007), reportaron que la producción de estas estructuras por las especies de $\boldsymbol{A}$. tubingensis no siempre se obseva. Se conoce que otras especies de la sección Nigri tienen la capacidad de producir estas estructuras incluyendo A. carbonarius, A. ellipticus, A. aculeatus, A. costaricaensis, A. piperis, A. sclerotioniger, A. aculeatinus y A. sclerotiicarbonarius. Es por esto, que la identificación de los integrantes de $\boldsymbol{A}$. niger "aggregate", es aún controversial y es la biología molecular la que ha reducido y sigue reduciendo el número de sinónimos entre los Aspergillus negros (Susca et al, 2007; Silva et al, 2011; Hong et al, 2013).

A. tubingensis ha demostrado ser heterotálico, con cepas individuales que contienen ya sea los genes de cruzamiento MAT1-1 o MAT1-2 . Cepas de tipo opuesto de cruzamiento incubadas por 5-6 meses en agar con cereales, formaron ascocarpos con ascos y ascosporas en una manera similar al estado sexual (petromyces- morph) de la sección Flavi, la cual es muy relacionada con la sección Nigri. Sin embargo, sus ascosporas difieren de las de la sección Flavi en su reticuladas ornamentaciones y la presencia de 2 crestas ecuatoriales ( Horn et al, 2013).

A. tubingensis tiene amplia distribución en el suelo y se asocia a material vegetal muerto y alimentos. Es común en almendras, donde las cepas podrían ser productoras de Ocratoxina o Fumonisina B2. Palumbo \& O' Keeffe (2013), determinaron que el total de sus aislados identificados como A. tubingensis, no produjeron ambas micotoxinas (otros autores aseveran haber encontrado cepas con capacidad de producirlas).

Patología. Los aislados de Aspergillus desde pacientes trasplantados con aspergilosis invasoras mostraron que en un 9\% de los casos pertenecen a la sección Aspergillus Nigri, y un $32 \%$ de estos corresponden A. tubingensis (Alcazar-

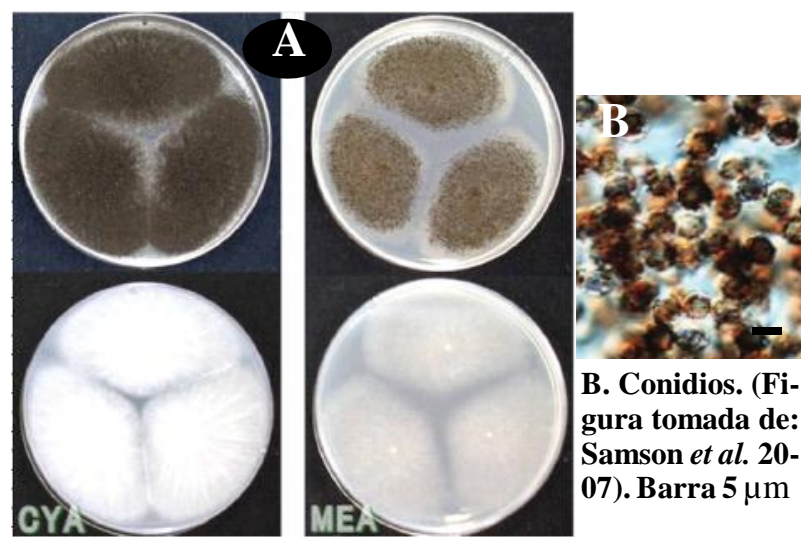

Figuras 24. A-B. A. tubingensis. A. Anverso y reverso de las colonias en CYA y MEA. (Figuras tomadas de: http://www.ffprikys.affrc.go.jp/situ/mic/miyazaki/gaikinHP/gaikindetails/ gaikindetailskrcf701/gaikindetails _c_krcf701.html).
Fuoli et al, 2009), demostrando la capacidad invasora de esta especie al causar también otros tipos de infecciones como osteomielitis y queratitis (Bathoorn et al,2013; Kredics et al, 2009).

\section{Aspergillus welwitschiae (Bresadola) Hen-}

nings apud Wehmer.(Fig. 25)

= Ustilago welwitschiae Bres.

= Sterigmatomyces welwitschiae (Bres.) Henn.

= Aspergillus welwitschiae (Bres.) Henn. apud Wehmer

= Aspergillus awamori sensu Perrone et al. (2011)

Coloniasen CYA, MEA, YES crecen lentamente en forma similar a A. niger.

Micromorfología. Vesículas 45-85 mm en diám. Conidios globosos finamente a distintamente rugosos, café a café negro, 3,5-5,5 $\mu \mathrm{m}$. Los aislados de A. niger yA. welwitschiae se sobreponen en sus estructuras ya sea en las formas, tamaño y color de sus conidios y ornamentaciones del estipe y su largo. Ambas especies contienen mutantes que tienen conidios más café. Estos caracteres morfológicos son idénticos con las estructuras morfológicas de las cepas típicas de $\boldsymbol{A}$. niger. A. welwitschiae tiene además los mismos rangos de de crecimiento que $\boldsymbol{A}$. nig er en los medios de CYA a 5, 25 y $37^{\circ} \mathrm{C}$, en $\mathrm{G} 25 \mathrm{~N}, \mathrm{CZA}, \mathrm{MEA}$ a $25^{\circ} \mathrm{C}$, en oscuridad como también en sus actividades de agua. A pesar de que morfológicamente es indistinguible de A.niger, algunos nucleótidos fijos muestran diferencias y son útiles en la clasificación (Hong et al, 2013). La producción de Ocratoxina A y Fumonisina B2 se han detectado en algunas cepas (Perrone et al, 2011). Esta especie se ha encontrado en varios ambientes internos en 6 paíases de Europa (Vargas et al, 2014), como en maíz contribuyendo a la producción de fumonisina B2 (Logriego et al, 2014).

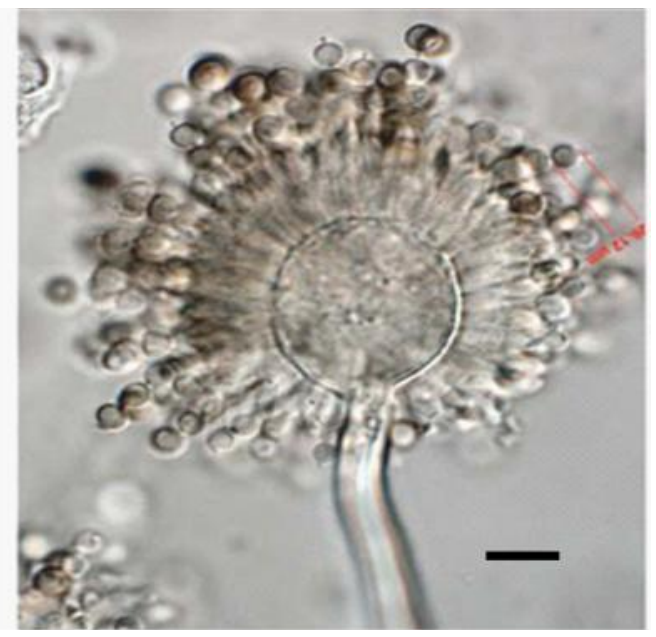

Figura 25. Cepa NBRC 4281, extipo de A.luchuensis creciendo por 3 días en arroz cocido. morfológicamente es similar a A. welwitschiae (Tomada de:Hong et al, 2013) 


\section{Clave tentativa de las especies oportunistas de la sección Nigri}

1.- $\quad$ Especies estrictamente monoseriadas................2

Especies biseriadas .............................................. 3

2.- - Conidióforos lisos, esclerocios presentes a veces, crecimiento en $\mathrm{CYA} \mathrm{a} 37^{\circ} \mathrm{C}, 22-33 \mathrm{~mm}$ en

7 días, conidios subglobosos a elipsoidales, $2-4 \mathrm{x}$ 2,3-4,4 $\mu \mathrm{m}$, eqinulados. A. aculiatinus

- Conidióforos lisos a levemente equinulados, esclerocios ausentes,crecimiento en CYA a $37^{\circ} \mathrm{C}, 12-26 \mathrm{~mm}$, conidios elipsoidales a levemente fusiformes,3,5-4,5(-6) $\mu \mathrm{m}$ um, café, toscamente rugosos a equinulados...A. brunneoviolaceus

3.- - Conidios globosos lisos a finamente rugosos, cabeza uniseriadas cuando jóvenes, con formación irregular de métulas, luego biseriadas (se observan algunas uni y biseriadas)

\section{A. luchuensis}

- Conidios globosos a subglobosos, rugosos o con diferentes tipos de ornamentaciones (crestas, barras) ............ vea descripción de: $A$. niger, A. brasiliensis, A. tubingensis, A. welwitschiae. (Es indispensable el uso de la biología molecular para separar estas especies).

\section{C). Subgénero Circumdati sección Flavi}

Aspergillus flavus complex. fue primeramente descito por Link (1809), y es el nombre empleado para describir la especie, como también el grupo de especies estrechamente relacionadas . A. flavus es la segunda especie común después de A.fumigatus como causa de aspergilosis hunama invasora. Además es la especie común capaz de infectar insectos (Campbell, 1994), como también considerada fitopatógena en importantes cultivos (maíz y maní) y productora de potentes micotoxinas

Ecología y distribución geográfica. Al igual que otras especies de Aspergillus, el complejo A. flavus presenta una distribución mundial, probablemente por la producción de numerosos conidios que se dispersan fácilmente por el aire o mediante una gran diversidad de insectos, en especial cuando la humedad aumenta. Esta especie crece mejor con una actividad de agua $\left(\mathrm{a}_{\mathrm{w}}\right)$ entre 0,86 y 0,96 (Vujanovic et al., 2001) y una temperatura óptima de $37^{\circ} \mathrm{C}$, pero puede crecer entre los 12 a $48^{\circ} \mathrm{C}$, lo que contribuye a la patogenicidad en humanos.

A. flavus es mayoritariamente un saprotrofo del suelo que cumple roles importantes en el reciclado de nutrientes aportados por restos de vegetales y animales (Scheidegger $\&$ Payne, 2003). Su habilidad de sobrevivir en duras condiciones lo convierte en un fácil competidor frente a otros microrganismos del suelo en especial por presentar estructuras resistentes en tiempos fríos, como los esclerocios, los cuales al germinar pueden producir ya sea hifas o conidios que se dispersan por el aire (Bhatnagar et al., 2000). Aspergillus flavus y otras especies del género se han encontrado con alta frecuencia en ambientes hospitalarios y sus hallazgos deben considerarse con alto interés en salud pública (Fernández et al., 2013a).

La caracterización de nutrientes tiene influencia en la selección de genotipos específicos de A.flavus y puede ser de utilidad en los criterios de selección de ce-pas no toxicogénicas empleadas en el biocontrol, sin embargo, se necesita un trabajo adicional para verificar el rol de los nutrientes en la dinámica de A.flavus en los suelos. Hay evidencias que algunos genotipos pueden adaptarse en ambientes con bajos nutrientes, situación que favorece las ventajas competitivas en los suelos, asì como su larga persistencia en el ambiente (Celar,2003; Hillary et al. 2013).

Sexualidad. Las especies de Aspergillus han demostrado ser de mucho valor en los estudios de la sexualidad fúngica, por incluir especies con modalidades reproduc-tivas diferentes, tales como: a) mitospóricas o asexuales, tradicionalmente conocidos en la antigua División 'deuteromycota' (Taylor et al., 1999a), b) meiospóricas o especies que también pueden reproducirse por moda-lidades sexuales, ubicándolas tradicionalmente en la División Ascomycota, por su producción de ascocarpos, ascos y ascosporas, las cuales pueden exhibir ya sea una modalidad heterotálica (obligados autoestériles) u homotálicos (autofértiles). La primera división taxonómica ya no es necesaria debido a que por análisis filogenético demuestran ser el mismo grupo que la segunda (Peterson, 2008), reemplazando el término 'deuteromycotina' por la terminología mitospórico o meiospórico (Kück \& Pöggeler, 2009). La mayoría de las especies aceptadas de Aspergillus se conocen solo por su medios reproductivo asexuales, mientras aquellas que presentan ciclos sexuales son irresitiblemente homotálicas en la naturaleza, con pocas especies heterotálicas descritas (Kwon-Chung \& Sugui, 2009; Dyer \& O'Gorman, 2012).

Basta nombrar los recientes descubrimientos de los ciclos sexuales en los Aspergillus (petromyces-morph) de este grupo como en A. flavus, A. parasiticus y A. nomius por su significado de sexualidad críptica e iportancia económica y médica (Horn et al. 2009 a-b-c-2011). La reproduccion sexual incluye fecundación cruzada (la cual es posible aun en las especies homotálicas) y puede generar grandes cantidades de variacion genetica y producir nuevos genotipos mas facilmente que mediante metodos asexuales, como se ha ob- 
servado en los nuevos genotipos que nacieron por el cruzamiento de cepas de A. fumigatus (O'Gorman et al., 2009). Debemos ser cautos con respecto al ciclo sexual de ciertas especies que aun no se han descubierto, debido a la fastidiosa naturaleza de sus demandas sexuales o la genuina evolución a la sexualidad (Kwon-Chung \& Sugui, 2009).

A. flavus es capaz de producir esclerocios; estas estructuras repoductivas semejan a cuerpos sexuales (Cleistotecios). Esta epecie se presenta bajo 2 morfotipos de tamaños de esclerocios (las cepas $\mathbf{L}$ con un diámetro $>400 \mu \mathrm{m}$ y las $\mathbf{S}$ con un diámetro $<400 \mu \mathrm{m})$. Las cepas $\mathbf{S}$, consistentemente producen más aflatoxinas que las cepas $\mathbf{L}$ cuando crecen bajo lasmismas condiciones. El porcentaje de las cepas $\mathbf{S}$ en las poblaciones naturales varía desde las indetectable, hasta sobre un $90 \%$ (Cotty, 1997). Las cepas S y $\mathbf{L}$ en el tiempo, parecen haber sido separadas reproductivamente unas de otras hace más de un millón de años (Ehrlich et al., 2005; 2007).

Las Micotoxínas, son metabolitos fúngicos secundarios potencialmente dañinos para el hombre y otros animales; Aspergillus flavus y A. parasiticus son las especies predominantes responsables para la conta-minación de las cosechas en el campo y durante el almacenamiento (Yu et al., 2004). La aflatoxina B1, B2, G1 y G2 son 4 mayores toxínas entre las más comunes relacionadas. La aflatoxin B1 es la más importante por ser la más tóxica y un potente compuesto hepatocarcinógeno natural (Bennett \& Klich, 1992-2003). Diferentes cepas de A. flavus, pueden o no producir ya sea aflataxina B1 y/o B2. Esta especie puede producir además otros compuestos tóxicos como esterigmatocistina, los ác.ciclopiazónico, kójico, aspergílico y ß-nitropropiónico, aspertoxina, aflatremos y gliotoxina entre otros metabolitos secun-darios (vea http://www.aspergillus.org.uk - mycotoxin section).

A. parasiticus produce aflatoxina $\mathrm{G} 1$ y G2, además de B1 y B2, poro no ác. ciclopiazónico (Yu, 2004). Las Aflatoxinas se producen también por otras especies del complejo Aspergillus flavus, incluyendo: A.toxicarius, A.nomius, A.bombycis y A.pseudotamarii. A. pseudo-tamarii, que también producen ác.ciclopiazónico. A. oryzae, raramente aparece como oportunista. Se ha empleado largamente en Oriente para preparar varios tipos de alimentos; puede producir ác. ciclopiazónico y $B$-nitropropiónico, pero no produce aflatoxinas. A. oryzae, A. parasiticus, $A$. sojae, A. nomius, $A$. bombycis, A. tamarii, A. caelatus y A. pseudotamarii pueden producir ác. kójico (Varga et al., 2003b).

Patología. A. flavus principalmente (y otros integrantes de la Sección Flavi) puede causar un amplio espectro de enfermedades en los humanos que van desde las reacciones de hipersensibilidad a las infecciones invasivas asociadas con la angioinvasión, siendo después de A. fumigatus, la segunda causa de aspergilosis invasiva o no invasiva (Morgan et al., 2005; Hedayati et al., 2007). La ruta primaria de la infección es la inhalación de las esporas fúngicas. El mayor tamaño de los conidios de A. flavus favorece su disposición en la parte superior del tractro respiratorio, situación que podría ser una razón de que esta especie es el agente etiológico de las sinusitis fúngicas e infecciones cutáneas, pero no de la neumonias invasivas.

Los factores climáticos y geográficos son importantes determinantes de la prevalencia local en las infecciones de $\boldsymbol{A}$. flavus. En países tales como Arabia Saudita y Sudan, que presentan condiciones áridas y semi áridas, A. flavus es el agente etiológico común de aspergilosis invasiva, así como en Africa, produciendo aspergilosis pulmonar (Kameswaran et al., 1992; Mahgoub \& el-Hassan, 1972; Hadrich et al.,2010). Por razones desconocidas la frecuencia de las infecciones causadas por A. flavus son bastante frecuentes en algunos hospitales y las semejanzas clínicas entre las especies de Aspergillus son muy similares, sin embargo la población genética de A. flavus es de gran interés, particularmente por asociarse a la sinusitis crónica granulomatosa, la queratitis, la aspergilosis cutánea, las infecciones profundas y la osteomielitis seguida al trauma y a la inoculación. Por otro lado, raramente se presenta como un agente etiológico de aspergilosis cavitaria crónica. En contraste con las infecciones de A. fumigatus, se ha investigado que muchas de los enfermedades causadas por A. flavus se deben a una unica cepa o varias cepas capaces de individualizarse mediante biología molecular. Además A. flavus parece ser más virulento y más resistente a las drogas antifúngicas que las otras especies de Aspergillus (Hedayati et al., 2007). Las aspergilosis humanas causadas por especieas de la sección Flavi pueden involucrar varios taxas, incluyendo A. flavus, A. oryzae, A. tamarii, A. parasiticus, A. alliaceus (petromyces-morph), A. nomius, A. qizutongi, A. beijingensis y A. novoparasiticus (Hedayati et al, 2007; Manikandal et al, 2009; Concalvez et al., 2012).

Morfología. En la sección Aspergillus Flavi, se han descrito en el pasado varias especies mediante métodos tradicionales (con parámetros morfológicos que incluyen diámetros de las colonias, color y textura, tamaño y textura de los conidios, estructura de los conidióforos y temperaturas máximas de crecimiento (Klich 2002). Sin embargo, la clasificación a nivel de especie puede ser dificultosa debido a la divergencia de los caracteres morfológicos producidos por el alto nivel de variabilidad genética (Kumeda \& Asao1996). Datos actuales indican que varias de las especies asignadas a la sección Flavi no pueden reconocerse basándonos solo en datos morfoló-gicos (Frisvad et al. 2005, Pildain et al. 2008; Vargas et al, 2011). Para las obsevaciones macromorfológicas se emplean los mismos medios descritos para los otros grupos 
de especies de Aspergillus, incubados a $25^{\circ} \mathrm{C}$ y $37^{\circ} \mathrm{C}$ en oscuridad, por 7 días y los datos micromorfológicos se obsevan en MEA en preparaciones con ác.láctico y azul de algodón, sin olvidar una gota de alcohol para remover las burbujas.

\section{Aspergillus alliaceus Thom \& Church (Fig26)}

(petromyces morph) (=Petromyces alliaceus Malloch \& Cain) (=Petromyces albertensis Tewari)

Diámetro de las colonias en CYA a $25^{\circ} \mathrm{C}$ por 7 días, 6870; MEA25, 65-70 mm CYA $37^{\circ} \mathrm{C}, 36-55 . \mathrm{mm}$. Cabezas conidiales en tonos verdes y colonias en CYA de color blanquecino, con conidios crema a amarillos o amarillo ocre, micelio blanco. Esclerocios/stromata, inicialmente blancos que se tornan gris oscuro a negros, reverso de la colonia canela a amarillo pálido o amarillo café. En MEA esporulación escasa, con colores amarillo dorado: esclerocios blancos que se tornan gris oscuro, reverso amarillo pálido a amarillo brillante. En CREA no produce base.

Micromorfología. Largas cabezas conidiales radiadas, algunas pequeñas columnares. Conidióforos de paredes gruesas, incoloros, toscamente rugosos, usualmente menores de $1 \mathrm{~mm}$ en su largo. Vesículas esféricas a piriformes, entre 10 a $65 \mu \mathrm{m}$ en diám., fiálides uniseriadas o biseriadas, métulas o fiálides que cubren como mínimo la mitad superior de la vesícula. Métulas 6-12 x 2,5-5 $\mu \mathrm{m}$; fiálides, 5-9 (13) x 22,5(4) $\mu \mathrm{m}$; conidios tipicamente globosos a subglobosos, conspicuamente equinulados, 2,5-3.5 (4) $\mu$ m en diámetro.

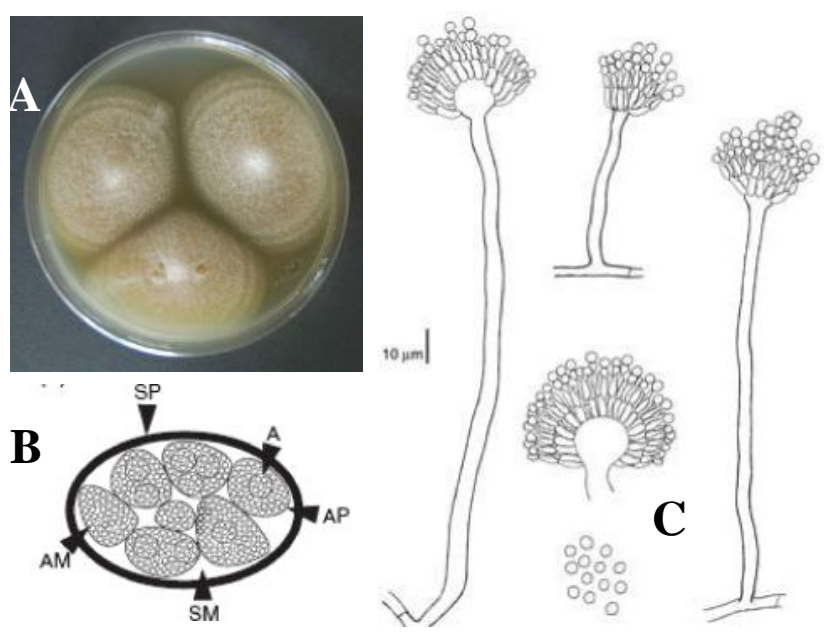

Figuras 26. A-B-C, A.alliaceus, A. Anverso en MEA, B. Clestotecio (petromyces-morph) SP. Células seuparenquimatosas del peridio de paredes gruesas, A. Ascos, con 8 ascosporas, AP, peridio del ascocarpo compuesto por células aplastadas, SM. Matriz del estroma, AM, matriz del ascocarpo, C. Conidióforos y conidios (A, tomado de: Fungi of Great Britain and Ireland, B,Tomado de: Dyer \& O'Gorman 2012. C, Tomado de: de Hoog et al, 2000.

Esta especie se distingue por sus colonias que ocupan toda la placa de Petri en MEA, sus conidios amarillos y sus esclerocios grises o negros. La especie se aisla comunmente de suelos desérticos, suelos cultivados y praderas, cactus, cebollas y bulbos de ajo entre las latitudes de $36-45^{\circ}$ (Klich, 2002).

\section{Aspergillus beijingensis D.M. Li, Y. Horie, Yu}

X. Wang \& R.Y. Li. (Fig. 27)

Diámetro de las colonias en CYA a $25^{\circ} \mathrm{C}$ por 7 días crecen ampliamente 56-60 mm diám. flocosas, formando

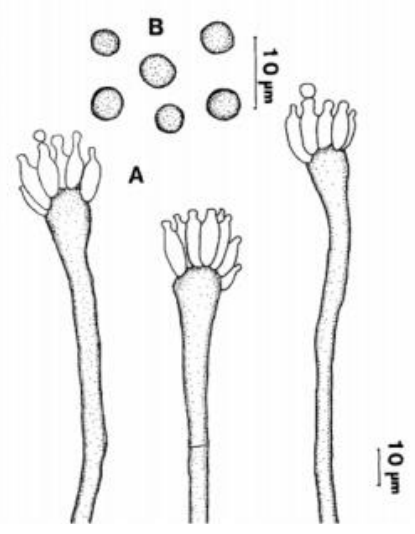

En MEA25, de $75-80 \mathrm{~mm}$ a $25^{\circ} \mathrm{C}$, con cabezas conidiales muy abundantes verde grisáceas; reverso blanco amarillento. Micromorfología. Cabezas conidiales, radiadas a laxamente columnares cortas, 50-150 x 20-100 $\mu \mathrm{m}$. Conidióforos $100-550$ x 4-5,5 $\mu \mathrm{m}$ en la parte central, de color verde grisáceo pálido, septado, de paredes gruesas, liso, con vesícula clavada, a veces en forma de frasco, 7-11 (-14) $\mu \mathrm{m}$ en diám., fértil sobre la mitad superior, uniseriado, con fiálides verde grisáceas pálidas, 10-19 x 4$5 \mu \mathrm{m}$. Conidios hialinos, verde grisáceos en masa, globosos a subglobosos, 3,5-6,5 x 3,5-5,5 $\mu \mathrm{m}$, micro-verrugosos (bajo SEM). Micelio compuesto por hifas hialinas a verde grisáceas pálidas, septado, liso, 5-7 $\mu \mathrm{m}$ de ancho, de paredes gruesas (hasta $1,5 \mu \mathrm{m}$ ). A $37^{\circ} \mathrm{C}$ se dispersa ampliamente pero el rango de crecimiento y las cabezas conidiales son menores que a $25^{\circ} \mathrm{C}$.

Esta cepa fue aislada de un paciente de 38 años con un aspergiloma maxilar (Li et al, 1998). Dentro de la sección Flavi A. beijingensis se semeja estrechamente a A. flavus Link var. columnaris Raper \& Fennell. Ambas especies tienen aspergilos uniseriados y globosos a subglobosos, conidios a menudo delicadamente rugosos, sin embargo, las vesículas y el largo de los conidios de $\boldsymbol{A}$. bejingensis son más pequeñas. En sus caracteres la especie a veces semeja A. avenaceus G. Smith, A. lucknowensis Rai, Tewari et Agarwal y A. zonatus Kwon \& Fennell, sin embargo, se separa de estas especies por ausencia de métulas y el tamaño y forma de los conidios. 


\section{Aspergillus flavus Link (Figuras. 28)}

(=Monilia flava (Link) Pers.,) (=Petromyces flavus Horn, . Carbone \& Moore) (=Aspergillus flavus var. proliferans Anguli, Rajam, Thirum., Rangiah \& Ramamu-rthi) (=Sterigmatocystis lutea Tiegh.) (A.flavus var.columna-ris Raper \& Fennel)

En CYA 25 durante 7 días, colonias, 65 -70 mm, de color verde amarillo. Colonia en MEA25-37, de crecimiento rápido similar al CYA. Pobre crecimiento en CREA. Cabezas conidiales típicamente radiadas, de color oliva a verde amarillento, posteriormente se abren formando columnas laxas, biseriadas pero con alguna cabezas monoseriadas. La var. columnaris Raper y Fennel, produce consistentemente columnas de conidios.

Microorfología. Conidióforos hialinos y toscamente rugosos, a menudo más visible cerca de la vesícula, incoloros, usualmente menores de $1 \mathrm{~mm}$ de largo. Vesículas subglobosas o globosas entre 10-65 $\mathrm{m}$ diám. Conidios globosos a subglobosos, verde pálidos y conspicuamente equinulados a casi lisos, 3,5-5,5 $\mu \mathrm{m}$. Algunas cepas son productoras de esclerocios cafesosos.

Aspergillus flavus, tiene un amplio rango de hospedadores y es un patógeno oportunista en humanos con compromiso inmune o un saprotrofo en los suelos. Su común presencia en éstos y en varios tipos de cosechas agrícolas, lo convierte en un gran productor de micotoxinas carcinogénicas (aflatoxinas), con peligro para la salud humana y animal. En el campo es un problema en las semillas oleáceas, maíz, algodón, maní, nueces, etc. Bajo condiciones inadecuadas de almacenamiento es capaz de crecer formando aflatoxinas en cualquier semilla. Es también un gran patógeno en insectos (Domsh et al, 2007).
Soares et al. (2012) y Varga et al . (2008-2009) entre otros, consideran que los extipos de aislados de A. orzyae, $\boldsymbol{A}$. fasciculatus, A. kambarensis, A. effusus y A. flavus var.columnaris son nombres sinónimos de A. flavus.

4. Aspergillus nomius Kurtzman, B.W. Horn \& Hesselt.(Fig.29) (petromyces morph).

(= Petromyces nomius ) B.W. Horn, I. Carbone et G.G. Moore,

Cultivos en CYA25 durante 7 días, 45-55 mm; MEA 25, 52-56 mm; CYA37, 73-85 mm; CYA20S, 57-62 mmy CZ, 40$50 \mathrm{~mm}$. En CYA 25, colonias pálidas, color pastel-amarillo, planas, usualmente aterciopeladas, con micelio vegetativo blanco y moderadas estructuras conidiales; reverso variable desde naranja pálido a gris naranja, esclerocios presentes o ausentes. Cuando presentes son subglobosos a elipsoidales entre 400-1650 $\mu \mathrm{m}$ o elongados indeterminados a vermiformes, de color rojo-café a negros, raramente caféclaros.

Micromorfología. Cabezas conidiales usualmente biseriadas y monoseriadas columnares o radiadas, que a menudo se abren en varias columnas, hasta unos $950 \mu \mathrm{m}$ diám., estipe incoloro, rugoso (inmediatamente bajo la vesícula), 450/600/ 1200 × 7-22 $\mu \mathrm{m}$; vesículas esféricas, 20/30/50 $\mu \mathrm{m}$, métulas 8,1-17,3 x 4-8,6 $\mu \mathrm{m}$, fíálides, 7-11,3 x 3-6,5 $\mu \mathrm{m}$. Conidios globosos a subglobosos, (3,3-) 4-6 (-8.1) $\mu \mathrm{m}$, tuberculados.

La posible producción de ascocarpos y ascosporas es morfológicamente similar en Petromyces nomius como en $P$. flavus y $P$. parasiticus. Las diferencias entre teleomorfo son insuficientes para separar las especies. La formación de ascocarpos maduros es infrecuente con solo un $24 \%$ de los cruzamientos que producen ascosporas viables.

La mayoría de las cepas de $\boldsymbol{P}$. nomius contiene un
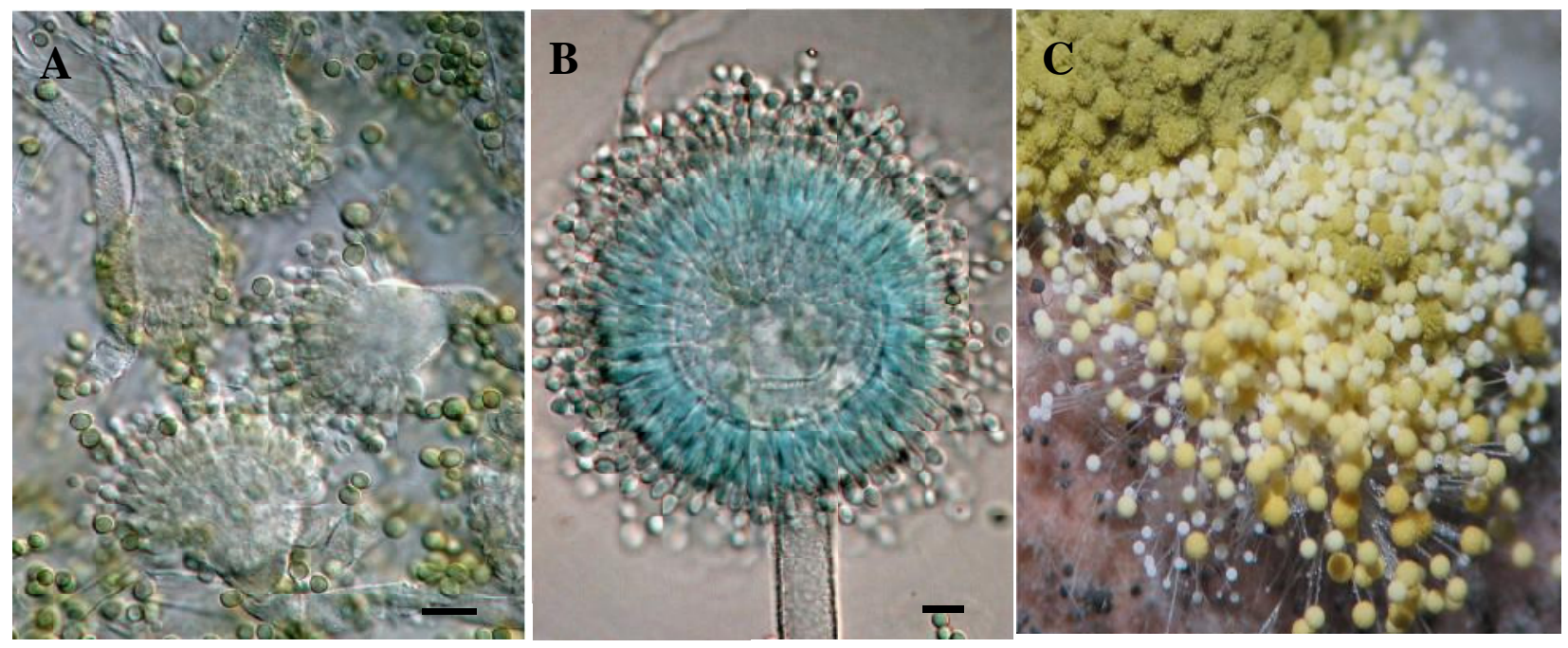

Figuras 28. A-B-C- Aspergillus flavus. A. Cabezas monoseriadas en MEA, B. Cabezas biseriadas en MEA, C. Típicas cabezas radiadas en desarrollo juvenil y más tardío sobre un semilla de poroto, puede aprecirse al mismo tiempo el desarrollo de un mucoral (Rhizopus oryzae). Barras $10 \mu \mathrm{m}$ 
único gen de tipo de cruzamiento (MAT1-1 o MAT1-2), sin embargo, varias cepas contienen ambos genes MAT1-1/ MAT1-2 y por ende son autofértiles y capaces de cruzarse con ambas cepas MAT1-1 y MAT1-2; por lo tanto, $P$. nomius es funcionalmente un heterotálico (Horn et al. 2011).

A.nomius, es una especie altamente variable morfológicamente, difícil de clasificar mediante los criterios convencionales (Kumeda \& Asao (2001). A. nomius, que fue descrito primariamente por Kurtzman et al. (1987), puede ser más común de lo que se espera, debido a su dificultad para distinguirlo de A. flavus del cual es muy fácil confundirlo. Presenta una distribución cosmopolita, incluyendo aislamientos previos desde suelos rojos en la India, como oportunistas en colonias de termitas y causante de una queratitis (Moody \& Tiler 1990; Chouvenc et al., 2012; Manikandan et al, 2009).

5. Aspergillus novoparasiticus Gonçalves, Stchigel, Cano, Colombo \& Guarro. (Fig.30)

Etimología: en referencia las estrechas relaciones filogenéticas con A.parasiticus

Colonias en CYA durante 7 días a 25 y $37^{\circ} \mathrm{C}, 58-63$ mm; Colonias en MEA 25, 56 - 60 mm diám. en 7 días a $25^{\circ} \mathrm{C}$, en MEA a $37^{\circ} \mathrm{C}, 52-59 \mathrm{~mm}$; pulverulentas verdosa-amarillas a oliva, consistentes en un denso fieltro de conidióforos, exudado hialino; reverso amarillo pálido a gris verdoso.

Micromorfología: Cabezas columnares, predominantemente uniseriadas, raramente biseriadas, oliva amarillo. Estipe hialino, verrugoso, usualmente con muchos septos cercanos a la vesícula, variables en largo, 150-500 x 8-10 $\mu \mathrm{m}$, diám., justo bajo la vesícula, $9-13 \mu \mathrm{m}$; vesícula espatulada a piriforme $20-28 \times 18-23 \mu \mathrm{m}$, fértil en los $2 / 3$ superiores,

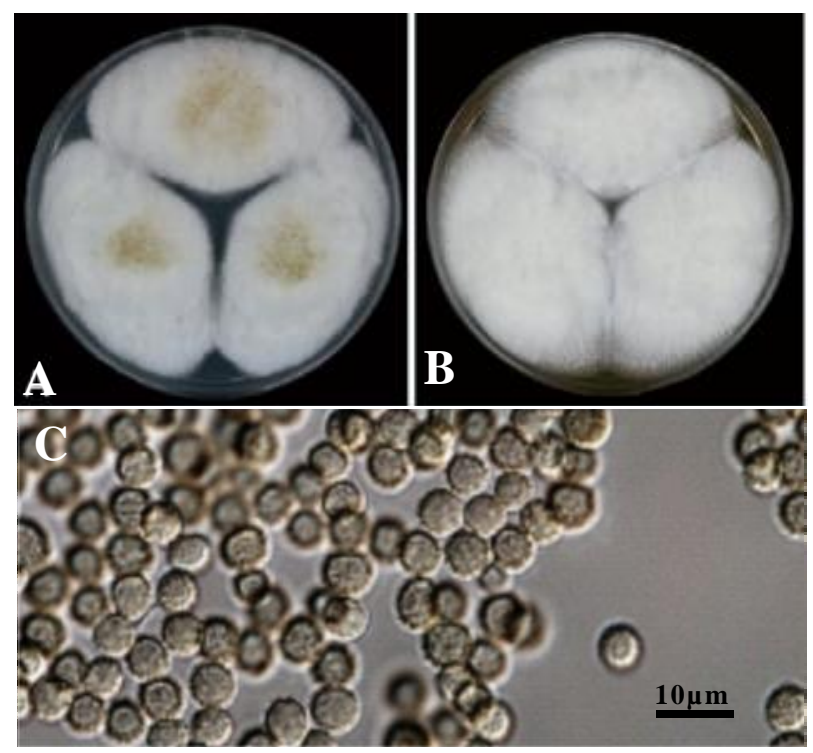

Figuras 29- A-B-C. A.nomius, A. Colonias en CYA, B, en MEA, C. Conidios (Tomado de:Varga et al, 2011)

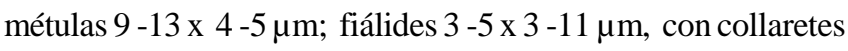
visibles. Conidios globosos a subglobosos, lobadosreticulados (SEM), verdes, $3-7 \mu \mathrm{m}$ en diám. Esclerocios no observados. Teleomorfo no observado.

CREA a $25^{\circ} \mathrm{C}, 25-35 \mathrm{~mm}$, sin producción de ácido. Pobre crecimiento a 15 y $42^{\circ} \mathrm{C}$. Los autores en un análisis de multilocus revelaron que $A$. novoparasiticus está estrechamente relacionado con $\boldsymbol{A}$. parasiticus, pero difiere de este último en los datos de secuencias combinadas cercanas al 3,4\%. Similares diferencias genotípicas se encontraron cuando se comparó $A$.parasiticus con A.flavus. A. novoparasiticum (identificado anteriormente como $\boldsymbol{A}$. flavus), se ha asilado desde suelos en Bogotá y en el aire y esputo de un paciente leucémico de un hospital en San Paulo Brasil colectado por P. Godoy-Martinez \& A. L. Colombo (Gonçalves et al, 2012).

\section{Aspergillus oryzae (Ahlb.) Cohn, (Fig.31)}

(=Aspergillus flavus var. oryzae (Ahlb.) Kurtzman, M.J. Smiley, Robnett \& Wicklow)

(=Eurotium oryzae Ahlb., )

Colonias en CYA25 de crecimiento rápido en 7 días a $25^{\circ} \mathrm{C}, 50-70 \mathrm{~mm}$, de color verde amarillento pálido, oliva amarillento o con diferentes tonalidades del verde, trípicamente con tonos café oscuros en el tiempo, colonias, consistentes en un conjunto de largos conidióforos a menudo intermezclados con micelio aéreo. En CYA37, colonias de 50$65 \mathrm{~mm}$. En MEA25, 60-70 mm, de color gris amarillento, de crecimiento rápido y a veces de specto delgado en grosor. Cabezas conidiales radiadas, de color verde amarillento pálido que se vuelven cafesosas en el tiempo. Pobre crecimiento en CREA y con un color crema en el reverso de AFPA.(Agar Aspergillus flavus-parasiticus).

Micromorfología. Conidióforos hialinos 150-300 x 10-25 $\mu \mathrm{m}$, mayormente de paredes rugosas, con cabezas radiadas a laxamente columnares. Vesículas piriformes, clavadas a
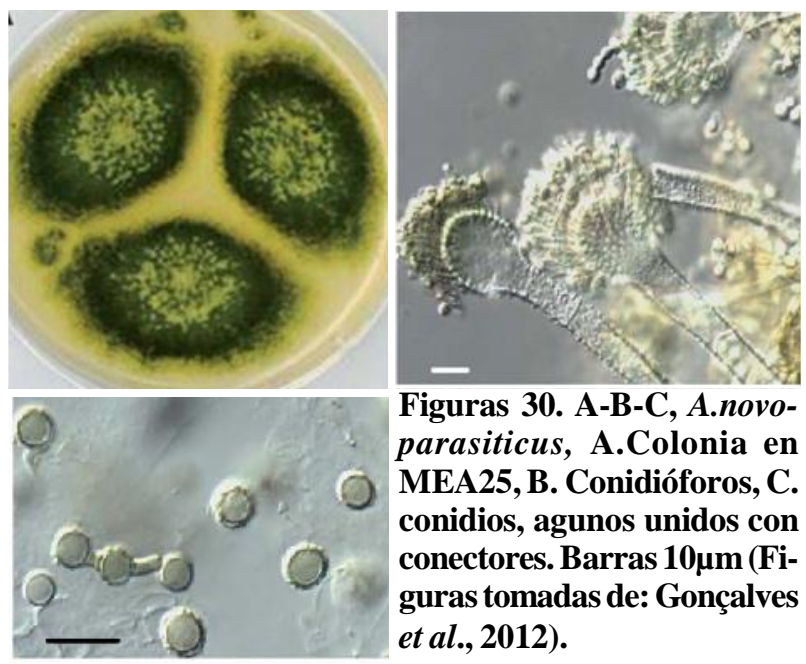

Figuras 30. A-B-C, A.novoparasiticus, A.Colonia en MEA25, B. Conidióforos, C. conidios, agunos unidos con conectores. Barras 10 $\mu \mathrm{m}$ (Figuras tomadas de: Gonçalves et al., 2012). 
subglobosas, 22- 50 (-80) $\mu \mathrm{m}$ en diám., fiálides a menudo nacen directamente sobre la vesícula o sobre métulas (uni o biseriadas), usualmente, 10-12 x 3-5 $\mu \mathrm{m}$. Métulas, 8-12 x 4-6 $\mu \mathrm{m}$; las métulas o fiálides cubren la entera superficie de la vesícula. Conidios elipsoidales cuando jóvenes, globososos a subglobosos al madurar, 4,5-8(-10) x 4,5-7 $\mu \mathrm{m}$ en diám., verdes a cafesosos, lisos a finamente rugosos. Esclerocios a veces presentes en MEA.

Patogenicidad. Esta especie ha sido reportada como responsable de invasiones de senos paranasales (Byard et al., 1986), implicada en casos de meningitis (Gordon et al., 1976), infecciones pulmonares (Retamal et al., 1988), otomicosis (Rinaldi, 1983) y escleritis (Stenson et al., 1982), entre otras patologías.

Esta especie se aisla predominantemente del suelo, detritus vegetales, semillas y en las fábricas de algodón. Se emplea frecuentemente en la fermentación de alimentos (Fig. 28 D), en la producción de saki, shoyu, miso, jugo de soya y como fuente de enzimas industriales. A pesar que la ocurrencia de $\boldsymbol{A}$. oryzae es restringida generalmente a alimentos fermentados o ambientes industriales, normalmente no la encontramos en muestras de alimentos o en ambientes internos (www.aspergillus.org.uk/secure/.../ oryzae.php).

La distinción con A. flavus es a veces dificultosa debido a las muchas cepas que presentan intergrados de similitud. Raper y Fennell (1965), consideraron el color y la rugosisdad del conidio, como caracter importante, pero estos son a menudos difíciles de reconocer. Los típicos aislados de $\boldsymbol{A}$.

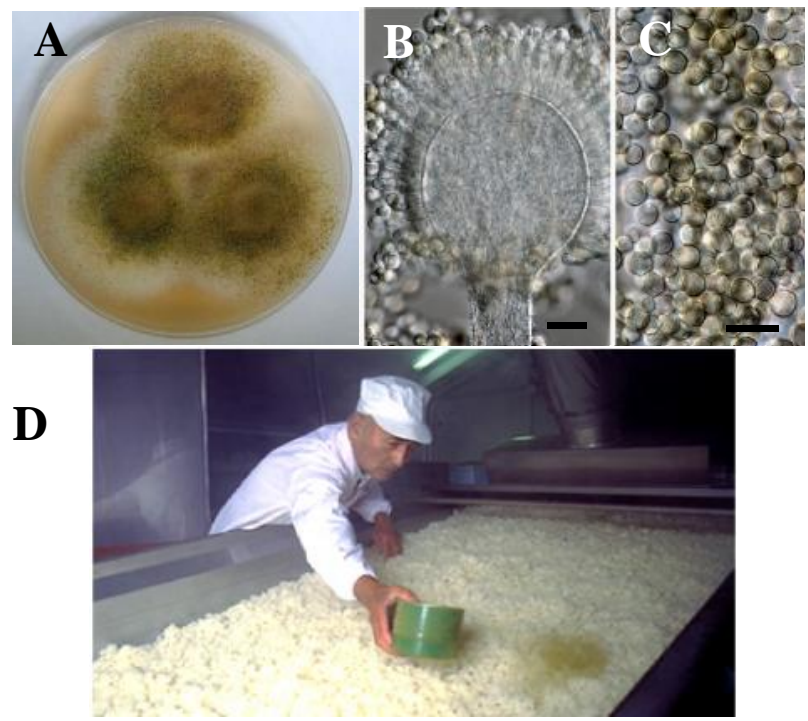

Figuras 31 A-B-C.D. A. oryzae A. Colonia en CZA(Tomada de:Fungi of Great Britain and Ireland). B. Conidióforo monoseriado(Tomado de Varga et al, 2011), C. conidios (tomada de:http://www. ncbi.nlm.nih.gov/pmc/about/copyright), D. Fermentación tradicional del koji, (Tomada de: http:// muso-intl.com/seasoning/koji/index.html) oryzae difieren de A. flavus por sus colonias grandes flocosas, con cabezas conidiales gris amarillentas a oliva y menos densas que A.flavus, con conidios menos ornamentados y normalmente más grandes en tamaño (Varga et al,2011).

\section{Aspergillus parasiticus Speare (Fig.32)}

(=Aspergillus toxicarius Murak.

(= Petromyces parasiticus Horn et al., 2009b)

Colonias en agar Czapek $25^{\circ} \mathrm{C}, 3-4,5 \mathrm{~cm}$ diám en 7 días ; a $37 \mathrm{C}^{\circ}$ en 7 días 4- 6,5 cm diám. En MEA 25, 5-6 cm, con tintes más verdosos que otras especies en el grupo. Superficie de la la colonia aterciopelada a debilmente funiculosa, con consistente y abundantes cabezas conidiales que en masa tienen un color verde oscuro en 14 días. Reverso amarillo café claro A. parasiticus también puede producir esclerocios similares a los de A. flavus, globosos a elipsoidales, (250-)300-1200(-1300) $\mathrm{mm}$, que se tornan rosados a café y finalmente café oscuro a negros.

Micromofología. Conidióforos: 250-600(-900) x 5-11 $\mu \mathrm{m}$ largo (especialmente bajo la vesícula), incoloros o café pálidos, con paredes rugosas (lisas en A.soyae); vesícula esférica, 20$35 \mu \mathrm{m}$ in diám., fértil en sus $3 / 4$ de la superficie, generalmente monoseriado pero a veces hasta con un $20 \%$ de cabezas biseradas ; métulas,7-10 x 3,5-7 $\mu \mathrm{m}$; fiálides, 7-11 x 2,5-5 $\mu \mathrm{m}$; conidios esféricos, mayormente entre 4-6 $\mu \mathrm{m}$ en diám., con una pared distintivamente rugosa. Usualmente presencia de cabezas radiadas. Crece bien a $42^{\circ} \mathrm{C}$.

Estructuras diferenciales. A. flavus y A. parasiticus se ditinguen por su rápido crecimiento a 25 y $37^{\circ} \mathrm{C}$ y por su brillante color conidial amarillo verdoso (ocasionalmente amarillo). Las diferencias definitivas entre las 2 especie son: $\boldsymbol{A}$. flavus produce conidios que son más bien variables en tamaño y forma, tienen relativamente una pared delgada que se presenta lisa a moderadamente rugosa. Los conidios de A.parasiticus son esféricos y relativamente de pared gruesa y rugosa. Las vesículas de A. flavus son usualmente grandes (hasta $50 \mu \mathrm{m}$ en diám.) con metulas, mientras las de $\boldsymbol{A}$. parasiticus raramente sobrepasan los $30 \mu \mathrm{m}$ y las métulas son bastante poco comunes.

A.parasiticus produce aflatoxinas B1,B2,G1,G2 y virtualmente todos los aislados conocidos son toxicogénicos, mientras las cepas aflatoxigénicas de A.flavus, solo producen típicamente B1 y B2 y otra micotoxina no relacionada como el ácido ciclopiazónico (que no lo produce A.parasiticus) (Horn et al., 1996).

A. parasiticus es bastante común en maní y almendras (Rodrigues et al. 2009), sin embargo, es bastante raro en otros alimentos. Es más restringido geográficamente si se compara con A. flavus. Análisis de variación entre 21 regiones intragenéricas han revelado distintos block de recombinaciones en $\boldsymbol{A}$. parasiticus, así como eventos de recombinación se han observado también entre diferentes 
grupos de compatibilidad vegetativa (Carbone et al. 2007). La equitativa distribución de los tipos de genes de cruzamiento en las poblaciones de $\boldsymbol{A}$. parasiticus son también indicativas de la presencia de un estado críptico sexual (Ramirez-Prado et al. 2008).

En clínica no es una especie muy común, pero se ha asilado de cuadros de sinusitis no invasora (Salim \& Runco, 2008) y en eambiente hospitalario (Fernández et al, 2013 a).

8. Aspergillus qizutongii D,-.M.Li, Y,-X Wang \& R,-Y,Li(1998) (Fig,33)

Colonias en CYA a $25^{\circ} \mathrm{C}$ por 7 días, de crecimiento amplio, $58-59 \mathrm{~mm}$, consistentes en un capa de micelio fino, flocoso, radialmente surcado, más o menos zonado, cabezas conidiales abundantes, oliva-café; reverso amarillo claro. Colonias en MEA25 de dispersión amplia, 75-76 mm en 14 días, que consisten en un micelio fino, flocoso.

Micromorfología. Cabezas conidiales muy abundantes, de color oliva amarillo a oliva café, radiadas, $60-120 \times 30-70 \mu \mathrm{m}$ o laxamente columnares largas, 120-300 (-500) x 25-50 $\mu \mathrm{m}$. Conidióforos que nacen del micelio basal y las hifas aéreas; estipe 100-300 (-500) x 6-8 $\mu \mathrm{m}$ (en la zona media), amarillo

A

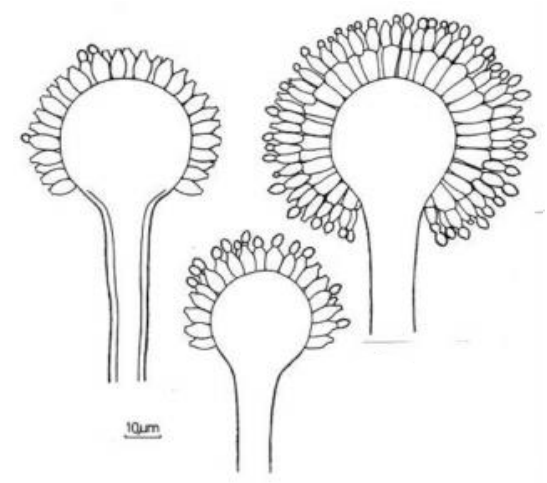

pálido a café, derechos a sinuosos, conspicuamente rugosos, septados, que se dilatan en la parte superior; vesícula en forma de frasco, oliva pálido, 9-17 $\mu \mathrm{m}$ en diám., fértiles solo en la mitad superior o los $3 / 4$, a menudo proliferantes (hasta unos $20 \mu \mathrm{m}$ de largo), para formar una pequeña segunda cabeza conidial con una vesícula de 4-7 $\mu$ m de diám., vesículas uniseriadas con fiálides oliva pálido a amarillo verdoso, 7$12 \times 2-4 \mu \mathrm{m}$. Conidios hialinos globosos a ovoides, 5-6,5 (7) $\mu \mathrm{m}$, lisos. Micelio compuesto por hifas anchas, gris verdosas, septadas, de paredes lisas, $2,5-5 \mu \mathrm{m}$. A $37^{\circ} \mathrm{C}$ crecimiento rápido, sin embargo, el crecimiento y las cabezas conidiales son reducidas como a $25^{\circ} \mathrm{C}$.

Esta especie fue aislada de material clínico en un aspergiloma maxilar en China. A. qizutongii semeja $\boldsymbol{A}$. beijingensis en las dimensiones del conidióforo y los conidios

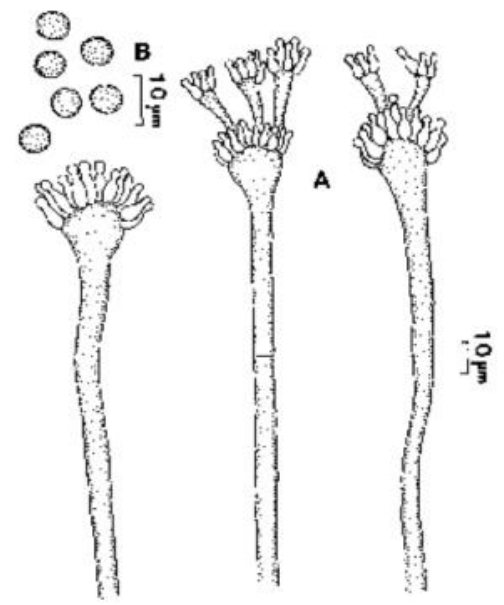

Figura 33. A. qizutongii . A. Conidióforos, fiálides y vesículas con prolongaciones apicales, B. Conidios (Tomado de: $\mathbf{L i}$, D-M, et al, 1998).
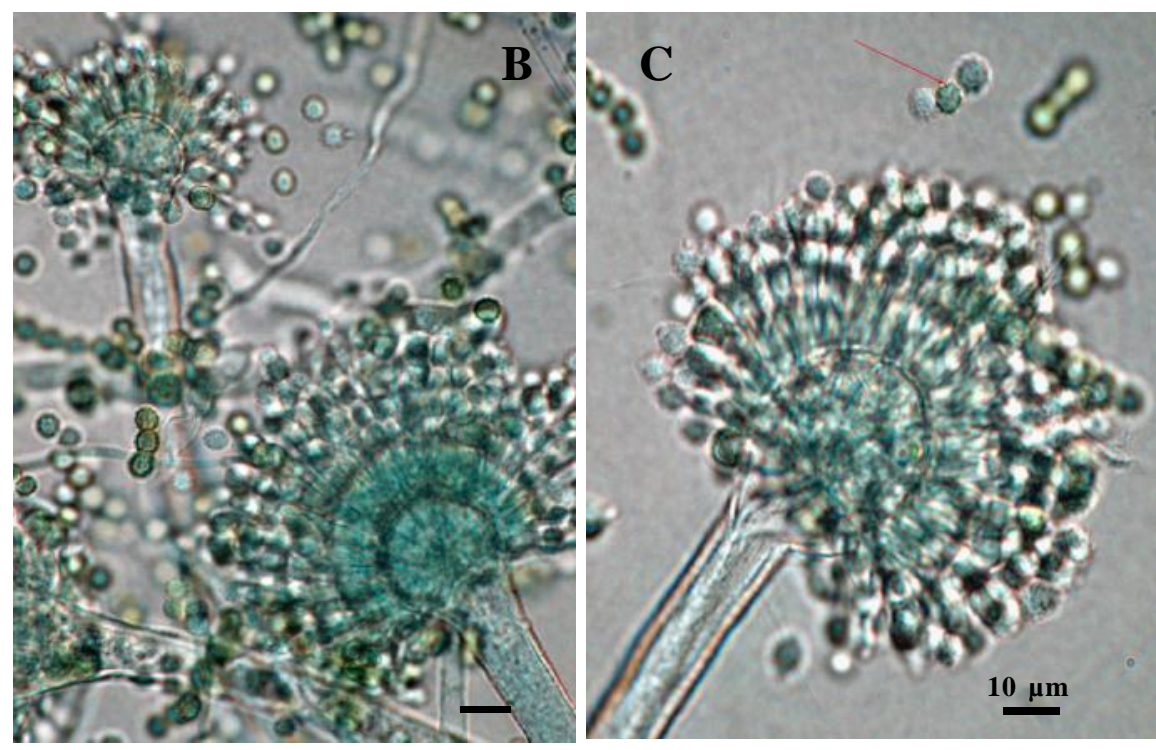

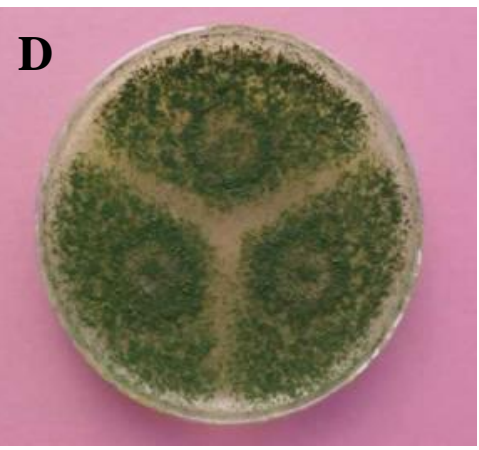

Figuras 32, A-B-C-D. A.parasiticus, A. Conidióforos mono y biseriados, B-C Conidióforos y conidios (observe la rugosidad del conidio indicado por la flecha), D Colonia en MEA (Tomada de: www.junglekey.fr) 
y en sus células conidiógenas uniseriadas, pero difiere de esta especie en sus conspicua rugosa pared del conidióforo y el tamaño de las fiálides (7-12 x 2-4 $\mu$ m en A. qizutongii, versus $10-19$ x 4-5 $\mu \mathrm{m}$ en $\boldsymbol{A}$. beijingensis). La proliferación secundaria en la cabeza aspergilar se ha observado en varias especies de Aspergillus, así como en A.flavus (Raper \& Fennell, 1965).

\section{9. $\quad$ Aspergillus tamarii Kita (Fig. 34)}

(=Aspergillus terricola var. bronzeus Saincl.,)

Colonias en CZA, de crecimiento rápido, 4-5 mm en 7 días, de color verde-café oscuro. Colonias en CYA25, 55-60 $\mathrm{mm}$, con conidios de color oliva verdoso oscuro, aterciopeladas; micelio blanco usualmente inconspicuo, reverso incoloro, a tintes rojos a chocolate café; esporulación densa con abundantes conidióforos, que rápidamente se tornan verde cafesosos oscuros; esclerocios, exudado y pigmento soluble ausente en todos los medios. En MEA 25, 60-65mm, colonias verdosas a café, con micelio usualmente inconspicuo, reverso café. Cabezas conidiales compactas, esféricas o laxamente radiadas, 500-600 $\mu \mathrm{m}$, escaso crecimiento en CREA.

Micromorfología. Conidióforos hialinos, mayoritariamente de pared conspicuamente rugosa, 1-2 mm de largo, vesículas globosas a subglobosas 20-50 $\mu \mathrm{m}$ en diám. Células conidiógenas uni y biseriadas; fiálides que nacen directamente de las vesículas o sobre las métulas (generalmente en las cabezas grandes), 10-15 x 4-8 $\mu \mathrm{m}$, métulas 7-10 x 4-6 $\mu \mathrm{m}$. Métulas y fiálides cubren la entera superficie de la vesícula, conidios globosos a subglobosos, equinulados a tuberculados, 5- $7 \mu \mathrm{m}$, cafesosos amarillos; se aprecia la pared interna y externa del conidio.

Esta especie de distribución mundial, se encuentran en especial en los trópicos ya sea en el suelo y alimentos, especias y maíz.

Existen 2 tipos de colonias de A.tamarii, las de tipo A con colores sugestivos llamados la serie de bronce (Thom y Raper, 1945); una serie que incluye las cepas cercanas a $\boldsymbol{A}$. tamarii con colonias verde amarillas cuando jóvenes y amarillas a café al madurar. Estas cepas fueron usadas por Raper \& Fennell (1965), para describir la especie. Horn et al.(1966), propusieron que las cepas de A. tamarii tipo B fueron distintivas, separandolas de A. tamarii y subsecuentemente descritas como una nueva especie, Aspergillus caelatus (Horn,1997). Las colonias de estos aislados son oliva, mientras el color de los aislados de A. tamarii son oliva cafe. Mas aun los aislados de A.caelatus producen un pigmento difusible amarillo cafe pálido en el medio, muy evidente en agar Czapek, mientras los aislados de $\boldsymbol{A}$. tamarii no lo producen. El diámetro de las vesiculas, ancho del estipe y el largo de éste en $\boldsymbol{A}$. caelatus son significativamente mas pequeños que los de las estructuras del conidióforo de los aislados de A. tamarii. El 69\% de los aislados de A.caelatus forman irregularmente esclerocios, mientras éstos no se presentan en ninguno de los aislados de A. tamarii. Egel et al. (1994), reportaron no haber encontrado esclerocios en varios cultivos de $\boldsymbol{A}$. tamarii. Sin embargo, en semejanza a los aislados de $\boldsymbol{A}$. caelatus, algunas cepas de A.tamarii producen un pigmento café pálido en agar Czapek y producen esclerocios; sin embargo, los esclerocios son uniformemente pequeños en tamaño y distintamente piriformes en forma.
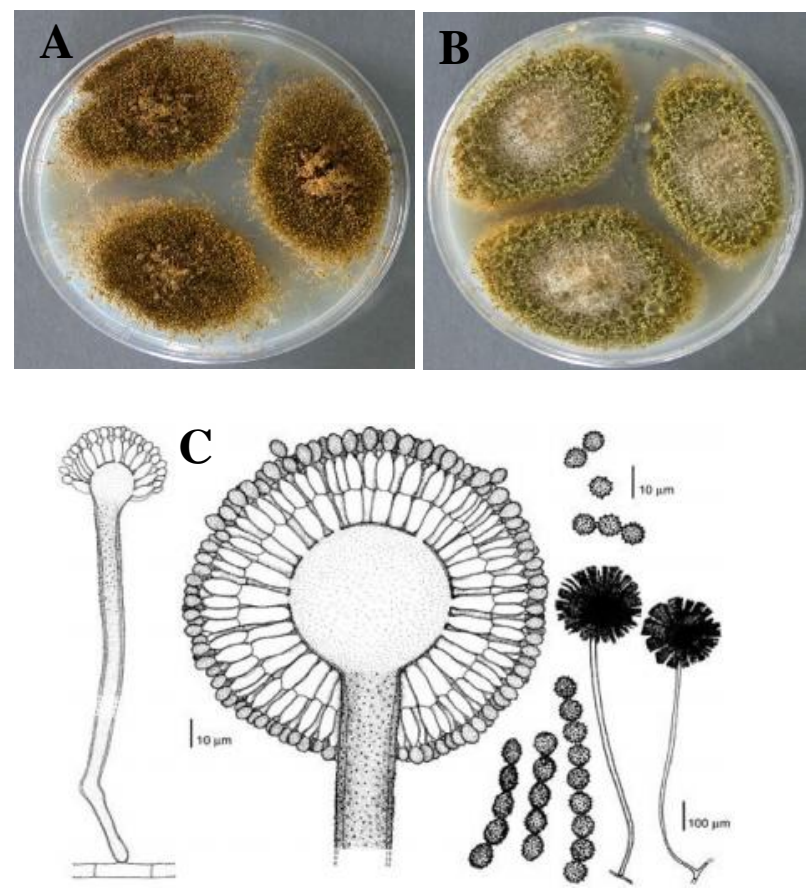

Figuras 34. A-B-C. A.tamarii, A y B, colonias en CzA y MEA (Tomado de:Fungi of Great Britain and Ireland) C. Morfología de la cabeza aspergilar y sus elementos, conidióforos, métulas, fiálides, conidios (Tomado de: De Hoog et al ,2000)

\section{Clave morfologica tentativa de las especies del} grupo Flavus de interes clinico

1.- - Cabezas conidiales predominantemente uni y biseriadas 2 - Cabezas conidiales uniseriadas estrictas.......7

2.- - Conidios en tonos verdes, oliva a oliva amarillentos. 3

- Conidios de color cafe-ocre o dorados .............. 6

3.- -Pared del conidio lisa a finamente rugosa ........ 4 -Pared del conidio ampliamente rugosa .............. 5

4.- - Conidios usualmente gris-amarillo a oliva cafe en el tiempo, lisos a finamente rugosos, 4-8,5 $\mu \mathrm{m}$, conidioforo rugoso.......... A.oryzae (Ahlburg) Cohn 
- Conidios que permanecen verde oliva a verde papagayo con la edad en CYAS25, diametro de los conidios 3-5,5 $\mu \mathrm{m}$, conidióforo rugoso.

A.flavus Link

5.- - - Usualmente presencia de cabezas radiadas, pre dominantemente uniseriadas, conidios usualmen te 3-6 $\mu \mathrm{m}$ en diam., rugosos, colonias en CYA25 permanecen con la edad de un color oliva oscuro o tonos del verde, conidióforos incoloros a cafe pálido, buen crecimiento a $42^{\circ} \mathrm{C}$, esclerocios a veces presentes. A.parasiticus Speare

- Cabezas columnares, predominantemente uniseriadas, conidios usualmente 3-7 $\mu \mathrm{m}$ en diám., rugosos, con conectores visibles, colonias verdosas a amarillas, verde oscuras en el tiempo en MEA, conidióforos hialinos, rugosos, usualmente con muchos septos bajo la vesícula, pobre crecimiento a $42^{\circ}$ C.... A. novoparasiticus Gonçalves, Stchigel, Cano, Colombo \& Guarro.

- Conidios 5,5-8 (-13) $\mu \mathrm{m}$, rugosos de gruesa pared visible, colonias en CYA25 usualmente de color oliva, café oscuro a verde café con la dad en CYA25 A.tamarii Kita

6.- - Conidios pequeños, 3-3,5 (4) $\mu \mathrm{m}$, lisos, cabeza conidial radiada cuando joven, conidios en amarillo a ocráceos, diámetro de las colonias en CYA37, usualmente menores de $55 \mathrm{~mm}$, conidióforos lisos A.alliaceus Thom \& Chtrch

- Conidios, 4-6(-8), rugosos, cabezas conidiales columnares a radiadas, colonias pálidas, color pastel-amarillo, diámetro de las colonias en CYA37, 73-85 mm, conidióforo rugoso

......A. nomius Kurtzman, B.W. Horn \& Hesselt.

7.- - Cabezas conidiales radiadas a laxamente columnares, de color amarillo a verde grisáceo, conidióforos largos, septados, de paredes gruesas, li sos; vesículas clavadas, fértiles en su mitad superior, 7-11 $\mu \mathrm{m}$ diám., conidios hialinos verde grisáceos en masa, verrugosos, globosos, 3,5-6,5 $\mu \mathrm{m}$ A. beijingensis D.M. Li, Y. Horie, Yu X. Wang \& R.Y. Li,

- Cabezas conidiales oliva amarillo a oliva café, radiadas a laxamente columnares, largas, conidióforos amarillo pálido a café, derechos a sinuosos, rugosos, septados, vesícula en forma de frasco, oliva pálido, 9-17 $\mu \mathrm{m}$ en diám, fértiles en la mitad superior o los 3/4, a menudo proliferante. Conidios hialinos globosos a ovoides, 5-6,5 (-7) $\mu \mathrm{m}$, lisos. .......Aspergillus qizutongii $\mathrm{D}$,-.M.Li, Y,-X Wang $\& \mathrm{R},-\mathrm{Y}, \mathrm{Li}$

D). Aspergillus subgénero Circumdati sección Terrei y Flavipedes

Esta sección incluye 2 grupos estrechamente relacio-

Terrei y Flavipedes. Las especies de ambas secciones incluyen conidióforos biseriados y algunas especies son capaces de reproducirse sexualmente (fennelia-morph).

Los Aspergillus de la sección Flavipedes, incluyen especies con conidióforos lisos con tonos amarillos a café o incoloros y cabezas conidiales radiadas (laxamente columnares). Además, A. neoniveus y A. flavipedes producen cleistotecios por ser especies homotálicas (Samson $e t$ al, 2011). La especie A. flavipedes, ha sido causante de patología en humanos, en especial aspergilosis pulmonar, osteomielitis y onicomicosis (De Hoog et al, 2000).

Los Aspergillus de la sección Terrei, que incluye en la actualidad 14 especies, presentan conidióforos lisos incoloros y cabezas columnares compactas generalmente de color avellana o canela. Actualmente se ha descrito el ciclo sexual (heterotálico) de A. terreus (Arabatzis \& Vele-graki, 2013). A. terreus principalmente y A. alabamensis, son las especies mas oportunistas en el hombre (Lass-Florl et al,2000; Baddley et al, 2003; Balajee, 2009; Fernández et al., 2013b; entre una extensa bibliografía).

Ecología y distribución geográfica.

A.terreus, es un hongo cosmopolita, frecuentemente aislado de suelos desérticos, praderas, compost apilado y un contaminante de productos almacenados, tales como maíz, avena, maní y nueces en climas tropicales y subtropicales (Pitt \& Hoking, 2009). Es prevalente en zonas temperadas, tropicales y subtropicales y sus mitosporas pueden germinar bajo un amplio rango de temperaturas que oscilan entre los $11-13$ y $45-48^{\circ} \mathrm{C}$. Es tolerante a las altas concentraciones de $\mathrm{NaCl}$ y puede encontrarse en suelos pantanosos como en playas marinas (Domsh et al, 2007). Económicamente, tiene gran importancia en la industria por la producción de compuestos orgánicos de utilidad en medicina, tales como lovastatina y agentes para la reducción del colesterol, como la mevinolina que se ha encontrado solo en A. terreus y $\boldsymbol{A}$. neoafricanus (Samson etal, 2011).

\section{Análisis moleculr y extrolitros}

La Seccíon Terrei ha sido recientemente analizada mediante estudios polifásicos (Samson et al, 2011), incluyendo análisis de seuencias de partes de genes de la beta-tubulina y calmodulina y de la región de los ITS, análisis macro y micromorfológicos y la examinación de los perfiles de extrolitos, para describir 3 nuevas especies en esta sección. 
La micotoxina hepatotóxica citrinina, se a encontrado en 8 especies: A. alabamensis, A. allahabadii, A. carneus, A. floccosus, A. hortai, A. neoindicus, A. niveus y A. pseudoterreus. Mientras el extrolitro neurotóxico citreoviridina solo en 6 especies: A. neoafricanus, $A$. aureoterreus, A. pseudoterreus, A.terreus y A.neoniveus.

Evidencia de la estructura de la población de A.terreus ligada a su origen geográfico. Varios estudios han demonstrado que $\boldsymbol{A}$. terreus es el agente etiologico predominante en la aspergilosis invasora en agunos centros medicos alrededor del mundo, incluyendo los de Houston, Texas e Insbruck en Austria (Lass.Flor et al ,2007; Hachem et al, 2004; Neal et al, 2011). El exámen molecular de los aislados en estos centros, no muestran endemismo, concluyendose que otros factores como los niveles de inmunosupresión y previos empleos de antifungicos en el hospedador, pueden ser responsables en parte por la prevalencia de A. terreus en estos centros médicos. Neil et al (2011), demostraron mediante métodos moleculares discriminatorios, que A.terreus puede exhibir endemismo. Queda por resolver si los aislados obtenidos de otras partes del mundo se agrupan acorde al lugar geográfico. Esta caracterización molecular de hongos importantes en medicina puede ser de sumo interés para entender la ecología y la adquisición y transmision de estos organismos.

\section{Patología clínicay resistencia a los antimicóticos}

A.terreus complex es un patógeno poco común productor de pneumonías e infecciones diseminadas en individuos inmunodebilitados al igual que A.fumigatus. Sin embargo, ha sido también causa de onicomicosis (Fernández et al, 2013), lesiones en la córnea, queratitis sinusitis alérgica, otitis, infecciones cutáneas y aspergilosis pulmonar alérgica, entre otras. La diferencia entre A. terreus y A. fumigatus, lleva a importantes implicaciones terapéuticas. La rápida identificación del complejo A.terreus permite iniciar una apropiada terapia antifúngica con triazoles debido a la resistencia a los polienos por este patógeno. Walsh et al, (2003), encontraron in vivo la formación de aleurioconidios a lo largo de la pared lateral del las hifas de A. terreus (Fig 35). Estos aleurioconidios en los tejidos son semejante a los encontrados en cultivos y su reconocimiento en los especímenes clínicos, como el lavado broncoalveolar, aspirado con jerigas finas o la biopsia, puede permitir una identificación preliminar d A.terreus y un inicio de terapia con triazoles. Al parecer esta especie no es la la única en los Aspergillus sección Terreus y Flavipedes que puede producir estos aleuroconidios in vivo. No se han encontrado diferencias en la respuesta fagocítica del hospedador en $\boldsymbol{A}$. terreus versus $\boldsymbol{A}$. fumigatus; sin embargo, el rango de germinación conidial de $\boldsymbol{A}$. terreus es lento. La cepas de $\boldsymbol{A}$. terreus con el más alto mínimo inhibitorio y mínima concentración letal de Anfotericina B, también tienen el contenido má bajo de ergosterol en la membrana. Si bien sabemos que A. terreus es resistente a la anfotericina B, hay estudios retrospectivos de casos de aspergilosis invasora por este agente (Steinbach et al, 2004), donde la mortalidad fue más baja con el empleo del Voriconazol.

\section{Aspergillus terreus Thom. (Fig. 36)}

Diámetro de las colonias en CYA25 (30) 40-60 cm. en 7 días (en CYA37, (55) 65 -70 mm), flocosas, radialmente surcadas, con margen irregular: micelio blanco, a veces amarillo centralmente, exudado amarillo a dorado cuando presente; reverso amarillo, dorado a café, con pigmento soluble a veces presente. Cabezas conidiales amarillentas blancas a vináceo-canela . Diámetro de las colonias en MEA25, (30) $40-70 \mathrm{~mm}$ a $25^{\circ} \mathrm{C}$, con cabezas conidiales columnares, color avellana a café; con esporulación más densa; reverso gris amarillento con pigmento soluble amarillo claro. Pobre crecimiento en CREA.

Micromorfología. En MEA37,vesículas 8 -20 $\mu$ m en diám., piriformes o hemiesféricas; estipes 48-220 x 4 -8,6 $\mu \mathrm{m}$, lisos, incoloros, generalmente flexuosos. Cabezas biseriadas estrictas con métulas que cubren $1 / 2$ a $2 / 3$ de la vesícula, 4,8- 7,2 x 2-2,5 $\mu \mathrm{m}$; fiálides 5,6-8 x 1,6 -2 $\mu \mathrm{m}$. Conidios globosos a subglobosos, 1,5-2,5 $\mu \mathrm{m}$ en diám., lisos. Un segundo tipo de conidios (aleuroconidios) globosos a ovoides, hialinos, se producen a menudo lateralmente sobre un corto pedúnculo en las hifas sumergidas, 3,6 - 6,4 $\mu$ m en diám. Metabolitos tóxicos importantes: Patulina, Citrinina, Citreoviridina.

Estructuras diferenciales: compactas columnas, naranja pálido a color habano canela, métulas empaquetadas y angostas $(2-2,5 \mu \mathrm{m})$, conidios lisos y aleuroconidios en el micelio sumergido.

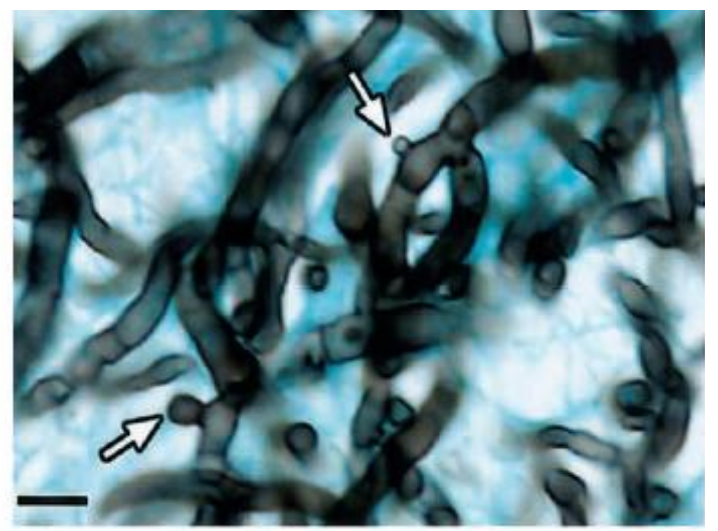

Figura 35. A.terreus. (Gomory metamina con tinción de plata). Las flechas indican la formación de aleurioconidios in vivo en los costados de elementos hifales (Tomado de:Walsh et al, 2003, Barra $10 \mu \mathrm{m}$ ) 


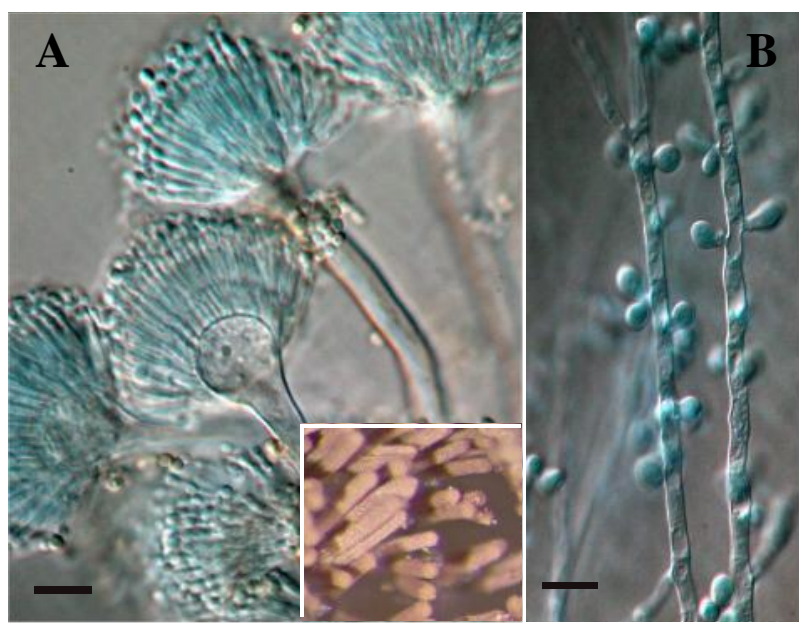

Figuras 36. A-B A.terreus. A. Típicas cabezas biseria-das estrictas y conidios (en el recuadro cabezas conidiales en cultivo, tomadas de: commons.wikimedia.org), B. Aleuroconidios desde el micelio vegetativo. Barras $10 \mu \mathrm{m}$.

\section{Aspergillus alabamensis Balajee, Baddley,}

Frisvad \& Samson (2009b) (Fig. 37)

Colonias en CYA25 y MEA25 de color amarillo-café a canela café, a menudo consisten en un denso fieltro de conidióforos, pero a veces muestran un crecimiento flocoso; en CYA25, presentan un crecimiento menor que en MEA y un pigmento difusible cafesoso alrededor de la colonia. En CYA la cepa crece a 37 y a $42^{\circ} \mathrm{C}$. En MEA, cabezas conidiales densamente columnares, 30 a $50 \mu \mathrm{m}$ en diám., $150-500 \mu \mathrm{m}$ o más en largas columnas al madurar; conidióforos biseriados, lisos, incoloros, $100-250 \times 4,5-6 \mu \mathrm{m}$. Vesículas subglobosas, 10 - $16 \mu \mathrm{m}$ diám., fiálides, 5-7 x 2-2,5 $\mu \mathrm{m}$, métulas estrechamente apretadas, 5,5 -7,5 x 1,5 - $2 \mu \mathrm{m}$. Conidios globosos a ligeramente elípticos, lisos, 1,8-2,4 $\mu \mathrm{m}$ en diámetro. No hay referencia en la descripción a la produccion de aleuroconidios en el micelio sumergido, Sin embargo, en un trabajo aspergilosis diseminada por A.alabamensis en un canino, hay registros en cortes histológicos (Gomory Grocott) de la presencia de hifas septadas con conidios laterales (aleuroconidios) (Burrough et al, 2012; Samson et al, 2014).

Evidencias preliminares sugieren que los miembros de esta especie son a menudo aislados como colonizadores (Balajee et al, 2009). Sin embargo, ningun aislado de A.alabamensis encontrados en los estudios de Neil et al,(2011) fueron colonizadores. Balajee et al, (2009a), agregan que a pesar que A. alabamensis y $\boldsymbol{A}$. terreus presentan muchos metabolitos secundarios similares. La citrinina es el metabolito característico en A. alabamensis, mientras en A.terreus es la mevinolina (ninguno de los aislados de A. alabamensis estudiados produce derivados de la lovastatina y citreoviridina). Estos patrones de metabolitos parecen ser las características principales para distinguir ambas especies y necesitan mayores estudios.

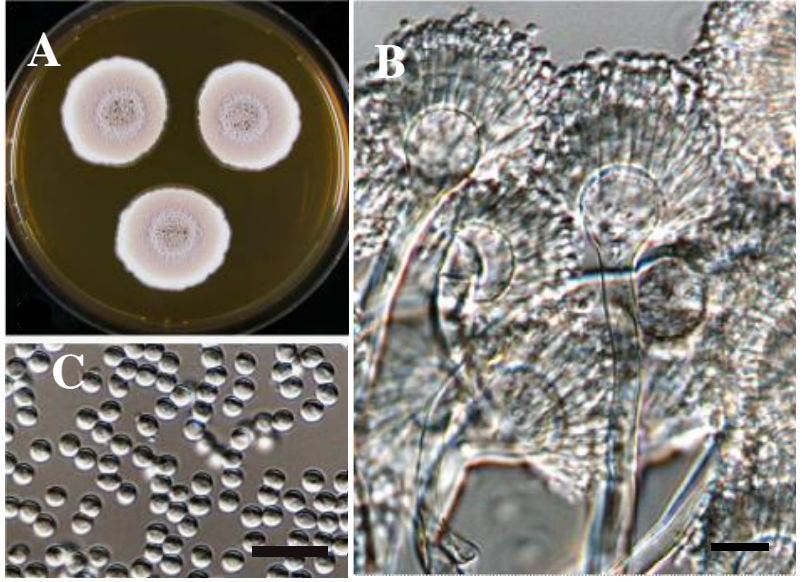

Figuras 37. A-B-C- A.alabamensis, A. Colonias en MEA,

(A,B,C. tomadas de: Balajee et al, 2009b)

$\mu \mathrm{m})$

\section{A. flavipes (Bain. \& Sart.) Thom \& Church.}

=Fennelia flavipes Wiley \& Simmons. (Fig.38)

Colonias en 7 días en CYA25, (19) 24-33(40) mm diám., micelio blanco a crema a amarillento, con cabezas conidiales gris naranja, exudado amarillento café cuando presente; reverso sin color, amarillo pálido o café pálido; en MEA25, 28-31 (37) mm diám., cabezas conidiales naranja blanco a rojizo, micelio blanco, reverso grias amarillento a café dorado; CYA37, 8-20 mm diám.

Micromorfología. En MEA25, cabezas radiadas a laxamente columnares, estipes $200-800 \times 4-8 \mu \mathrm{m}$, de paredes lisas a finamente rugosas, incloros a café pálido, vesículas espatuladas a subglobosas 10-20 $\mu \mathrm{m}$ de diám., biseriadas, con métulas de 5-6 (8) x 2,5-4 $\mu \mathrm{m}$, que cubren por lo menos la mitad superior de la vesícula, fiálides, 5-8 x 2-3 $\mu \mathrm{m}$. Conidios globosos a subesféricos, lisos, 2-3 $\mu$ m diám., de color naranja claro en masa. Aleuroconidios globosos se producen ocasionalmente en las hifas vegetativas. Homotálico, con cleistotecios amarillos cuando presentes, rodeados por células de Hulle redondas, ascos globosos, 10-12,5 $\mu \mathrm{m}$ diám., dehiscentes, usualmente con 4 esporas que maduran en unas 3 semanas, hialinas, a amarillo pálido, subglobosas, 6,4$8 \times 5,6-6,4 \mu \mathrm{m}$, lisas, con un inconspicuo surco longitudinal.

Esta especie ha causado cuadros clínicos cutáneos y osteomielitis (Tack et al., 1982).

\section{4. $\quad$ Aspergillus niveus Blochwitz (Fig.39)}

( =Fennelia neonivea Samson.S.W.Peterson, Frisvald \& Varga 2011)

(=Aspergillus eburneus Biourge)

(=Aspergillus niveus var. bifidus Maia \& Alecrim)

Diámetro de las colonias en CYA25, 20-38 mm; en MEA25, 23-38 mm, CYA37, 0 o 30-45mm. En CYA25, colonias blancas, aterciopeladas, planas o radialmente surcadas, ocasionalmente con sectores amarillos con cabezas 

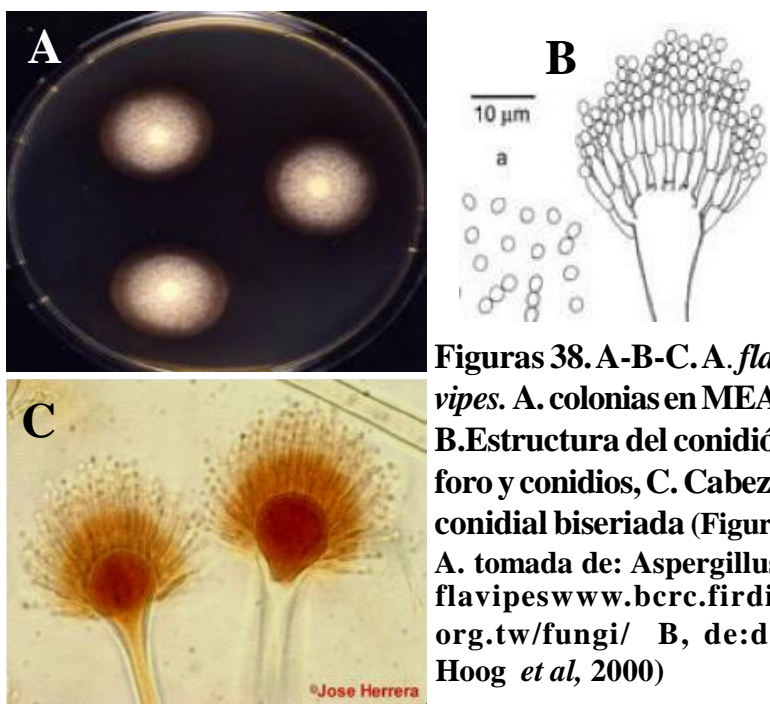

Figuras 38. A-B-C. A. flavipes. A. colonias en MEA, B.Estructura del conidióforo y conidios, $C$. Cabeza conidial biseriada (Figura A. tomada de: Aspergillus flavipesw ww.bcrc.firdi. org.tw/fungi/ $B$, de:de Hoog et al, 2000)

conidiales blancas, blanco amarillentas o amarillo pálido; a veces presencia de células de Hülle, exudado incoloro, amarillo, rojo profundo a verde oscuro, café o verde, reverso café amarillento; pigmento soluble amarillo cuando presente. En MEA25, micelio blanco o con una base amarillenta a veces en sectores; cabezas conidiales blancas a naranja blanco, exudado ausente o incoloro, reverso incoloro o en tonos amarillo oscuro a café.

Micromorfología. En MEA25, cabezas radiadas a laxamente columnares; estipes100-500 (1000) x 3-7 $\mu$ m, incoloros, lisos, de paredes más gruesas en MEA que en CYA, con vesículas espatuladas o piriformes; predominantemente biseriadas, ocasionalmente uniseriadas y biseriadas en la misma vesícula, métulas muy entrecruzadas que cubren la parte superior o la mitad de las vesículas, 5-9 x2-3,5 $\mu \mathrm{m}$, fiálides 5$8 \times 2-3 \mu \mathrm{m}$. Conidios globosos a subglobosos, lisos a finamente rugosos, (2)2,5-3,5 $\mu \mathrm{m}$. Ocasionalmente aleuroconidios presentes. Células de Hülle cuando presentes, amarillas globosas a elongadas. Cleistotecios amarillos cuando presentes, con ascosporas lenticulares hialinas a levemente amarillentas 4,5-6 x 3,2-4,8 $\mu \mathrm{m}$, con pared espinosa, un inconspicuo surco longitudinal y 2 crestas longitudinales muy bajas. (Fennelia nivea no corresponde a A. niveus sino que a una especie nueva A. neoniveus (Samson et al, 2011).

A.niveus es uno de las 2 persistentes especies de Aspergillus blancos: las cabezas conidiales de A. niveus son fértiles solo en la parte superior de la vesícula o en sus $2 / 3$, mientras $A$. candidus es fértil en su entera superficie de la vesícula. El diámetro de las vesículas es mayor en A.candidus, mientras que en A niveus es menor de $15 \mu \mathrm{m}$ (Klich, 2002).

A. niveus ha sido reportado causando aspergilosis pulmonar (Auberger et al, 2008).

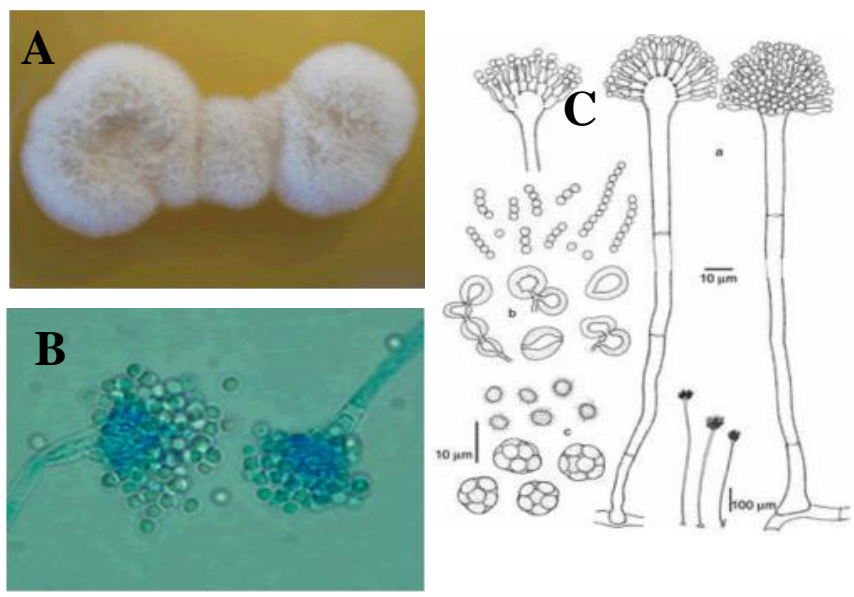

Figuras 39. A-B-C-A.niveus. A. Colonia en MEA, B . Cabezas conidiales (Ambas tomadas de:www.aspergillus. org.uk) C. Conidióforos conidios, células Hülle, ascos y ascosporas (Tomado de: de Hoog et al, 2000).

Clave politómica tentativa para las especies oportunistas de la sección Terrei y Flavipedes

1. - Colonias en CYA, generalmente mayores de $40 \mathrm{~mm}$ en 7 días a $25^{\circ} \mathrm{C}$. Cabezas conidiales pequeñas compactamente columnares, conidios de color canela, predominantemente menores de $3 \mu \mathrm{m}$, aleuroconidios frecuentes en el micelio A.terreus Thom

- Colonias en CYA generalmente menores de $40 \mathrm{~mm}$ en 7 días a $25^{\circ} \mathrm{C}$

2. - Cabezas conidiales pequeñas commpactamente columnares, conidios de color amarillo café a café canela, predominantemente menores de $3 \mu \mathrm{m}$, lisos, aleuroconidios ocasionalmente en el micelio vegetativo....... A. alabamensis Balajee, Braddley, Fisvad \& Samson

(Nota. la sola morfología no permite la separación de esta especie de A.terreus deben emplearse métodos moleculares)

- Cabezas radiadas a laxamente columnares, conidios lisos de color cafesoso-naranja oscuro, 2-3 $\mu \mathrm{m}$, estipes de paredes lisas, a finamente rugosas, incoloros a café pálido, aleuroconidios a veces presentes en el micelio vegetativo. A veces presencia de ascomas A.flavipes

(Bainier \& Sartory)Thom \&Church 
- Cabezas radiadas a laxamente columnares, conidios lisos a finamente rugosos 2-3,5 $\mu \mathrm{m}$, estipes lisos, incoloros, aleuroconidios en el micelio vegetativo y células de Hülle a veces presentes, a veces ascomas presentes......... A.niveus Blochwitz

\section{E). Subgenero Nidulantes seccion Usti}

Raper \& Fennell (1965) clasificaron A. ustus en el grupo Aspergillus ustus como biseriado junto a otras 4 especies: $\boldsymbol{A}$. panamensis, A. puniceus, A. conjunctus y A. deflectus. Posteriormente Kozakiewicz (1989), en una revisión morfológica del grupo incluyó dos especies mịs: $\boldsymbol{A}$. pseudodeflectus y A. granulosus, estableciendo el grupo A. deflectus, incluyendo A. deflectus, A pulvinus y $A$. silvaticus. Peterson (2000), mediante biolog a molecular transfirió la mayoria de las especies de la seccion Usti a la sección Nidulantes. De los miembros integrantes de la seccion Usti, A. ustus es a menudo reportado como agente causal de infecciones invasivas, mientras A. puniceus y $\boldsymbol{A}$. pseudodeflectus no se han reportado clinicamente. Solo hay un reporte de $\boldsymbol{A}$. granulosus, como agente de una infección diseminada en un transplante card aco (Fakih et al. 1995). Otros autores empleando la región parcial de la ß-tubulina, calmodulina y el gen de la actina demostraron que las cepas de A. ustus recibidas desde multiples centros (Panackal et al. 2006; Yildiran et al. 2006) revealaron la presencia de una nueva especie, que posteriormente se determinó como $\boldsymbol{A}$. calidoustus (Varga et al, 2008). Las diferencias fenotipicas entre A. ustus y A. calidoustus son faciles de reconocer ya que el primero no crece a $37^{\circ} \mathrm{C}$, mientras el ultimo si lo hace. Los Aspergillus de la seccion Usti sensu stricto incluyen 8 especies: A. ustus, A. puniceus, A. granulosus, A. pseudodeflectus, A. calidoustus, A. insuetus y A. keveii juntos con A.compatibilis (=Emericella heterothallica).

\section{1). A. calidoustus Vargas et al. (2008) (Fig.40)}

Macromorfologia. Diametro de las colonias en 7 dias en CYA25, 27-32 mm; CYA37, 20-35 mm; MEA 25, 35-48 mm; YES, 36-41mm. Color en CYA: gris amarillento, cafesoso-gris o gris café. Conidiación abundante en CYA: Reverso amarillo con beige u oliva café en el centro. Colonia flocosa con cabezas conidiales biseriadas laxamente columnares.

Micromorfologia. Estipe: $150-300$ x 4-7 $\mu \mathrm{m}$, liso, café; diametro de las vesiculas, 9-15 $\mu \mathrm{m}$, piriformes a ampliamente espatuladas, métulas que cubren la mitad superior de la vesicula, 5-7 x 2,5-3,5 $\mu \mathrm{m}$; fialides, 5-7x 2,3-3 $\mu \mathrm{m}$. Conidios globosos, muy rugosos (0,5-08 $\mu \mathrm{m}$ de alto), 2,7-3,5 $\mu \mathrm{m}$, con ambas paredes visibles; células de Hülle escasamente producidas, irregularmente elongadas, en grupos dispersos. Crecimiento en creatina débil a moderado, con micelio hialino, sin producción de acido. Diagnóstico diferencial: buen crecimiento a $37{ }^{\circ} \mathrm{C}$, reaccion de Ehrlich violeta, conidios rugosos a equinulados. Especie similar: A. pseudodeflectus. Distribución: U.S.A., Turkia, Finlandia, Alemania, Holanda (al parecer mas disperso). Ecologia: aire interno, goma, material de construccion, humanos.

\section{2). Aspergillus insuetus (Bainier)Thom \& Chur- ch.(Fig.41) \\ (= Sterigmatocystis insueta Bainier)}

Macromorfologia. Diametro de las colonias en $7 \mathrm{~d}$ as en CYA25, 28-32 mm; CYA37 sin crecimiento; MEA25,36-41 mm; YES 23-30 mm. Color de la colonia : a veces negra en el centro con tonalidades grises a blancas con įreas con mįrgenes flocosos estériles. Conidiación en CYA: moderada a buena, con reverso amarillo oliva a café negro en el tiempo.Cabezas conidiales: radiadas a hemiesféricas, biseriadas.

Micromorfologia. Estipe: 300 x $48 \mathrm{~mm}$, liso, café con ves culas de11-16 $\mu \mathrm{m}$, de diịmetro, hemiesféricas, esféricas a subglobosas métulas que cubren la mitad de la vesicula,

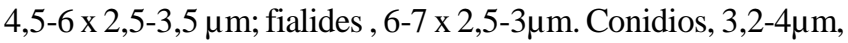
globosos, distintamente rugosos y con sus 2 paredes visibles, fuligeneos, con el color mayormente agregado en las equinulaciones de la pared celular y aśn formando barras y tubérculos al mismo tirmpo. Células de Hülle: variadamente recurvadas o curvas en grupos dispersos, reacción de Ehrlich: violeta, crecimiento en creatina: bueno con micelio hialino, sin producción de acido. Especie similar: A. keveii

Distribución: Sudafrica, Espańa, Argentina.

Diagnóstico diferencial: no crece a $37^{\circ} \mathrm{C}$, Ehrlich, violeta, restringido crecrimiento en $\mathrm{YES}$, conidios ampliamente equinulados.

Ecologia: suelo (?), humanos

Patogenicidad: causante de infección subcutanea (Gené et al. 2001)
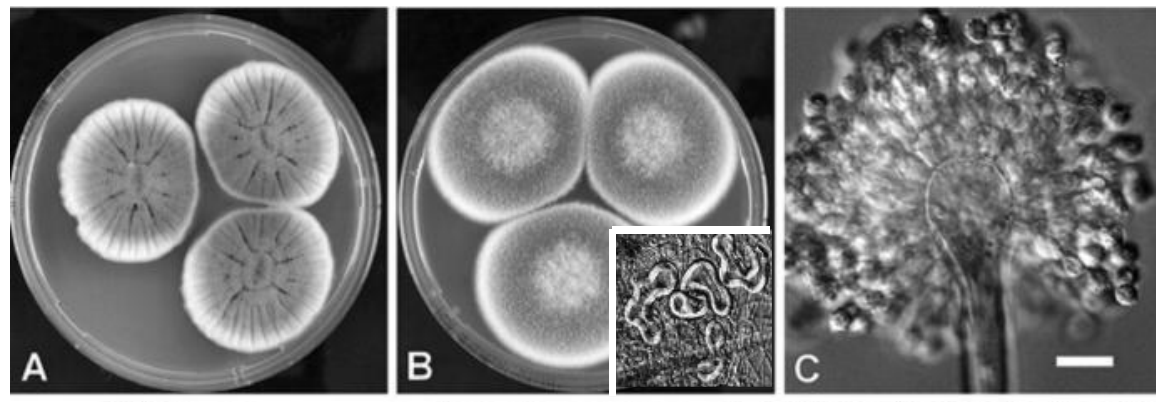

Figuras 40, A-B-C. A. calidoustus. A. Colonias creciendo en CYA y B en MEA a $25^{\circ} \mathrm{C}$ por 7 dias (Celulas deHülle en el recuadro), C. Conidióforo y conidios, D. Barra, $10 \mu \mathrm{m}$ (Figuras tomadas de: Vargas et al. 2008) 


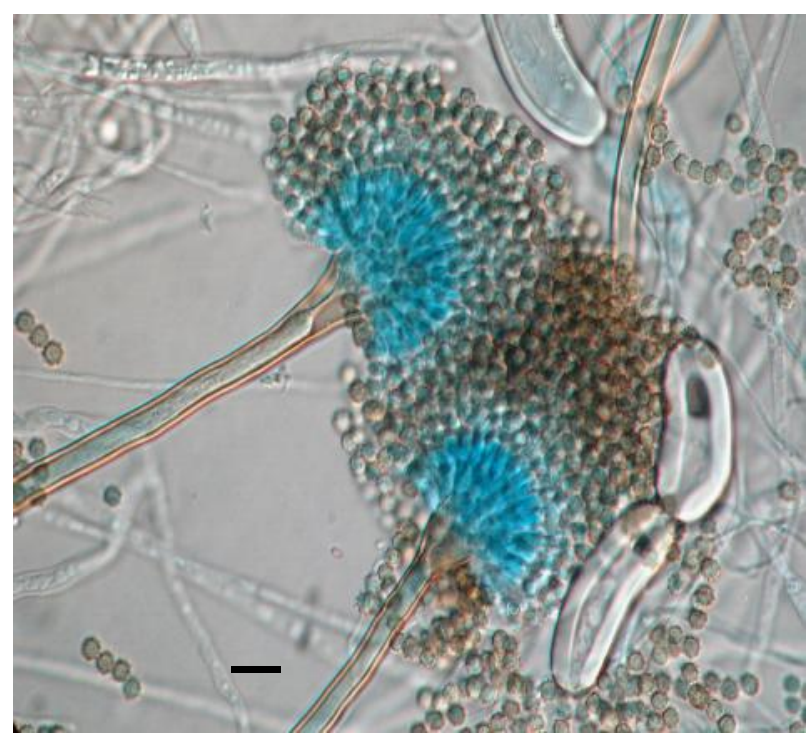

Figura 41. Aspergillus insuetus, Conidióforos vesículas, métulas, fiálides y conidios, al mismo tiempo se observa la presencia de células de Hülle alargadas, ligeramente curvas. Barra $10 \mu \mathrm{m}$.

3). Aspergillus ustus (Bainier) Thom \& Church (Fig.42) (= Sterigmatocystis usta Bainier)

(= Aspergillus humus Abbott)

Macromorfologia. Diametro de las colonias a los 7 dias en CYA25, 36-43mm; CYA37 no crece; MEA25, 39-46 mm; YES, 42-50 mm, colonias flocosas, planas, surcadas a umbonadas. Color de las colonias en CYA25: gris café a café oscuro con conidiación moderada. Reverso en (CZA): amarillo oliva con oliva café en el centro. Cabezas conidiales radiadas a hemiesféricas. Estipe: 400 x 3-6 $\mu \mathrm{m}$, generalmente sinuoso

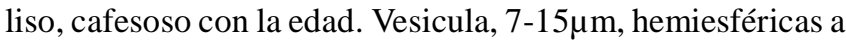
subglobosas. Métulas, 5-7 x 2,5-3 $\mu \mathrm{m}$, fialides, 4-7 x 3-4 $\mu \mathrm{m}$. Conidios, 3,2-4,5 $\mu \mathrm{m}$, globosos, rugosos, grises a amarillo oscuro, células de Hülle irregularlmente ovoides a forma de salchicha. Ehrlich sin reacción. Crecimiento en creatina: buen crecimiento con micelio ligeramente amarillo, sin producción de acido

Diagnóstico diferencial: No crece a $37^{\circ} \mathrm{C}$; buen crecimiento en CREA; células Hülle tipicamente en forma de salchicha y a veces forman masas irregulares no asociadas con el micelio pigmentado. Especie similar: A.puniceus. Distribución U.S.A., Polonia, Holanda, Canada, América del Sur. Ecologia: suelo, aire interno, cereales, excrementos de murciélagos.

No se efectuó una clave dicotómica para estas 3 especies debido a que las diferencias fisiológicas son de mucha ayuda: para mayor información ver: J. Houbraken et al, 2007; Asgari et al, 2012.

La presente reseńa sobre las especies oportunistas de Aspergillus, no involucra a todas las detectadas en la literatura, sino a las mįs comunes y de dispersa información. Es necesario para la obtención de mayores datos, recurrir a la literatura incluida y la presente en internet para una mejor comprensión acerca de ciertas descripciones de algunas especies. No se ha incluido A.nidulans (Fig. 3 A) y especies relacionadas debido a que su morfofisiologia permite un buen diagnóstico primario y existe abundante información en la literatura.

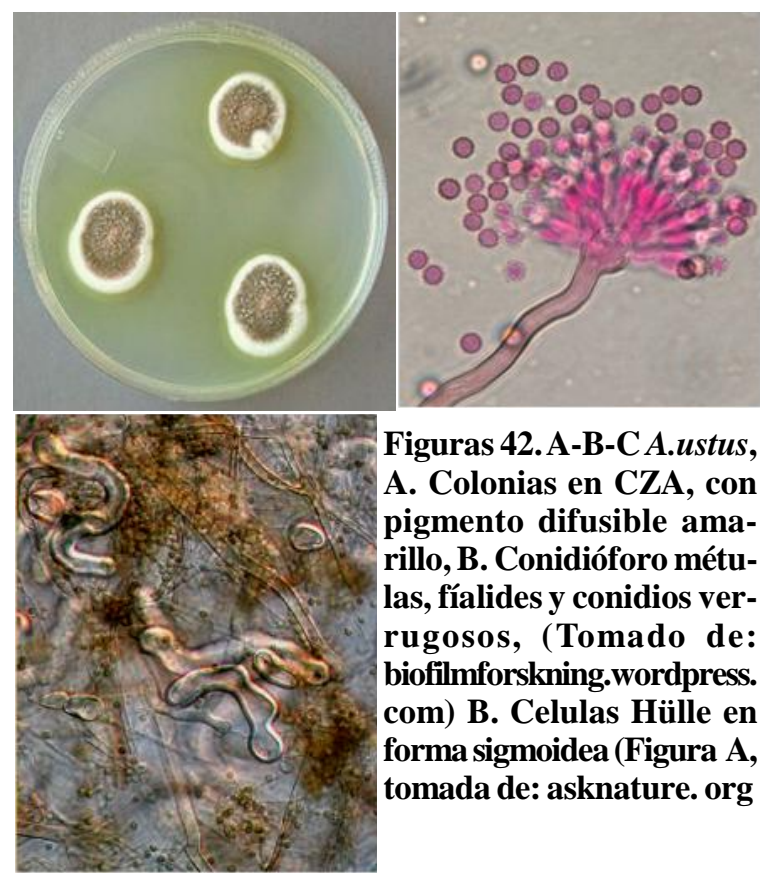




\section{REFERENCIAS}

Abdin, M.Z.; M alik, M. A. \& Saleem, J. (2010). Advances in molecular detection of Aspergillus: an Update. Arch. Microbol. Online 01 April. Springer DOI 10.1007/s00203-010-0563-y

Alcazar-Fuoli, L.; Mellado, E,; Alastruey-Izquierdo, A. et al. (2009). Species identification and antifungal susceptibility patterns of species belonging to Aspergillus section Nigri. Antimicrobial Agents and Chemotherapy 53:4514-4517

Al-Musallam, A. (1980). Revision of black Aspergillus species. Thesis, Utecht University, CBS Baarn

Arabatzis. M. \& Velegraki, A. (2013). Sexual reproduction in the opportunistic human pathogen Aspergillus terreus. Mycologia 105:7179

Asgari, S.; Zare, R.; Reza,Zamanizadeh,H. \& Rezaee,S. (2012). Systematics of Aspergillus species of subgenus Nidulantes in Iran. Rostaniha 13:126-151

Auberger, J.; Lass-Flörl, C.; Clausen, J. et al. (2008). First case of breakthrough pulmonary Aspergillus niveus infection in a patient after allogeneic hematopoietic stem cell transplantation. Diagnostic Microbiology and Infectious Disease 62:336-339

Baddley, J.W.; Pappas, P.G.; Smith, A.C. \& Moser, S.A. (2003). Epidemiology of Aspergillus terreus at a university hospital. Journal of Clinical Microbiology 41:5525-5529

Balajee, S.A., J. Gribskov, M. Brandt, et al. (2005a). Mistaken identity: Neosartorya pseudofischeri and its anamorph masquerading as Aspergillus fumigatus. J. Clin. Microbiol. 43:5996-5999

Balajee, S.A.; Gribskov, J.L.; Hanley, E. et al. (2005b) Aspergillus lentulus sp. nov., a new sibling species of $\boldsymbol{A}$. fumigatus. Eukaryot Cell $4: 625-632$

Balajee, S.A.; Nickle, D.; Varga, J.; Marr, K.A. (2006). Molecular studies reveal frequent misidentification of Aspergillus fumigatus by morphotyping. Eukaryot Cell 5:1705-1712.

Balajee, S. A., J. Houbraken, P. E. Verweij, S. B. et al. (2007). Aspergillus species identification in clinical setting. Studies Mycol. 59:39-46

Balajee, A.S.; Barbara, D.; Alexander,R.K. et al. (2009). Molecular Identiūcation of Aspergillus Species Collected for the TransplantAssociated Infection Surveillance Network. J. Clin. Microbiol. 47:31383141

Balajee, S.A, et al.; ISHAM Working Group on A. terreus (2009 b). Aspergillus alabamensis, a new clinically relevant species in the section Terrei. Eukaryotic Cell 8:713-722

Barrs, V.R.; Beatty, J.A.; Lingard, A.E. et al. (2007). Feline sinoorbital aspergillosis: an emerging clinical syndrome? Australian Veterinary Journal 85:N23

Barrs, V.R. et al. (2012). Sinonasal and sino-orbital aspergillosis in 23 cats: aetiology, clinicopathological features and treatment outcomes. Vet. J. 191:58-64

Barrs, V.R. et al, (2013). Aspergillus felis sp. nov., an Emerging Agent of Invasive Aspergillosis in Humans, Cats, and Dogs. PLoS ONE 8(6): e64871. doi:10.1371/journal.pone.0064871
Batista, A.C.; Maia, H.S. \& Alecrim, I.C. (1955). Onicomicose produizida por «Aspergillus clavato-nanica»n. sp. Anais da Faculdade de Medecina da Universidade do Recife 15:197-203

Bathoorn, Erik.; Escobar, S.E.; Sepehrkhouy, S, et al, (2013) Involvement of the opportunistic pathogen Aspergillus tubingensis in osteomyelitis of the maxillary bone: a case report. BMC Infectious Diseases 13:59

Bennett, J.W.\& Klich, M.A. (eds).(1992). Aspergillus. Biology and Industrial Applications, Boston, Butterworth-Heinemann.

Bennett, J. W. \& Klich, M. (2003). Mycotoxins. Clin Microbiol Rev 16:497-516

Bennett, J.W. (2010). An overview of the genus Aspergillus. In Aspergillus: Molecular Biology and Genomics. (Machida M, Gomi K, eds) Caiser Academic Press, Portland: 1-17

Bhatnagar, D.; Cleveland, T. E. \& Payne, G. A. (2000). Encyclopedia of Food Microbiology, pp. 72-79. London: Academic Press

Burrough, E.;Deitz, K.; Kinyon, J.et al., (2012). Disseminated aspergillosis in a dog due to Aspergillus alabamensis. Medical Mycology Case Reports 1:1-4

Byard, R. W.; R.A. Bonin, \& A. Haq. (1986). Invasion of paranasal sinuses by Aspergillus oryzae. Mycopathologia 96:41-43.

Campbell, C. K. (1994). Forms of aspergillosis. In The Genus Aspergillus, pp. 313-320, Edited by K. A. Powell, A. Renwick \& J. F.Peberdy. New York: Plenum.

Carbone, I.; Jakobek, J.L.; Ramirez-Prado, J.H. \& Horn, B.W. (2007). Recombination, balancing selection and adaptive evolution in the aflatoxin gene cluster of Aspergillus parasiticus. Molecular Ecology $16: 4401-4417$

Celar, F. (2003). Competition for ammonium and nitrate forms of nitrogen between some phytopathogenic and antagonistic soil fungi. Biol. Control 28:19-24

Chouvenc,T.; Efstathion,C.A.; Elliott, M.L.\& Su,Nan-Yao. (2012). Resource competition between two fungal parasites in subterranean termites. Naturwissenschaften 99:949-958

Christensen M. (1982).The Aspergillus ochraceus group: two new species from western soils and a synoptic key. Mycologia 74: 210225

Coriglione, G.; Stella, G.; Gafa, et al. (1990). Neosartorya fischeri var. fischeri (Wehmer) Malloch and Cain 1972 (anamorph: Aspergillus fischerianus Samson and Gams 1985) as a cause of mycotic keratitis. European Journal of Epidemiology 6:382-385

Cotty, P.J. (1997) Aflatoxin-producing potential of communities of Aspergillus section Flavi from cotton producing areas in the United States. Mycol. Res. 101:698-704

De Hoog, G.S. et al, (2000). En: Baarn and Delft, Editors. Atlas of clinical fungi. 2.ed. TheNetherlands:Centraalbureau voor Schimmelcultures 2000 .

Denning, D.W., A. Pleuvry \& D.C. Cole.( 2011). Global burden of 
chronic pulmonary aspergillosis as a sequel to pulmonary tuberculosis. World Health 89:1-21

Denning, D. W. (2006). Aspergillus spp. and aspergillosis progress on many fronts. Med. Mycol. 44(Suppl. 1):S1-S2.

Domsh, H,K.;Gams, W \& Anderson T-H (2007). Compendium of soil fungi. Aec. Ed.. IHW.Verlag, Eching

Dyer, P.S. \& O'Gorman,C-M. (2012).Sexual development and cryptic sexuality in fungi: insights from Aspergillus species.FEMS Microbiol. Rev 36:165-192.

Egel, D. S.; Cotty, P. J. \& Elias, K. S. (1994). Relationships among isolates of Aspergillus sect. flavi that vary in aflatoxin production. Phytopathology 84:906-912

Ehrlich, K.C.; Yu, J. \& Cotty, P.J. (2005). Aflatoxin biosynthesis gene clusters and flanking regions. J. Appl. Microbiol. 99:518-527

Ehrlich, K.C.; Beverly G. Montalbano, B.G. \& Cotty, P.J. (2007). Analysis of single nucleotide polymorphisms in three genes shows evidence for genetic isolation of certain Aspergillusfavus vegetative compatibility groups. FEMS Microbiol. Lett. 268:231-236

Erjavec, Z.; Kluin-Nelemans, H. \& Verweij, P. E. (2009). Trends in invasive fungal infections, with emphasis on invasive aspergillosis. Clinical Microbiology and Infection, 15: 625-633

Fakih, M.G.; Barden, G.E.; Oakes, C.A. \& Berenson, C.S. (1995). First reported case of Aspergillus granulosus infection in a cardiac transplant patient. Journal of Clinical Microbiology 33: 471-473

Fernández, M.; Cattana. M.; Rojas, F. et al.(2013a). Original especies de Aspergillus en ambientes hospitalarios con pacientes pediátricos en estado crítico. Rev. Iberoam. Micol.http://dx.doi.org/ 10.1016/j.riam.2013.09.007

Fernández, M. et al, (2013b). Aspergillus terreus complex: an emergent opportunistic agent of Onychomycosis. Mycoses 56:477-481

Franco, A.E. (2006). Aspergillus sección Nigri : estudio fisiológico y molecular de especies ocratox genas. Tesis de Doctorado- Universitat Aut noma de Barcelona. Facultat de Veterinąria, Departament de Sanitat i Anatomia Animals.

Frisvad, J.C. \& Thrane, U. (1987). Standardized High-Performance Liquid Chromatography of 182 mycotoxins and other fungal metabolite based on alkylphenone indices and UV-VIS spectra (diode array detection). J. Chromatogr. 404:195-214

Frisvad, J.C, Samson, R.A. (2004). Polyphasic taxonomy of $\boldsymbol{P}$ enicillium subgenus Penicillium. A guide to identification of food and air-borne terverticillate Penicillia and their mycotoxins. Studies in Mycology 49: 1-173

Frisvad, J.C.; Skouboe, P.; Samson, R.A. (2005). Taxonomic comparison of three different groups of aflatoxin producers and a new efficient producer of aflatoxinB1, sterigmatocystin and 3-Omethylsterigmatocystin, Aspergillus rambellii sp.nov. Systematic and Applied Microbiology 28:442-453

Galagan, J.E.; Calvo, S.E.; Cuomo, C. et al. (2005). Sequencing of Aspergillus nidulans and comparative analysis with A. fumigatus and $A$. oryzae. Nature 438:1105-1115

Gams W, Christensen M, Onions AH, Pitt JI, Samson RA (1985).
Infrageneric taxa of Aspergillus. In: Advances in Penicillium and Aspergillus Systematics. (Samson, RA, Pitt JI, eds). New York, Plenum Press:pp. 55-62

Geiser, D.M.; Klich, M.A.; Frisvad, J.C. et al, (2007). The current status of species recognition and identification in Aspergillus. Studies in Mycology 59:1-10

Geiser, D.M. (2009). Sexual structures in Aspergillus: morphology, importance and genomics. Medical Mycology 47:S21-S26

Gonçalves, S.S.; Stchigel, A.M.; Cano, J.F. et al. (2012). Aspergillus novoparasiticus: a new clinical species of the section. Med. Mycol. 50:152-160

Gene, J, Azon-Masoliver, A, Guarro, J. et al, (2001). Cutaneous infection caused by Aspergillus ustus, an emerging opportunistic fungus in immunosuppressed patients. Journal of Clinical Microbiology 39:1134-1136

Guarro, J.; Kallas, E.G.; Godoy, P. et al, (2002).Cerebral aspergillosis caused by Neosartorya hiratsukae, in Brazil. Emerging Infectious Diseases 8:989-991

Goddard, P.A. \& McCue, K.A. (1996). Phenolic Compounds. In S. S. Block (Ed.), Disinfection, Sterilization, and Preservation (5th ed., pp. 255-281). Philadephia P.A.: Lipincott, Williams and Wilkins.

Gordon, M.A.; R.S. Holzman,; H. Senter,; E.W. Lapa,; M.J. Kupersmith. (1976). Aspergillus oryzae meningitis. JAMA 235:21222123 .

Gyotoku, H, et al, (2012). A case of bronchial aspergillosis caused by Aspergillus udagawae and its mycological features. Medical Mycology 50:631-636

Hachem, R.Y.; Kontoyiannis, D.P.; Boktour, M.R. et al., (2004). Aspergillus terreus: an emerging amphotericin B-resistant opportunistic mold in patients with hematologic malignancies. Cancer 101:15941600

Hadrich,I.; Makni, M.; Ayadi, A. \& Ranque, S. (2010), Microsatellite Typing To Trace Aspergillus flavus Infections in a Hematology Unit ?. J. Clin. Microbiol. 48:2396-2401

Hawksworth, L.D. (2012). Managing and coping with names of pleomorphic fungi in a period of transition. IMA Fungus 3:15-2

Hedayati, M.T.; Pasqualotto, A.C.; Warn, P.A.;P. Bowyer,P.\& Denning, D.W. (2007). Aspergillus flavus: human pathogen, allergen and mycotoxin producer. Microbiology 153:1677-1692

Hillary, L.; Mehl, \& Peter, J. Cotty. (2013).Genotypes Com-petition among Aspergillus flavus Nutrient Environments Influence. Appl. Environ. Microbiol. 79:1473-1480

Hong, S. B., S. J. Go, H. D. Shin, J. C. Frisvad, and R. A. Samson. (2005). Polyphasic taxonomy of Aspergillus fumigatus and related species. Mycologia 97:1316-1329

Hong, S-B.; Cho,H-S.; Shin,H-D.; Jens C. Frisvad,C.J.; Samson, R.A. (2006). Novel Neosartorya species isolated from soil in Korea. Int. J. Syst. and Evol. Microbiol. 56: 477-486

Hong SB, Shin HD, Hong J, et al. (2008). New taxa of Neosartorya and Aspergillus in Aspergillus section Fumigati. Antonie van Leeuwenhoek 93:87-98. 
Hong, S.B.; Kim, D-H.; Park, I-C.; Samson, R.A.; Shin, H.D. (2010a) Isolation and identification of Aspergillus section Fumigati strains from arable soil in Korea. Microbiology 38:1-6

Hong, S-B.; Lee, M.; Kim, D-H. et al. (2013). Aspergillus luchuensis, an Industrially Important Black Aspergillus in East Asia. PLoS ONE 8(5):e63769. doi:10.1371/journal.pone.0063769

Horn, B.W, et al. (1996). Association of morphology and mycotoxin production with vegetative compatibility groups in A.flavus, A.parasiticus and A.tamarii. Mycologia 88:574-587

Horn,B.W. (1997). Aspergillus caelatus a new species in setion Flavi . Mycotaxon 61:185-191

Horn, B.W.; Ramirez-Prado, J.H. \& Carbone, I. (2009a) Sexual reproduction and recombination in the aflatoxin-producing fungus Aspergillus parasiticus. Fungal Genet Biol 46:169-175

Horn, B.W.; Ramirez-Prado, J.H. \& Carbone, I. (2009b). The sexual state of Aspergillus parasiticus. Mycologia 101:275-280

Horn, B.W.; Moore. G.G. \& Carbone, I. (2009c). Sexual reproduction in Aspergillus flavus. Mycologia 101:423-429

Horn, B.W.; Moore, G.G. \& Carbone, I. (2011). Sexual reproduction in aflatoxin-producing Aspergillus nomius. Mycologia 103:174-183

Horn, B,W.; Olarte, R.A.; Peterson, S.W. \& Carbone, I. (2013). Sexual reproduction in Aspergillus tubingensis from section Nigri.Mycologia. 105:1153-1163

Houbraken, J.; M. Due.; J. Varga. et al, (2007). Polyphasic taxonomy of Aspergillus section Usti.Studies in Mycology 59: 107128.

Houbraken, P.J. \& Samson, R.A. (2011). Phylogeny of Penicillium and the segregation of Trichocomaceae into three families. Studies in Mycol. 70:1-51

Houbraken, P.J. de Vries,R.P. \& Samson, R.A. (2014).Modern taxonomy of biotechnologically important Aspergillus and Peni-cillium species. Advances in Applied Microbiology 86:199-249

Howard, S.J.; Harrison, E.; Bowyer, P.; Varga, J.; Denning, D.W. (2011). Cryptic species and azole resistance in the Aspergillus niger complex.Antimicrob Agents Chemother. 55:4802-4809

Hubka, V. \& Kolarik M. (2012).-ßtubulin paralogue tubC is frequently misidentified as the benA gene in Aspergillus section Nigri taxonomy:primer specificity testing and taxonomic consequences. Persoonia. 29:1-10

Jarv, H.; Lehtmaa, J.; Summerbell, R.C. et al. (2004). Isolation of Neosartorya pseudofischeri from blood: first hint of pulmonary aspergillosis. Journal of Clinical Microbiology 42:925-928

Jurjevic', E.; Peterson,S.W.; Stea, G. et al. (2012).Two novel species of Aspergillus section Nigri from indoor air. IMA Fungus. 3:159173

Kamal, Rai K.R.A.; Chetan, R.C.R.S. \&Radhika, K.R.KJ. (2010) Fungal infection of the ear: A common problem in the north eastern part of Haryana. International Journal of Pediatric
Otorhinolaryngology 74:604-607

Kameswaran, M.; al-Wadei, A.; Khurana, P. \& Okafor, B. C. (1992). Rhinocerebral aspergillosis. J. Laryngol. Otol. 106: 981-985

Kano R, Shibahashi A, Fujino Y, Sakai H, Mori T, et al. (2013). Two cases of feline orbital aspergillosis due to A. udagawae and A. virdinutans. J. Vet. Med. Sci. 75:7-10

Kaya, A. D. \& Kiraz. N .(2007). In vitro susceptibilities of Aspergillus spp. causing otomycosis to amphotericin B, voriconazole and itraconazole. Mycoses 50:447-450.

Kizis, D.; Natskoulis, P.; Nychas, G-J.E. \& Panagou, E.Z. (2014). Biodiversity and ITS-RFLP Characterisation of Aspergillus Section Nigri Isolates in Grapes from Four Traditional Grape-Producing Areas in Greece. PLoS ONE 9: e93923. doi:10.1371/journal. pone.0093923

Klich, M.A. (2002). Identification of common Aspergilli. CBS, Utrecht, The Nederlands.

Klitgaard, A.; Iversen, A.; Andersen, M.R. et al. (2014). Ag-gressive dereplication using UHPLC-DAD-QTOF - screening extracts for up to 3000 fungal secondary metabolites. Analytical and Bioanalytical Chemistry 406:1933-1943

Kozakiewicz, Z. (1989). Aspergillus species on stored products. Mycological Papers 161:1-188

Kredics, L.; Varga, J.; Kocsubé, S, et al, (2009). Infectious keratitis caused by Aspergillus tubingensis. Cornea 28:951-954

Krijgsheld, P. R.; Bleichrodt, G.J.; van Veluw, F. et al.(2013). Development in Aspergillus. Studies in Mycology 74:1-30

Krimitzas, A.; Pyrri, I.; Vassili N. Kouvelis, N.V. et al, (2013). A Phylogenetic Analysis of Greek Isolates of Aspergillus Species Based on Morphology and Nuclear and Mitochondrial Gene Sequences. BioMed Research InternationalVolume 2013,doi.org/10.1155/2013/ 260395

Kück ,U \& Pöggeler, S. (2009). Cryptic sex in fungi. Fungal Biol. Rev. 23:86-90

Kumeda, Y., \& Asao, T (1996). Heteroduplex panel analysis, a novel method for genetic identifcation of Aspergillus section Flavi strains. Appl. Environ.Microbiol. 67:4084-4090

Kurtzman, C.P.; Horn, B.W. \& Hesseltine, C.W., (1987). Aspergillus nomius, a new aflatoxin-producing species related to Aspergillus flavus and Aspergillus tamarii. Antonie van Leeuwenhoek 53:147-158

Kwon-Chung, K.J. \& Sugui, J.A. (2009). Sexual reproduction in Aspergillus species of medical or economic importance: why so fastidious? Trends Microbiol 17:481-487

Larsen, T.O.; Smedsgaard, J.; Nielsen, K.F.; Hansen, M.E.; Frisvad, J.C. (2005). Phenotypic taxonomy and metabolite profiling in microbial drug discovery. Na.t Prod. Rep. 22:672-695

Lass-Flörl, et al. (2000). Aspergillus terreus infections in haematological malignancies: molecular epidemiology suggests association with in-hospital plants. Journal of Hospital Infection $46: 31-35$ 
Lass-Florl, C.; Grif, K. \& Kontoyiannis, D.P(2007). Molecular typing of Aspergillus terreus isolates collected in Houston, Texas, and Innsbruck, Austria:evidence of great genetic diversity. J Clin Microbiol 45:2686-2690

Laszló, K, et al .(2008). Black aspergilli in tropical infections. Reviews in Medical Microbiology: 19:65-78

Lau, A.; Chen, S.; Sorrell, T. et al, (2007). Development and clinical application of a panfungal PCR assay to detect and identify fungal DNA in tissue specimens. Journal of Clinical Microbiology 45:380385

Li, D. M. et al, (1998).Three new Aspergillus species isolated from clinical sources as a causal agent of human aspergillosis. Mycoscience 39:299-305

Lonial, S.; Williams, L.; Carrum, G.; Ostrowski, M.; McCarthy, P.Jr. (1997). Neosartorya fischeri: an invasive fungal pathogen in an allogeneic bone marrow transplant patient. Bone Marrow Transplantation 19:753-755

Logrieco, A.F.; Haidukowski, M.; Susca, A. et al. (2014). Aspergillus section Nigri as contributor of fumonisin $\mathrm{B}(2)$ contamination in maize.Food Addit. Contam. Part. A Chem. Anal. Control. Expo. Risk. Assess. 31:149-55

Lopez-Diaz, T.M. \& Flannigan, B. (1997). Production of patulin and cytochalasin E by Aspergillus clavatus during malting of barley and wheat. International Journal of Food Microbiology 35:129-136

Mahgoub, E. S. \& el-Hassan, A. M. (1972). Pulmonary aspergillosis caused by Aspergillus flavus. Thorax 27:33-37

Malejczyk,K.; Sigler, L.; Fe, C.; Smith, W. (2013). Invasive Sino-Orbital Mycosis in an Aplastic Anemia Patient Caused by Neosartorya laciniosa. Journal of Clinical Microbiology 51:1316-1319

Malloch, D.\& Cain, R. F. (1972). The Trichocomataceae: Ascomycetes withAspergillus, Paecilomyces, and Penicillium imperfect states. Canadian Journalof Botany 50:613-2628

Manikandan P, Varga J, Kocsubé S, Samson RA, et al., (2009). Mycotic keratitis due to Aspergillus nomius. J. Clin. Microbiol. 47:338233

Manikandan, P. et al., (2009) Mycotic Keratitis Due to Aspergillus nomius. J. Clin. Microbiol. 47:3382-3385

McKenzie, R.A.; Kelly, M.A.; Shivas, R.G, et al. (2004). Aspergillus clavatus tremorgenic neurotoxicosis in cattle fed sprouted grains. Austalian Veterinary Journal 82: 635-638.

Mayer, K.M.; Ford, J.; Macpherson, G.R. et al. (2007).(2007). Exploring the diversity of marine-derived fungal polyketide synthases Can. J. Microbiol. 53:291-302

McNeil, M. M.; Nash, S. L.; Hajjeh, R. A. et al. (2001). Trends in mortality due to invasive mycotic diseases in the United States, 19801997. Clinical Infectious Diseases, 33:641-647

Meijer, M.; Houbraken, J.A.; Dalhuijsen, S.; Samson, R.A; de Vries, R.P. (2011). Growth and hydrolase profiles can be used as characteristics to distinguish Aspergillus niger and other black aspergilli. Stud Mycol. 2011;69:1930
Mellado, E.; Alcazar-Fuoli, L.; Garcia-Effro.et al. (2006). New resistance mechanisms to azole drugs in Aspergillus fumigatus and emergence of antifungal drugs-resistant A. fumigatus atypical strains. Medical Mycology 44:S367-S371

Moody, O, S. F.\& Tyler, B. M. (1990). Restriction enzyme analysis of mitochondrial DNA of the Aspergillus flavus group: A. flavus, $A$. parasiticus, and A. nomius. Appl. Environ. Microbiol. 56:2441-2452

Moragues, M.D.; Brena, S.; Miranda, I. et al.(2006). Colo-nización pulmonar por Neosartorya udagawae en un paciente trasplantado de pulmón. VIII Congreso Nacional Micologia, Barcelona, Spain,D15.

Morgan, J.; Wannemuehler, K. A.; Marr, K. A.; et al., (2005). Incidence of invasive aspergillosis following hematopoietic stem cell and solid organ transplantation: interim results of a prospective multicenter surveillance program. Med. Mycol. 43:(Suppl.1), S49-S58

Murakami, H. (1976). Origin of strain of the black Aspergilli. Taxonomic studies on Japanese industrial strains of the Aspergillus (Part 25). J Brew Soc Japan 71: 956-959

Nam, H.-S.; K. Jeon, S.-W.; Um, et al. (2010). Clinical characteristics and treatment outcomes of chronic necrotizing pulmonary aspergillosis: a review of 43 cases. Int. J. Infect. Dis. 14:e479-e482

Neal, C.O.S. et al., (2011). Global population structure of Aspergillus terreus inferred by ISSR typing reveals geographical subclustering. BMC Microbiology 11:203-230

Noonim, P.; Mahakarnchanakul, W.; Varga, J.; Frisvad, J.C.; Samson, R.A. (2008). Two novel species of Aspergillus section Nigri from Thai coffee beans.International Journal of Systema-tic and Evolutionary Microbiology 58:1727-1734

Nováková, A.; Hubka, V.; Dudová, et al, (2014). New species in Aspergillus section Fumigati from reclamation sites in Wyoming (U.S.A.) and revision of A. viridinutans complex. Fungal Diversity. 64:253-274

O'Gorman, M.C.; Fuller,T.H. \& Dyer, S.P. (2009) Discovery of a sexual cycle in the opportunistic fungal pathogen Aspergillus fumigatus Nature, doi:10.1038/nature 07528

Opal, S.M.; Reller, L.B.; Harrington, G. \& Cannady, P. Jr. (1986). Aspergillus clavatus endocarditis involving a normal aortic valve following coronary artery surgery Reviews of Infectious Diseases 8:781785

Pagano, L.; Caira, M.; Picardi, M., et al. (2007). Invasive aspergillosis in patients with acute leukemia: Update on morbidity and mortality - SEIFEM-C report [6]. Clinical Infectious Diseases, $44: 1524-1525$

Panackal, A,A.; Imhof, A.; Hanley, E.W. \& Marr, K.A. (2006). Aspergillus ustus infections among transplant recipients. Emerging Infectious Diseases 12:403-408.

Padhye, A.A.; Godfrey, J.H.; Chandler, F.W \& Peterson SW (1994). Osteomyelitis caused by Neosartorya pseudofischeri. Journal of Clinical Microbiology 32:2832-2836.

Palumbo, Jeffrey D. \& O'Keeffe, Teresa L. (2013).Distribution and Mycotoxigenic Potential of Aspergillus Section Nigri Species in Naturally Contaminated Almonds. Journal of Food Protection $®$, $4: 560-735$ 
Perrone, G.; Stea,G.; Epifani, F. et al, (2011). Aspergillus niger contains the cryptic phylogenetic species A. awamori. Fungal Biology 115:1138-1150

Perrone,G.; Epifani, F.; Rambukwelle, K.; Wijedasa, H.; Arseculeratne, S. (2012). Aspergillus aculeatinus (new species) in chronic human dacryocystitis: The first report on itspathogenic role J. Infect. Dis. Antimicrob. Agents. 29:89-97

Perrone, G. et al, (2013).Aspergillus fijiensis n. sp. isolated from bronchial washings in a human case of bronchiectasis with invasive aspergillosis: the first report. Microbiology Discovery. http:// www.hoajonline.com/journals/pdf/2052-6180-1-9.pdf

Person,A. K.; Chudgar, S. M.; Norton,B. L.; Tong,B. C. \& Stout, J. E. (2010). Aspergillus niger: an unusual cause of invasive pulmonary aspergillosis. Journal of Medical Microbiology 59:834-838

Peterson, S.W. (2000). Phylogenetic relationships in Aspergillus based on rDNA sequence analysis. In: Integration of modern taxonomic methods for Penicillium and Aspergillus classification. (Samson RA, Pitt JI, eds). Amsterdam. Harwood, Academic Publishers: 323-355

Peterson, S.W. (2008). Phylogenetic analysis of Aspergillus species using DNA sequences from four loci. Mycologia 100:205-226

Pildain, M.B.; Frisvad, J.C.; Vaamonde, G. et al. (2008). Two novel aflatoxin-producing Aspergillus species from Argentinean peanuts.International Journal of Systematic and Evolutionary Microbiology 58:725-735

Piontelli,E.; Rodrigo, C. \& Amaro, J. (2013). Notas micológicas XI:Tritirachium oryzae, Paecilomyces formosus y alcances en la Sección Fumigati de Aspergillus con énfasis en el complejo Aspergillus viridinutans. Bol. Micol. 28:58-70

Pitt,J.I \& Hoching, A,D. (2009). Fungi and fud spoilage. N.Y. Springer

Ramirez-Prado, J.H.; Moore, G.G.; Horn, B.W.; Carbone, I. (2008). Characterization and population analysis of the mating-type genes in Aspergillus flavus and Aspergillus parasiticus. Fungal Genetics and Biology 45:1292-1299

Raper, K.B \& Fennell, D.I. (1965). The genus Aspergillus. Baltimore, Maryland.Williams \& Wilkins.

Retamal, C.; Diaz, C.; Salamanca, L.; Ferrada, L. \& Alvarez, de Oro, R. (1984). Aspergilosis pulmonar en Chile. Enfoque inmunologico. Bol. Micol. 2:11-16.

Rinaldi, M.G. (1983). Invasive aspergillosis. Reviews of Infectious Diseases 5:1061-1077

Rodrigues, P.; Venancio, A.; Kozakiewicz, Z. \& Lima, N. (2009). A polyphasic approach to the identification of aflatoxigenic and nonaflatoxigenic strains of Aspergillus section Flavi isolated from Portuguese almonds. International Journal of Food Microbiology 129:187-193

Ryan, K. J. (2004). Candida, Aspergillus, and Other Opportunistic Fungi. In Ryan, K.J. and Ray, C.G. (Ed.), Sherris Medical Microbiology (4th ed., pp. 659-668). USA: McGraw-Hill.

Salim, R. \& Runco, R. (2008). Aspergilosis sinusal no invasiva por Aspergillus parasiticus en niño inmunocomprometido. Bol. micológico 23:1-7
Samson, R.A. (1979). A compilation of the Aspergilli described since. Stud Mycol 1979; 18: 1-38

Samson, R.A. (1993). Taxonomy - current concepts of Aspergillus systematic In: Smith JE (ed.). Aspergillus Biotechnology Handbooks, vol. 7. New York: Plenum Press, pp. 1-22.Williams and Wilkins.

Samson, R.A. (1994). Taxonomy-Current concept of Aspergillus systematics In: Aspergillus Biotechnology Handbooks. Vol 7(Ed, J.E. Smith) pp. 1-22 N.Y. Plenum Press.

Samson, R.A.; Pitt, J.I. (eds). (2000). Integration of Modern Taxonomic Methods for Penicillium and Aspergillus Classification. Amsterdam: Harwood Academic Publishers.

Samson, RA.; Houbraken, JAMP. et al. (2004a)."New ochra-toxin A or sclerotium producing species in Aspergillus section Nigri". Studies in Mycology 50:45-60

Samson, R.A.; Hoekstra, E.S. \& Frisvad, J.C. (2004b). Introduction to Food- and Airborne Fungi. 7th edition. Centraal-bureau voor Schimmelcultures, Utrecht, The Netherlands.

Samson, A.R.; Hong, S-B.\& Frisvald, C.J. (2006).Old and new concepts of species differentiation in Aspergillus. Medical Mycology. 44: S133-S148

Samson, R.A.; Hong, S-B.; Peterson, S.W.; Frisvad, J.C.; Varga, J.(2007a). Polyphasic taxonomy of Aspergillus section Fumigati and its teleomoorph Neosartorya. Studies in Mycology 59:147-207

Samson, R.A.; Noonim, P.;Medijer, M. et al. (2007b). Diag-nostic tools to identify black aspergilli. Studies in Mycology 59:129-145

Samson R.A. \& Varga. J. (2007). Aspergillus systematics in the genomic era. Studies in Mycology 59:1-206

Samson, R.A., Varga, J., Witiask, M.S.,\& Geiser, D.M.(2008). The species concept in Aspergillus: recommendations of an international panel. In: Aspergillus Systematics in the Geno-mic Era, Samson, R.A.\&Varga, J., eds. (Utrecht: CBS Fungal Biodiversity Center) pp.71-79

Samson, R.A. \& Varga, J. (2009). What is a species in Aspergillus? Medical Mycology 47: S13-S20

Samson,R.\&J.Varga.(2010).Molecular Systematics of Aspergillus and its Teleomorphs. In: Aspergillus: Molecular Biology and Genomics. M. Machida \& K. Gomi, Eds. pp.19-40

Samson, R.; Houbraken,J.; Thrane, U. et al, (2010b). Food and indoor fungi. Utrecht CBS KNAW biodiversity Center

Samson, R.A.; Peterson,S.W.; Frisvad, J.C. \& Varga, J. (2011).New species in Aspergillus section Terrei. Stud. Mycol. 69: 39-55

Samson, R.A.; Visagie, M.C.;Houbraken, J. et al, (2014). Phylogeny, identification and nomwnclature of the genus Aspergillus. (www.fungaltaxonomy.org/files/8114/0673/5235/ 20140721_SIM78_Aspergillus_nomenclature.pdf -)

Scheidegger, K. A. \& Payne, G. A. (2003). Unlocking the secrets ehind secondary metabolism: a review of Aspergillus flavus from pathogenicityto functional genomics. J. Toxicol 22:4234-59 
Segal, B. H. (2009). Aspergillosis. New England Journal of Medicine, 360:1870-1884

Seye,F.; Faye, O.; Ndiaye, M.; Njie, E.; Afoutou, J-M. (2009). Pathogenicity of the fungus, Aspergillus clavatus, isolated from the locust, Oedaleus senegalensis, against larvae of the mosquitoes Aedes aegypti, Anopheles gambiae and Culex quinque-fasciatus. Journal of Insect Science 9:art.53 7pp.

Scott, E. M. \& Gorman, S. P. (1996). Glutaraldehyde. In S. S. Block (Ed.), Disinfection, Sterilization, and Preservation ed., pp. 361-381. Philadelphia P.A.: Lipincott Williams and Wilkins.

Shuster, E.; Dunn-Colemaman.; Frisvad,J.C. \& van Dijck, P. W. M. (2002). On the safety of Aspergillus niger - a review. Appl Microbiol Biotechnol 59:426-435

Silva, Daiani M et al, (2011). Identification of fungi of the genus Aspergillus section nigri using polyphasic taxonomy. Braz. J. Microbiol. 42:761-773

Smedsgaard, J. (1997). Micro-scale extraction procedure for standardized screening of. fungal metabolite production in cultures. J. Chromatogr. A. 760: 264-270

Smith, J.E. (ed). (1994).Aspergillus . Biotechnology Handbooks 7, Plenum Press, New York.

Soares, C.; Rodriguez, P.; Peterson S.W.; Lima, N.; Venan-cio, A. (2012). Three new species of Aspergillus section Flavi isolated from almonds and maize in Portugal. Mycologia, 104:682-697

Sogui, J.A.; Vinh, D.C.; Nardone, G. et al .(2010). Neosartorya udagawae (Aspergillus udagawae), an emerging agent of aspergillosis: how different is it from Aspergillus fumigatus? J. Clin. Microbiol. 48:220-228

Susca, A.; Stea, G.; Mule, G. \& Perrone, G. (2007). Polymerase chain reaction (PCR) identification of Aspergillus niger and Aspergillus tubingensis based on the calmodulin gene. Food Addit. Contam. 24:1154116

Steinbach, W. J., D. K. Benjamin, Jr., D. P. Kontoyiannis, J. R. et al, (2004). Infections due to Aspergillus terreus: a multicenter retrospective analysisof 83 cases. Clin. Infect. Dis. 39:192-198

Stenson, J.; Brookner, A. \& Rosenthal, S., (1982). Bilateral endogenous necrotising scleritis due to Aspergillus oryzae. Ann. Ophthalmol. 14:67-72

Swilaiman, S.S.; O'Gorman, M.C.; Balajee, S.A. \& and Paul S. Dyer, S.P. (2013). Discovery of a Sexual Cycle in Aspergillus lentulus, a Close Relative of A. fumigatus. Eukaryotic Cell 12:962 -969

Tack, K.J.; Rhame, F.S.; Brown, B. \& Thompson, R.C., (1982). Aspergillus osteomyelitis: report of four cases and review of the literature. Am. J. Med. 73:295-300

Taylor, J.W.; Jacobson, D.J. \& Fisher, M.C. (1999). The evolution of asexual fungi: reproduction, speciation and classification.Annu. Rev. Phytopathol. 37:197-246

Taylor, J.W. (2011). One fungus = One name: DNA and fungal nomenclature twenty years after PCR. IMA Fungus 2:113-120

Thom, C. \& Church, M.B. (1926). The Aspergilli, Baltimore, U.S.A, William and Wilkins
Thom, C., \& K. B. Raper. (1945). A manual of the aspergilli. Williams $\&$ Wilkins, Baltimore.

Varga, J.;Vida, Z.; Tóth, B.; Debets, F.; Horie Y.(2000). Phylogenetic analysis of newly described Neosartorya species. Antonie Van Leeuwenhoek 77:235-239

Varga, J.; Rigo, K.; Toth, B.; Téren, J. \& Kozakiewicz, Z. (2003a). Evolutionary relationships among Aspergillus species producing economically important mycotoxins. Food Technol Biotechnol 41:29-36

Varga, J.; Rigó, K.; Molnár, J. et al. (2003b).Mycotoxin production and evolutionary relationships among species of Aspergillus section Clavati. Antonie van Leeuwenhoek 83:19-200

Varga, J.; Due,M.; J.C. Frisvad, J.C. \&. Samson, R.A. (2007a). Taxonomic revision of Aspergillus section Clavati based on molecular, morphological and physiological data. Study in Mycology. 59:89-106

Varga, J.; Kocsubé, S.; Tóth, B.; Frisvad, J.C.; Perrone G, et al. (2007b). Aspergillus brasiliensis sp. nov., a biseriate black Aspergillus species with world-wide distribution. International Journal of Systematic and Evolutionary Microbiology 57:1925-1932

Varga, J. \& Samson, R.A. (Eds.) (2008) Aspergillus in the genomic era. Wageningen Academic Publishers. The Netherlands.

Varga, J.; Houbraken, J.; Van Der Lee, H.A.; Verweij, P.E.; Samson. R.A. (2008). Aspergillus calidoustus sp. nov., causative agent of human infections previously assigned to Aspergillus ustus. Eukaryot. Cell 7:630-638

Varga, J.; Frisvad, J.C. \& Samson, R.A. (2009). A reappraisal of fungi producing aflatoxin. World Mycotoxin Journal 2:263-277

Varga, J.; Frisvad, J.C.; Samson, R.A. (2010). Pokyphasic taxonomy of Aspergillus section Sparsi. IMA Fungus 1:187-195

Varga, J.; Frisvad, J.C.; Kocsubé, S. et al. (2011). New and revisited species in Aspergillus section Nigri. Studies in Mycology 69:1-17

Vargas, J. et al, (2014).Occurrence of black Aspergilli in indoor environments of six countries. Europe PubMed Central. DOI: 10.2478/10004-1254-65-2014-2450

Vermeulen, E.; Maertens, J.; Meersseman, P. et al. (2013). Invasive Aspergillus niger complex infections in a Belgian tertiary care hospital. Clinical Microbiology and Infection. DOI: 10.1111/ 1469-0691.12394

Verweij, P.E.\& Brandt, M.E. (2007). Aspergillus, Fusarium and other opportunistic moniliaceous fungi. In P. R. Murray (Ed.), (9th ed., pp.1802-1838). Washington D.C.: ASM Press

Vinh, D.C.; Shea, Y.R.; Sugui, J.A. et al. (2009) Invasive aspergillosis due to Neosartorya udagawae. Clin. Infect. Dis . 49:102 -111

Visage, C.M.; Varga, J.; Houbraken, J et al, (2014). Ochratoxin production and taxonomy of the yellow aspergilli (Aspergillus section Circundati, Studies in Mycology 78:1-61

Vujanovic, V.; Smoragiewicz, W. \& Krzysztyniak, K. (2001). 
Airborne fungal ecological niche determination as one of the possibilities for indirect mycotoxin risk assessment in indoor air. Environ Toxicol 16:1-8

Walsh, T.J.; Petraitis, V.; Petraitiene, R. et al. (2003). Experimental pulmonary aspergillosis due to Aspergillus terreus: pathogenesis and treatment of an emerging fungal pathogen resistant to amphotericin B.Journal of Infectious Diseases 188: 305-319

Williams, J.P. \& Hallsworth, J.E. (2009). Limits of life in hostile environments: no barriers to biosphere function? Environmental Microbiology 11:3292-330

Yaguchi, T.; Horie, Y.; Tanaka, R. et al. (2007). Molecular phylogenetics of multiple genes on Aspergillus section Fumigati isolated from clinical specimens in Japan. Nippon Ishinkin Gakkai Zasshi 48:37-46

Yildiran, S.T.; Mutlu, F.M.; Saracli, M.A. et al, (2006). Fungal endophthalmitis caused by Aspergillus ustus in a patient following cataract surgery. Medical Mycology 44:665-669

Yu, T.S.; Yeo, S.H.; Kim, H.S. (2004a). A new species of hyphomycetes, Aspergillus coreanus sp. nov., isolated from traditional Korean nuruk. J Microbiol Biotech 14:182-187

Yu, J. (2004b). Genetics and biochemistry of mycotoxin synthesis. In: Fungal Biotechnology in Agricultural, Food, and Environmental Applications, vol. 21, pp. 343-361, edited by D. K. Arora. New York: Marcel Dekker. 